\title{
Experimental Validation of a Time to Instability Theory for Viscoelastic Rings
}

\author{
by \\ Eugene Lee, B.Eng. \\ A thesis submitted to the \\ Faculty of Graduate and Postdoctoral Affairs \\ in partial fulfillment of the requirements for the degree of
}

Master of Applied Science in Mechanical Engineering

Ottawa-Carleton Institute for Mechanical and Aerospace Engineering

Department of Mechanical and Aerospace engineering

Carleton University

Ottawa, Ontario

January 2017

(C) Copyright

Eugene Lee, 2017 


\section{Abstract}

A novel method of estimation of time to instability of viscoelastic structures has been developed by Dr. C. G. Merrett and has been applied to rings. This theory has applications to the nuclear industry as once the stability of viscoelastic rings is understood, the theory can be expanded to predict the stability of viscoelastic helical coils, which are found in the CANDU nuclear reactor as tight fitting spacers. The theory takes the elastic mechanics of a ring with a uniform pressure load, changes this pressure load to a two point load, applies the elastic-viscoelastic correspondence principle, and then uses Drozdov and Kolmanovskii's stability theory to estimate service life. A computer code using this theory plots the service life of a ring versus viscoelasticity and load.

The objective of this project was to verify if the time to instability theory for viscoelastic rings is correct. Multiple polymethyl methacrylate (acrylic) rings were made and tested over a range of loads, and their times to failure were plotted and compared with the theory. Photoelasticity was used with polycarbonate rings to observe the changing stresses in a viscoelastic ring as it crept over time.

The tests showed a decrease in life time of the rings as the load was increased from an average of 1774 seconds at $60 \mathrm{~N}$ to $203 \mathrm{~s}$ at $80 \mathrm{~N}$, whereas the stability theory showed two times to failure over the load range, one being approximately 800s and the other being 35000s. The trend of the decreasing life with increasing load over the load range is clear in the experiments, and the lack of a similar trend in the theory does not appear to be correct. Further refinement of the theory to reflect this trend should be made, but more testing over a greater range of materials, loads and geometries should be performed to better confirm or disprove the theory. 


\section{Acknowledgments}

The author would like to thank the following people, in no particular order, for their assistance in the completion of this project:

- Dr. C. G. Merrett for his guidance and patience

- Dr. J. Polansky for his suggestion of using imageJ and his general wisdom

- K. Lee Slew for his help with MATLAB and LaTeX

- J. Dewar and W. Zanetti of the Industrial Design department for their assistance with laser cutting 


\section{Table of Contents}

Abstract

Acknowledgments $\quad$ iii

Table of Contents $\quad$ iv

List of Tables $\quad$ vii

List of Figures $\quad$ viii

Nomenclature $\quad$ x

1 Introduction 1

1.1 Thesis outline . . . . . . . . . . . . . . . . . . 1

2 Theory Review 3

2.1 CANDU reactor . . . . . . . . . . . . . . . . . 3

2.1.1 Garter springs . . . . . . . . . . . . . . . 4

2.2 Viscoelasticity . . . . . . . . . . . . . . . . . . . . . 7

2.3 Temperature effects . . . . . . . . . . . . . . . . 9

2.3.1 Glass transition temperature . . . . . . . . . . . . . 9

2.3.2 Time-temperature correspondence . . . . . . . . . . . . . . 10

2.4 Photoelasticity . . . . . . . . . . . . . . . . . . 11

2.4.1 Light . . . . . . . . . . . . . . . . . . 11

2.5 Photoviscoelasticity . . . . . . . . . . . . . . . . 15

2.6 Polymers. . . . . . . . . . . . . . . . . . . . . . 15

2.6.1 Polymer scatter . . . . . . . . . . . . . . . . 18

2.7 Viscoelastic ring stability theory . . . . . . . . . . . . . . 18 
3 Experimental Setup $\quad 27$

3.1 Material Choice and Manufacturing Samples . . . . . . . . . . . . . 27

3.2 Polariscope . . . . . . . . . . . . . . . . . . . . . . . . . 30

3.3 Annealing Procedure . . . . . . . . . . . . . . . . . 33

3.4 Thermal Chamber . . . . . . . . . . . . . . . 33

3.5 Testing Procedures . . . . . . . . . . . . . . . . . . . 37

3.5.1 Testing procedure: Photoelastic testing . . . . . . . . . . 37

3.5.2 Testing procedure: Time to failure testing . . . . . . . . . . 37

4 Results $\quad 38$

4.1 Photoelastic observation of stresses . . . . . . . . . . . . . 38

4.2 Time to failure testing . . . . . . . . . . . . . . . . 44

4.2.1 Trend comparison . . . . . . . . . . . . . . . 44

4.3 Sources of error . . . . . . . . . . . . . . . . . 46

4.3.1 Thermal effects . . . . . . . . . . . . . . . . . 46

4.3 .2 Misalignment . . . . . . . . . . . . . . . . . 48

4.3.3 Ring dimension variation . . . . . . . . . . . . . . . . . 49

4.3.4 Ring orientation . . . . . . . . . . . . . . . . . 49

4.3.5 Weights ..................... 50

4.3.6 Annealing ................... 50

4.3.7 Experimental error ................. . . 52

4.4 Validity of results . . . . . . . . . . . . . . . . . . . . . . . . . . . . . . .

4.5 Observations . . . . . . . . . . . . . . . . . . 52

4.5.1 Failure mode . . . . . . . . . . . . . . . . 52

4.5.2 Long life outliers . . . . . . . . . . . . . . . 56

5 Conclusions and Future Work $\quad 57$

5.1 Conclusions . . . . . . . . . . . . . . . . 57

5.2 Future work . . . . . . . . . . . . . . . . . 57

List of References $\quad 58$

$\begin{array}{ll}\text { Appendix A } & 60\end{array}$

A.1 Data collected during acrylic ring testing . . . . . . . . . . . 60

A.1.1 Graphs of times to failure for each load case . . . . . . . . . . 68

A.1.2 Plot with trend and all data points . . . . . . . . . . . 71 
A.1.3 Confidence and variance . . . . . . . . . . . . . . . 72

A.1.4 Outliers .................... 73

A.1.5 Sample ring dimensions . . . . . . . . . . . . . . . . . 74

A.2 Ring manufacturing jig . . . . . . . . . . . . . . . . . . 74 


\section{List of Tables}

2.1 Properties for Lexan $[16] \ldots \ldots$. . . . . . . . . . . . . 17

2.2 Properties for Plaskolite Optix [17] . . . . . . . . . . . . . 17

2.3 Acrylic ring dimensions used for MATLAB simulation . . . . . . . . . 25

3.1 Nominal Dimensions of Rings. . . . . . . . . . . . . . . . . . . 28

4.1 Time to failure of three polycarbonate rings . . . . . . . . . . . 39

4.2 Ring dimensions and conditions for photoelastic analysis . . . . . . . 39

4.3 Temperature effect on time to failure . . . . . . . . . . . . . 47

4.4 Ring dimension effect on time to failure . . . . . . . . . . . . 49 


\section{List of Figures}

2.1 CANDU reactor core construction [3] . . . . . . . . . . . . 4

2.2 CANDU reactor core construction [4] . . . . . . . . . . . . . 5

2.3 CANDU garter spring (48) between pressure tube (36) and calandria tube $(32)[7] \ldots \ldots \ldots \ldots \ldots$. . . . . . . . . . . . . . . . 6

2.4 Cross section of CANDU calandria tube showing pinched section of garter spring (circled in red) [5] . . . . . . . . . . . . 7

2.5 Maxwell (a), Voigt (b), and general Wiechert (c) and Kelvin (d) viscoelastic models [9] . . . . . . . . . . . . . . . . . . . . . . 9

2.6 Temperature shifting to create a master curve [9] . . . . . . . . . . . 10

2.7 Linear, circular and elliptically polarized light [12] . . . . . . . . . 12

2.8 Photoelastic fringe order . . . . . . . . . . . . . . . 13

2.9 Typical fringe sensitivity variation with time $[13] \ldots \ldots . . . . .15$

2.10 Ring parameters $[1] \ldots \ldots$. . . . . . . . . . . . . 19

2.11 MATLAB code output graph . . . . . . . . . . . . . 25

2.12 2-D graph at viscosity $=0.2 \ldots \ldots \ldots \ldots$

3.1 C series acrylic ring design dimensions and tolerance. . . . . . . . . 28

3.2 D2 series polycarbonate ring dimensions and tolerance . . . . . . . 29

3.3 Polariscope with labeled components . . . . . . . . . . . . . . . . . 31

3.4 Polariscope view from camera end . . . . . . . . . . . . . . . 31

3.5 Polariscope view from light source end . . . . . . . . . . . . 32

3.6 Thermal chamber . . . . . . . . . . . . . . . . . . 34

3.73 view of thermal chamber with annotations for cutouts . . . . . . 35

3.8 Ring positioner with ring aligned with marks . . . . . . . . . . 35

3.9 Thermocouple reader and probe . . . . . . . . . . . 36

4.1 Ring 26 at initial load . . . . . . . . . . . . . . . . . 39

4.2 Ring 27 at initial load . . . . . . . . . . . . . . . . . . . . . 40

4.3 Ring 28 at initial load . . . . . . . . . . . . . . . . . 40 
4.4 Ring 26 before buckling, with arrow 26 indicating its height . . . . . 41

4.5 Ring 27 before buckling, with arrow 27 indicating its height . . . . . 42

4.6 Ring 28 before buckling, with arrow 28 indicating its height . . . . . 42

4.7 Ring 26 dynamic visualization . . . . . . . . . . . . . . . . 43

4.8 Ring 27 dynamic visualization . . . . . . . . . . . . . . . . . . . 43

4.9 Ring 28 dynamic visualization . . . . . . . . . . . . . . . . . . 43

4.10 Experimental results versus theory over experimental load range . . . 44

4.11 Experimental results versus theory over theoretical load range . . . . 45

4.12 Experimental results versus theory over theoretical load range . . . . 45

4.13 Overview of thermal gradient in ring showing average temperature . 47

4.14 Location of lowest temperature . . . . . . . . . . . . . . . . . . 48

4.15 Location of highest temperature . . . . . . . . . . . . . . . . 48

4.16 Appearance of annealed rings. Ring segment A is fully annealed, ring $\mathrm{B}$ has had no annealing done to it; ring $\mathrm{C}$ has been annealed but has residual stresses. . . . . . . . . . . . . . . . . . . 51

4.17 Ring showing out of plane bending . . . . . . . . . . . . . . 53

4.18 Failed acrylic rings, showing typical failure mode. . . . . . . . . . . . 54

4.19 Bent ring, showing failure mode typical at glass transition temperature, but not expected at testing temperature. . . . . . . . . . . . . 55

4.20 Partially snapped ring. . . . . . . . . . . . . . . . . . 55

A.1 Times to failure for $60 \mathrm{~N}$ load . . . . . . . . . . . . . . . 68

A.2 Times to failure for $64 \mathrm{~N}$ load . . . . . . . . . . . . . . . . 69

A.3 Times to failure for $68 \mathrm{~N}$ load . . . . . . . . . . . . . . . . 69

A.4 Times to failure for $72 \mathrm{~N}$ load . . . . . . . . . . . . . . . 70

A.5 Times to failure for $76.4 \mathrm{~N}$ load . . . . . . . . . . . . . . . 70

A.6 Times to failure for $80 \mathrm{~N}$ load . . . . . . . . . . . . . . . . . 71

A.7 Averages with individual data points (all points) . . . . . . . . . 71

A.8 Averages with individual data points (showing concentration of points 72

A.9 Collet part A for holding polycarbonate rings for drilling centre hole. 74

A.10 Collet part B threads into part A . . . . . . . . . . . . . . 75 


\section{Nomenclature}

\begin{tabular}{ll}
\hline Symbol & Definition \\
\hline$\sigma$ & Stress \\
$E$ & Modulus of elasticity \\
$\epsilon$ & Strain \\
$N$ & Fringe order \\
$f_{\sigma}$ & Fringe sensitivity for stress \\
$f_{\epsilon}$ & Fringe sensitivity for strain \\
$H$ & Material thickness \\
$\nu$ & Poisson's ratio \\
$P$ & Load \\
$D$ & Diameter \\
$I$ & Second moment of area \\
$R$ & Radius \\
$w$ & Outward radial displacement \\
$v$ & Tangential displacement \\
$u$ & Displacement perpendicular to plane of ring \\
$\theta$ & Angular rotation of cross section of ring \\
$A$ & Cross sectional area of ring \\
\hline & Second moment of inertia about radial axis \\
\hline
\end{tabular}




$\begin{array}{ll}I_{p} & \text { Polar moment of inertia } \\ J & \text { Torsion constant of cross section } \\ \rho & \text { Density } \\ G & \text { Modulus } \\ T & \text { Time } \\ \phi & \text { Circumferential coordinate } \\ \delta & \text { Dirac delta } \\ P_{c} & \text { Load magnitude } \\ \chi & \text { Viscosity } \\ \mathcal{T} & \text { Relaxation time } \\ R & \text { Universal gas constant } \\ E_{a} & \text { Activation energy }\end{array}$




\section{Chapter 1}

\section{Introduction}

The Canada Deuterium Uranium (CANDU) nuclear reactor is a type of reactor designed in Canada and in service in 7 countries around the world. The pressure and calandria tubes within the CANDU reactor core are kept from touching with spacers called 'garter springs' or 'tight fitting spacers'; these are coil springs that have their ends joined to form a ring. Because of the high temperatures that the garter springs are subjected to, they fail in a viscoelastic manner. No prediction models exist for the failure of these springs to date, which is problematic since both failure of the springs and premature removal are detrimental to the profitability of the CANDU reactor.

C. G. Merrett's paper [1] outlines one use of a general viscoelastic life theory, applied to a ring in diametral compression. The objective of this thesis is to verify whether this mathematical theory is correct or not, and also to use photoelasticity to observe the changing stress field in the ring as it is compressed over time. Verification of the viscoelastic life theory could allow the theory to be refined, and then eventually used to predict the life of viscoelastic helical springs, as used in the CANDU reactor, for better understanding of the life of the garter springs and more economical running of the reactor.

\subsection{Thesis outline}

This thesis consists of 5 chapters:

1. Chapter 1: Introduction 
Introduces the context and problem to be solved by the thesis.

2. Chapter 2: Theory review

Presents theory and background information needed to understand the mathematical model and context of the research.

3. Chapter 3: Experimental Setup

Describes the apparatus and procedure used to perform the experiments.

4. Chapter 4: Results

Presents the results of the testing.

5. Chapter 5: Conclusions

Describes the conclusions made from the experiments, and recommendations for future work. 


\section{Chapter 2}

\section{Theory Review}

This chapter serves to describe the information required to understand the thesis problem within its context. The CANDU reactor design and the garter spring and its operating environment are described; after which viscoelasticity, photoelasticity, polymers and Merrett's viscoelastic stability theory are described.

\section{$2.1 \quad$ CANDU reactor}

CANDU (CANada Deuterium Uranium) reactors are nuclear reactors of Canadian design that can be found operating in seven countries around the world. CANDU reactors have several features that make them unique: they can run on natural, unenriched uranium; they use pressurized tubes instead of a pressure vessel; and they can be refuelled while running. Running on natural uranium is an advantage because the cost of enriching the fuel is not incurred. The pressurized tube design makes it possible to refuel the reactor as it is running, as one pressure tube can be opened and new fuel bundles can be pushed in one end and the old fuel bundles collected on the other end.

The CANDU reactor generates power in a manner similar to other nuclear reactors. Fission reactions occur in the reactor core and heat the heavy water surrounding the fuel bundle, and this heated heavy water is pumped to a heat exchanger where it boils the water of a secondary light water circuit, which drives a steam turbine to generate electrical power.

CANDU construction is a series of tubes within tubes: the fuel pellets are put 
in a tube, and each fuel bundle consists of around 40 tubes of fuel pellets. The fuel bundles are located in the pressure tubes, through which heavy water flows. The pressure tubes are put in calandria tubes. Between the pressure and calandria tubes, carbon dioxide flows to prevent heat transfer. The fuel channels are located in the reactor vessel, or calandria, which is filled with heavy water as a moderator. There are typically 380-480 calandria tubes in a CANDU reactor [2]. The construction of a CANDU reactor core is shown in Figures 2.1 and 2.2.

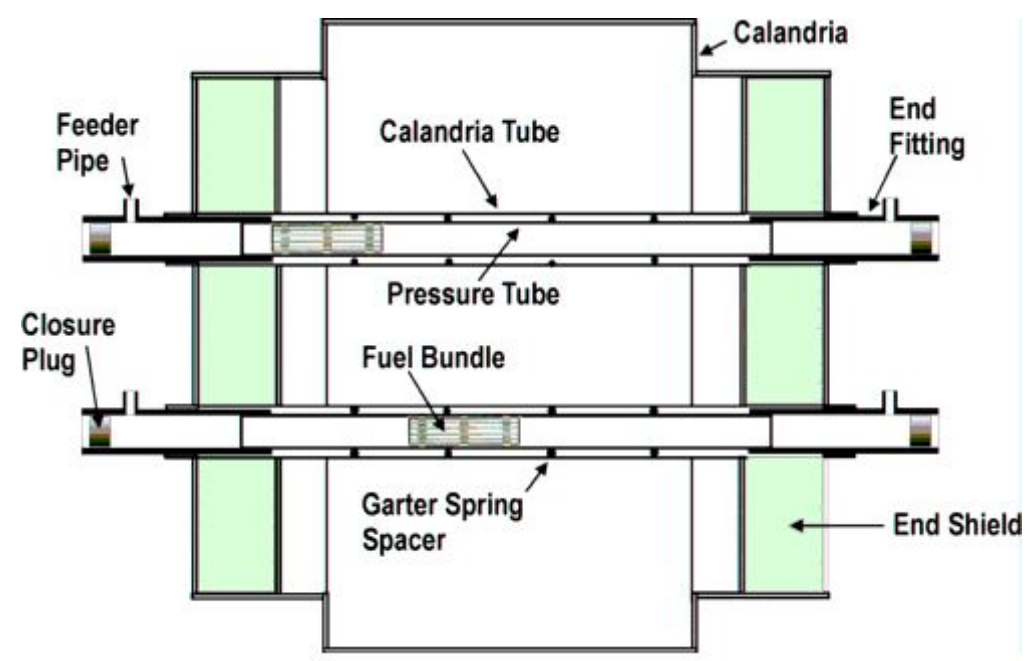

Figure 2.1: CANDU reactor core construction [3]

\subsubsection{Garter springs}

The investigation into the life of viscoelastic rings was prompted by investigations into the life of tight fitting spacers or garter springs in the CANDU reactor. These garter springs, shown in Figure 2.3 are helical springs made of Inconel X-750 connected end-to-end to form a ring, located between the pressure and calandria tubes to prevent them from touching. Contact between the tubes would lower the efficiency of the reactor by allowing heat transfer from the hot pressure tube and the cold calandria tube, and would result in hydride blistering of the tubes. Each pressure tube has four garter springs equally spaced throughout its six metre length. Between the two tubes and around the garter spring, carbon dioxide [5] flows to prevent heat transfer. Initially, the weight of the pressure tube is taken entirely 


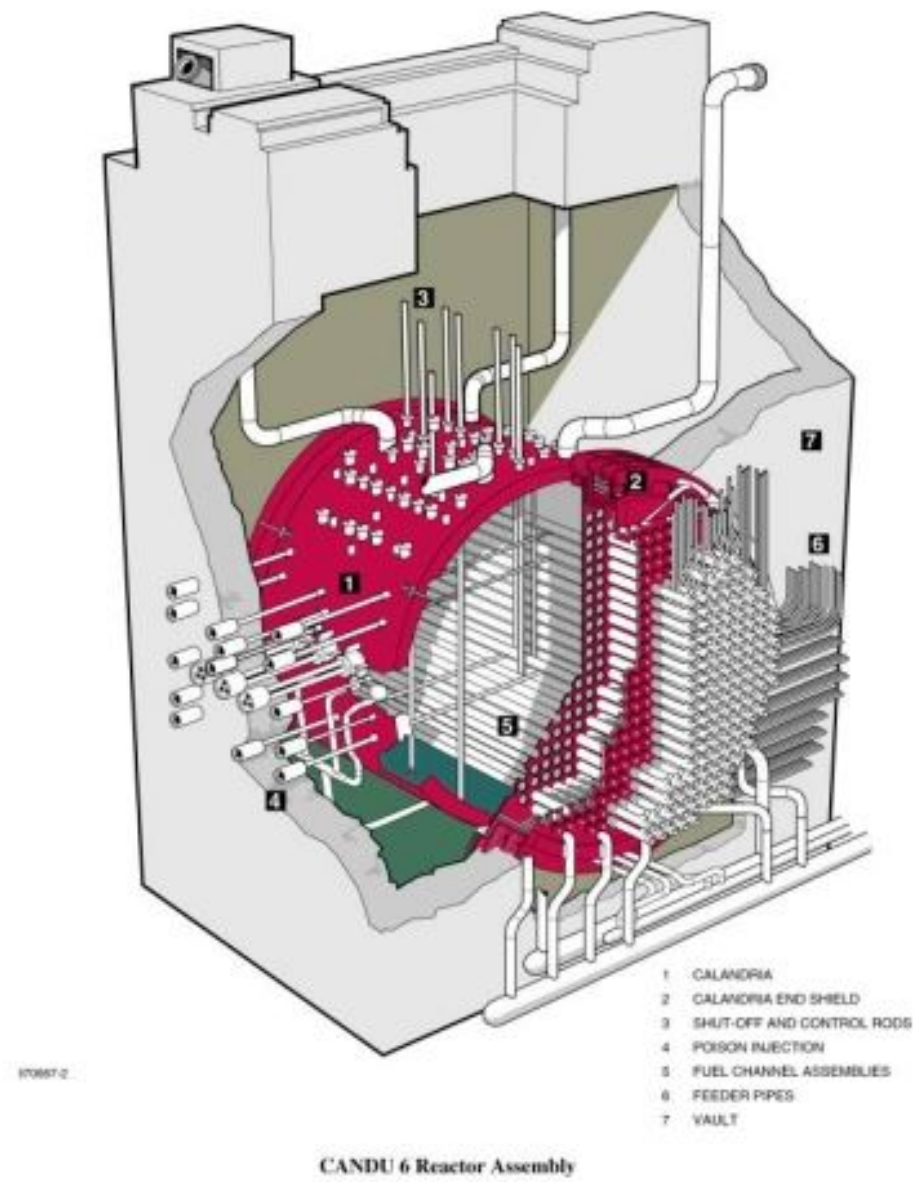

Figure 2.2: CANDU reactor core construction [4] 
by its supports at the end. When the pressure tube sags due to creep from the weight it carries, the garter springs will be pinched between the pressure tube and the calandria tube. This pinched section, shown in figure 2.4 is about $4 \mathrm{~cm}$ long, and its temperature is between that of the pressure tube $\left(300{ }^{\circ} \mathrm{C}\right)$ and the calandria tube $\left(70{ }^{\circ} \mathrm{C}\right)$. The remainder of the unpinched garter spring is hotter than $300{ }^{\circ} \mathrm{C}$ due to nuclear heating. The sagging of the pressure tube takes some time and the middle two garter springs are pinched first, in less than 1000 hours of operation, with the two springs closer to the ends being pinched much longer afterwards. Like the sagging pressure tubes, the garter springs also creep, reducing their tension on the pressure tube; and hence they are designed so that they will have some tension on the pressure tube until they are pinched to prevent them from sliding. The relaxation of the spring is somewhat countered by the expansion of the pressure tube over time. The unpinched, hotter sections of the garter springs are more embrittled and weaker by radiation than the pinched section, which is due to the temperature difference [6]. Garter springs removed after 12 years of service have been found to be intact [5], so replacement of garter springs is relatively infrequent. Compression failures of the pinched section of the springs have been identified as a failure mode, as highlighted in a discussion the C.G Merrett had with staff at the Canadian Nuclear Safety Commission.

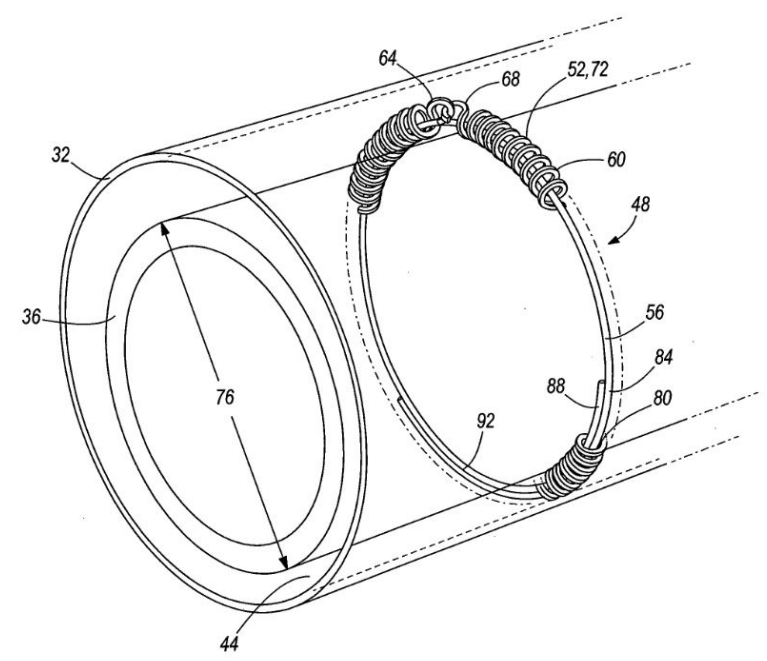

Figure 2.3: CANDU garter spring (48) between pressure tube (36) and calandria tube (32) [7] 


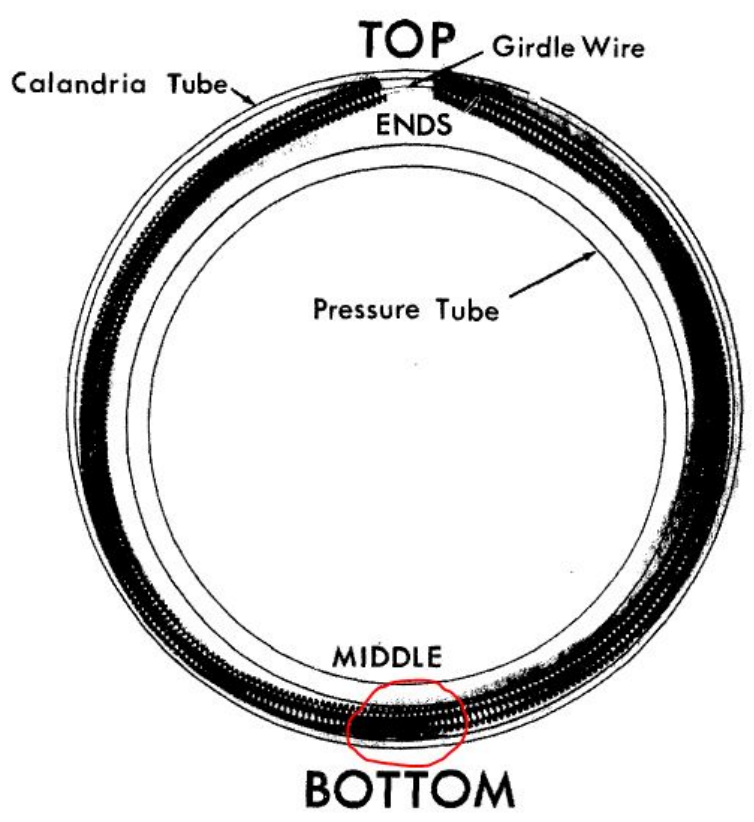

Figure 2.4: Cross section of CANDU calandria tube showing pinched section of garter spring (circled in red) [5]

\subsection{Viscoelasticity}

Most solid materials are assumed to be elastic. The theory of elasticity states that under a load, an elastic material will deform according to its stiffness, and will remain deformed until the load is removed and then it will regain its original shape, provided that the stress caused by the load does not cause the material to yield. A load that causes a stress greater than the yield strength of the material will cause the material to permanently deform, or yield, but there will still be an amount of temporary, or elastic, deformation proportional to the material's stiffness. Thus deformation of an elastic material within the elastic zone depends only on load.

Many materials assumed to behave elastically are in fact viscoelastic; plastics, natural or synthetic rubbers and fibres, wood, concrete, biomaterials and metals at elevated temperatures are some examples. The Inconel X-750 garter springs in the CANDU reactor are over $300^{\circ} \mathrm{C}$ across most of their diameter and do creep viscoelastically over time. 
Viscoelastic materials have a time dependant factor. A viscoelastic material, when loaded, will instantly deform elastically, but will creep over time like a viscous fluid. Upon removal of the load, the elastic component of the deformation will become undone immediately, and some or all of the viscous deformation will creep back over time. [8]

Elastic materials are often modelled as springs, following Hooke's law:

$$
\sigma=E \epsilon
$$

where $\sigma$ is stress, $E$ is Young's modulus and $\epsilon$ is strain.

Viscous elements can be modelled as dashpots, where the stress is proportional to the viscosity and strain rate of the material:

$$
\left.\sigma=\chi \frac{d \epsilon}{d t}\right)
$$

where $\chi$ is viscosity and $t$ is time.

These elements can be added together to form mathematical viscoelastic models. The simplest two models are the Maxwell model, a spring and a dashpot in series; and the Voigt model, spring and dashpot in parallel. These models, while simple, are somewhat effective in predicting the response of certain materials. A more general viscoelastic model like the Wiechert or Kelvin model has many elements and can be tailored to the measured response of any viscoelastic material. These mechanical models are shown in Figure 2.5. 


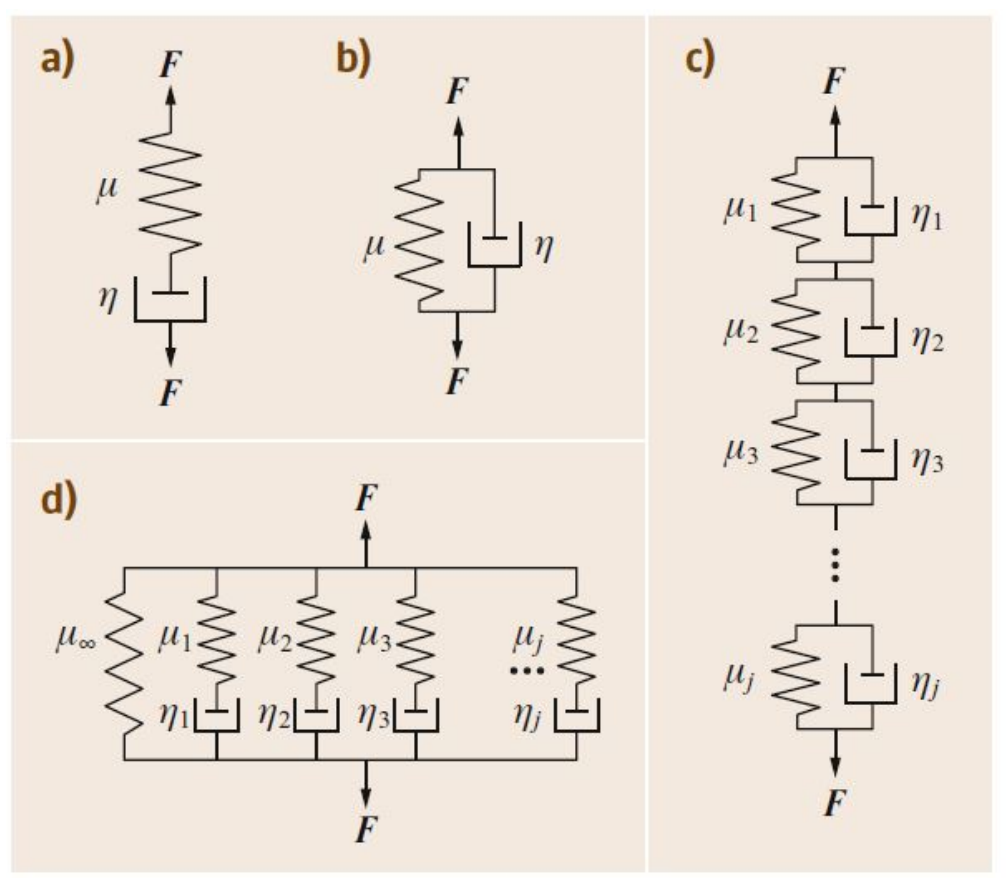

Figure 2.5: Maxwell (a), Voigt (b), and general Wiechert (c) and Kelvin (d) viscoelastic models [9]

\subsection{Temperature effects}

Changes in temperature affect the properties of viscoelastic materials. In this section, glass transition temperature and melting temperature are discussed, as well as the time-temperature superposition principle which can be used to predict the properties of a material at any temperature below melting if its properties at one temperature are known.

\subsubsection{Glass transition temperature}

In addition to having a melting temperature, where the material transitions from solid to liquid, plastics have a glass transition temperature - the temperature at which the usually hard or stiff material will change to a still solid, but rubbery state. Above the melting temperature, the polymer chains in the material have enough thermal energy to change places with each other. Between the glass transition temperature and the melting temperature, the chains haven enough energy to overcome intermolecular interactions, and this makes the normally hard material 
rubbery. Below the glass transition temperature, the chains are still in a disorganized state, but cannot move, and this is referred to as the 'glassy' state. The glass transition and melting temperatures depend on the type of polymer chains that the material is made of - rigid chains or cross-linked chains would have an effect of increasing the glass transition and melting temperatures [10].

\subsubsection{Time-temperature correspondence}

As the temperature of a viscoelastic material is increased, its viscoelastic properties will become more apparent. If the viscoelastic function is plotted against log time for tests taken at different temperatures, the plots look alike, but shifted. Superimposing the plots, shown in Figure 2.6 creates what is called a "master curve", and this curve can be shifted using empirical data to make a plot for any temperature below the glass transition temperature. Thus tests performed at one temperature can be used to predict the material behaviour at a different temperature [10].

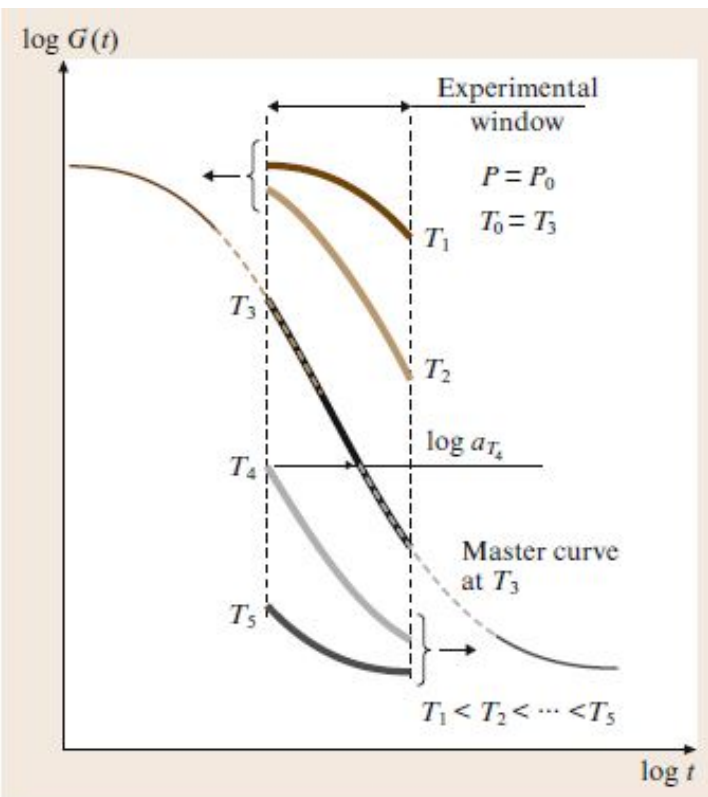

Figure 2.6: Temperature shifting to create a master curve [9]

This time-temperature correspondence principle allows for experiments to be performed at a number of temperatures to predict the behaviour of the material at one 
temperature over a long time period. This effect is used in the experiments when the rings are heated, which has the same effect as shortening time.

\subsection{Photoelasticity}

The principle of photoelasticity first observed in by the Scottish physicist Sir David Brewster in 1816, who suggested it could be used as a way to analyze stresses in arches [11]. In the decades following, it was investigated but not applied by many physicists - likely due to glass being the only practical medium for photoelastic analysis at the time, which would be a difficult material to manufacture specimens from. Two events in the early 1900s made photoelasticity practical; the invention of cellulose meant that specimens for stress analysis could now be machined and the publication of Coker and Filon's Treatise on Photo-Elasticity in 1930 popularized the method for stress analysis. Photoelastic analysis took off soon after as a serious experimental stress analysis method; new materials were used and the stress freezing method for examining the stresses in a 3 dimensional part was developed [11]. Photoelasticity was largely replaced in the $80 \mathrm{~s}$ and onwards as finite element methods became easier to perform, and did not require physical models to be made. Photoelastic analysis however in still relevant where complex geometries or load conditions make accurate computer simulation very difficult or impossible.

\subsubsection{Light}

Light can be considered as sinusoidal waves, where the amplitude of the wave corresponds to the intensity of the light, and the wavelength its colour. Visible light has wavelengths varying from 3900 to 7700 Ångströms, where 1 Ångström is $10^{-} 8 \mathrm{~cm}$. Ordinary, or unpolarised white light consists of light waves with random orientations and frequencies. Polarization takes these random orientations of vibration, and filters them down to only vibrate in one orientation.

There three types of polarization: linear, circular and elliptical. The state of polarization depends on the difference of the electric and magnetic phases of the light, which can be thought of as the $\mathrm{X}$ and $\mathrm{Y}$ components of the wave. These $\mathrm{X}$ and $\mathrm{Y}$ components are added to give the resultant wave, which propagates in the $\mathrm{Z}$ 
direction. Linearly polarized light has the electric and magnetic waves are in phase, and the light is polarized in the plane $45^{\circ}$ between the electric and magnetic planes. If the electric and magnetic waves are out of phase by $1 / 4$ of a wavelength, the resulting wave will be a circular spiral. If the wave offset is not a multiple of $1 / 4$ of a wavelength, the light will trace an ellipse in the X-Y plane and is thus called elliptically polarized. These states of polarization are shown in Figure 2.7

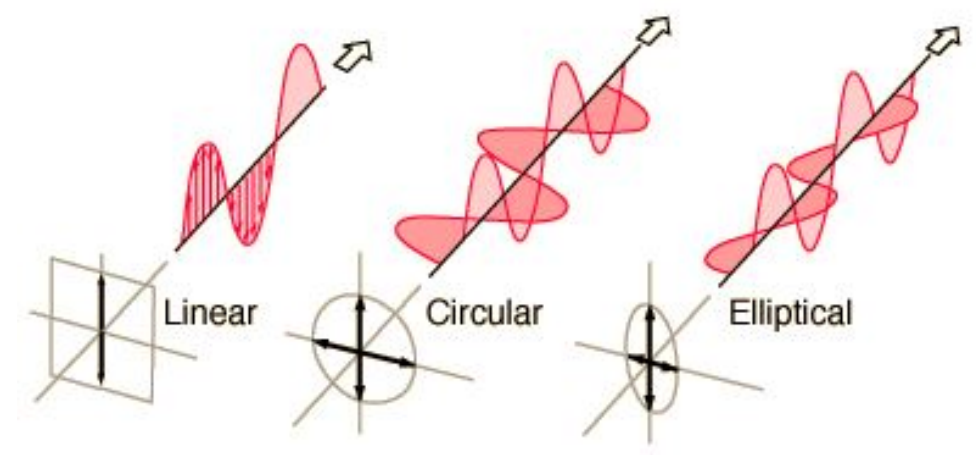

Figure 2.7: Linear, circular and elliptically polarized light [12]

Most transparent materials are optically isotropic, meaning that light passing through travels at the same speed regardless of the orientation. Photoelastic materials under stress are optically anisotropic, meaning that a certain component of the light will be slowed down as it passes through the material. The amount of retardation, or slowing of light, is proportional to the amount of strain in a photoelastic material; and this in essence is the property that allows the photoelastic principle. The change in speed of light causes wave interference, which causes cancellation or amplification of the light intensity. This is what causes the fringe pattern observed in photoelasticity. If the light source is monochromatic, the pattern produced will be black and white; but if white light is used a colour sequence will be observed, where the colour that is destructively interfered will be absent and its opposite will be seen - for example, if red light is being interfered, then blue will be observed.

Quarter wave plates are used to make circularly polarized light. These are plates made of a material that slows one component of the light by a quarter of a 
wavelength. When quarter wave plates are put on a polariscope, it becomes a circular polariscope, and is used to observe stresses without considering the stress orientations.

When stressed, birefringent materials will change their refractive index, which results in the creation of fringe patterns when viewed through the polariscope. Birefringence of the material changes linearly with the difference in principle stresses that the material is subjected to, which means that the stress or strain the material is subject to can be determined by the fringe pattern observed. The lines of constant colour seen in the stressed material are known as isochromatics and the strain is the same along the isochromatic. The fringe pattern order is shown in Figure 2.8. The fringe order is linearly related to the amount of strain, and the fringe order coefficient can be determined experimentally [13].

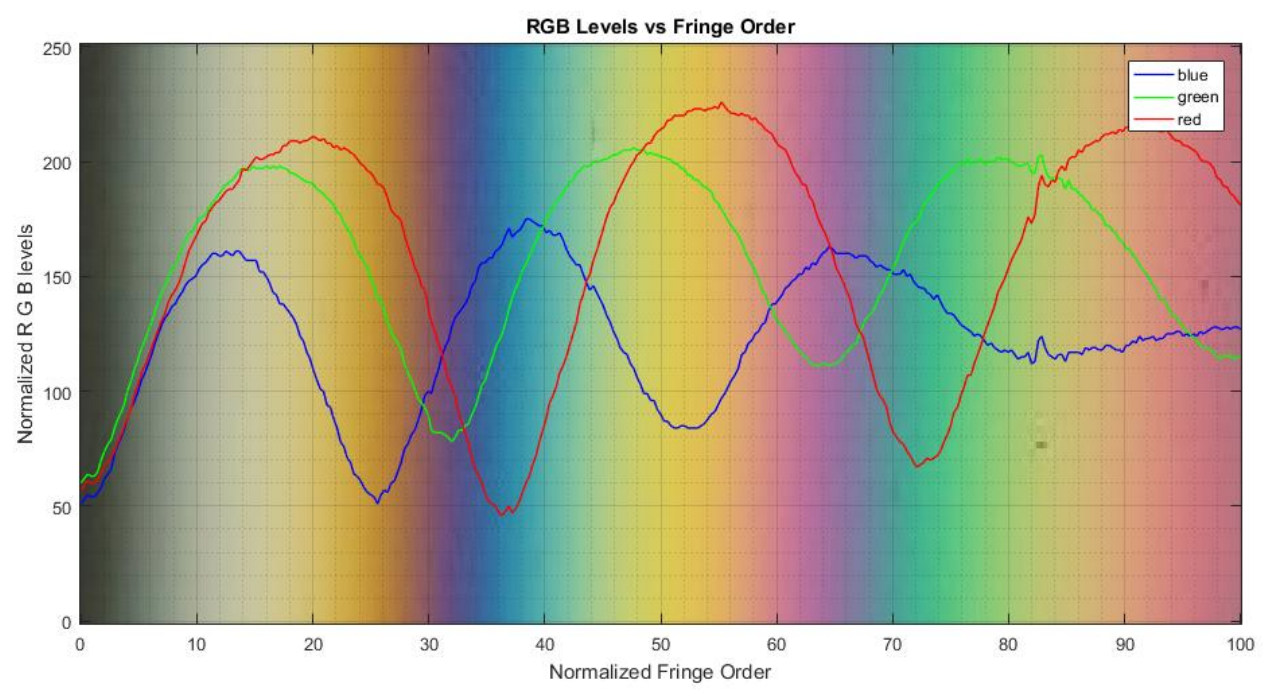

Figure 2.8: Photoelastic fringe order

A general idea of the stress levels in a part can be had by simply counting the fringes in the area in question, since the higher the fringe order the higher the stress. For determining the precise stress at a point, counting fringes is not as accurate, so optical methods are available, such as using Tardy or Babinet-Soleil compensators, which shift the fringe pattern and allow for optical means of determining the inter-fringe value [13]. Now, digital means are available to determine the fringe value at any point. Digital photoelasticity was an early method, which required six images 
with different orientations of the analyzer and analyzer $1 / 4$ wave plate to determine the stresses at any point. This method is fully automated but cannot be used for dynamic loads because it requires six images to be taken for a single load case. A newer method, RGB photoelasticity, is a single image method that uses a look-up table and analysis of the intensity of the individual red, green and blue values from the digital camera to determine the stresses at any given point, which makes it possible to perform automatic photoelasticity on structures under dynamic loading. For a review on digital photoelastic methods, the reader is referred to [14].

To determine stresses using photoelasticity requires accurate determination of the fringe order and knowledge of the material's fringe value, $f_{\sigma}$ in fringes / unit stress. This is done with the same equation used to determine the principle stress difference:

$$
\sigma_{1}-\sigma_{2}=\frac{N f_{\sigma}}{h}
$$

where $N$ is the fringe order and $h$ is the material thickness [13]. This equation is however not valid at high stresses [9]. Strain can likewise be determined in an elastic material with

$$
\begin{gathered}
\frac{N f_{\epsilon}}{h}=\epsilon_{1}-\epsilon_{2} \\
f_{\epsilon}=\frac{1+\nu}{E} f_{\sigma}
\end{gathered}
$$

where $f_{\epsilon}$ is the fringe sensitivity for strain, and $\nu$ is Poisson's ratio. To determine the fringe value, a test specimen with a known analytical solution is required. Beams in bending or tension can be used but a circular disc is usually preferred. The fringe sensitivity of a disc is given by

$$
f_{\sigma}=\frac{8 P}{\pi D N}
$$

where $D$ is the diameter of the circle. Multiple loads are applied and a best fit line is used to find $P / N$ to determine the fringe sensitivity [9]. 


\subsection{Photoviscoelasticity}

Most photoelastic materials are also viscoelastic at room temperatures, which means that under sustained load, they will creep and the fringe pattern will change over time to reflect the changing strains. This time dependence means that the fringe sensitivity $f_{\sigma}$ is now time dependent, which changes Equations 2.3 and 2.4 to

$$
\begin{gathered}
\sigma_{1}-\sigma_{2}=\frac{N f_{\epsilon}(t)}{h} \\
\epsilon_{1}-\epsilon_{2}=\frac{N f_{\epsilon}(t)}{h}
\end{gathered}
$$

The fringe sensitivity of a material tends to change rapidly with time and then become more stable after about an hour. This trend must be determined experimentally and it depends on the material type, age, temperature and other factors. An general trend for the fringe sensitivity variation with time is shown in Figure 2.9.

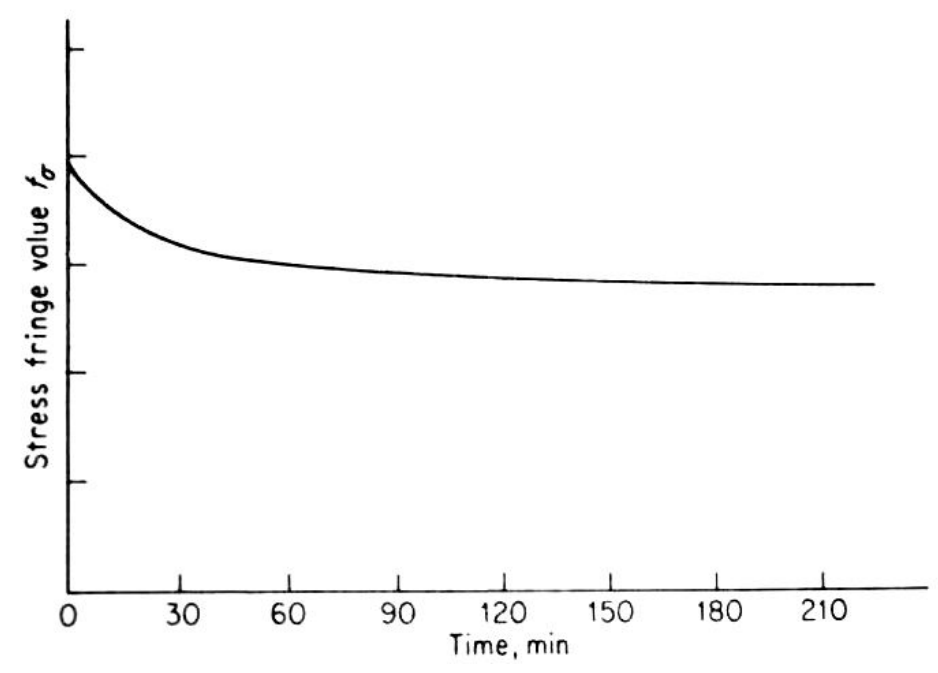

Figure 2.9: Typical fringe sensitivity variation with time [13]

\subsection{Polymers}

Polymers - "many parts" in Greek- are a group of materials so named because of their composition of many repeated units. Natural polymers such as silk, rubber and 
wool exist and have been used since antiquity but synthetic polymers such as nylon, polyvinyl chloride or silicone are important materials both to engineering and to our everyday lives. Polymer synthesis was started in the late 1800s in search of ways to synthesize replacements for scarce materials such as silk or ivory. Bakelite, originally intended to be a replacement for shellac, was one of the first synthetic polymers to be mass produced, and found diverse uses in moulding, electrical insulation, or as jewelry [15]. Synthetic rubber was conceived around the time as a replacement for natural rubber which was during wartime scarce or expensive for certain nations. The 1940s and 50s saw the rise of polymers in place of traditional materials, and this trend has continued to today where many objects are made of polymers where the inexpense, resistance to environmental effects or ease of manufacturing make them ideal materials [15].

Polymers chains are made of repeating units called monomers, which are held together with covalent bonds. These chains are of random length, and orientation. Some polymers have side branches, which are like smaller lengths of polymer attached to the side of the main polymer chain; or are cross-linked which means that they are attached to other polymer chains in a grid-like manner. Van der Waals force holds the polymer chains together. Unlike metals, polymer microstructure is not crystalline and regular but rather random arrangements of random lengths of polymer molecules.

Polymers are classified as either thermoplastics or thermosetting polymers. Thermoplastics do not change chemically as they are heated, but become mouldable. This allows thermoplastics to be recycled. Thermosetting plastics on the other hand, can only be melted and solidified once, after which they undergo a chemical change which cannot be reversed by heating, and thus are not easily recyclable.

Two materials were chosen for the experiments - polycarbonate and acrylic. The materials had to be clear to allow for the use of photoelasticity, and easy to make rings out of. Both of these materials were suitable for the experiments because as polymers they would be viscoelastic, and unlike metals, they would show obvious viscoelastic behaviour at temperatures low enough that specialised equipment was not needed. The two materials selected are discussed below. An explanation of why these materials were chosen for the experiments is in Section 3.1. 
Polycarbonate, sometimes known by its trademark names such as Lexan or Makrolon, is a thermoplastic polymer valued for its transparency and impact resistance. As the name 'polycarbonate' implies, it consists of polymers containing carbonate groups. Polycarbonate was a good choice for the experiments because of its photoelastic sensitivity and ductility - it can be bent at room temperature to sharp angles without fracturing. Properties of polycarbonate used in the experiments is shown below in Table 2.1.

Table 2.1: Properties for Lexan [16]

\begin{tabular}{ccc}
\hline Property & Value & Unit \\
\hline \hline Density & 1.2 & $\mathrm{~g} / \mathrm{cm}^{3}$ \\
Shear modulus & 2.9 & $\mathrm{GPa}$ \\
Elastic modulus & 2.6 & $\mathrm{GPa}$ \\
Glass transition temperature & 147 & ${ }^{\circ} \mathrm{C}$ \\
\hline
\end{tabular}

Polymethyl methacrylate (PMMA), more commonly known as acrylic or by trademark names such as Perspex or Plexiglas, was the other choice for use as a viscoelastic ring material, since it is easily available, clear, and has the great advantage of being able to be laser cut, which simplifies manufacturing. However, acrylic is not very birefringent, has a lower glass transition temperature than polycarbonate and fails in a brittle manner. The material properties for the acrylic used are shown below in Table 2.2.

Table 2.2: Properties for Plaskolite Optix [17]

\begin{tabular}{ccc}
\hline Property & Value & Unit \\
\hline \hline Density & 1.2 & $\mathrm{~g} / \mathrm{cm}^{3}$ \\
Shear modulus & 1.08 & $\mathrm{GPa}$ \\
Elastic modulus & 2.82 & $\mathrm{GPa}$ \\
Glass transition temperature & 105 & ${ }^{\circ} \mathrm{C}$ \\
\hline
\end{tabular}




\subsubsection{Polymer scatter}

Because of their non-crystalline, random structure, polymers are known to have variabilities in their material properties in the order of 50-100\%, which is much more than the less than $5 \%$ variation guaranteed in metals. Variability of creep strain in the order of up to $75 \%$ has been observed by Cook et al [18] in seven types of fibre reinforced polymers, and variability over $100 \%$ in the strain of vinyl esters has been observed by Simsiriwong et al [19].

\subsection{Viscoelastic ring stability theory}

To help predict the life of CANDU garter springs, C. G. Merrett has developed a stability theory for viscoelastic rings. This is an intermediate step into predicting the life of helical coils, like the garter springs, but springs are complex enough that simplification to a ring is justified. The theory takes the elastic mechanics of a ring under a uniform pressure load, converts this pressure load to a two point loads across the diameter. and then uses the elastic-viscoelastic correspondence principle to make suitable equations for a viscoelastic ring. The stability theory provides an estimate of the non dimensional stability time given geometry, material properties and load. A brief summary of the derivation of the theory is shown below; for a complete derivation refer to [1].

Merrett's viscoelastic ring stability theory starts with Wah's formulation for the dynamics of an elastic ring under a uniform pressure load:

$$
\begin{gathered}
\frac{E I}{R^{4}}\left(\frac{\partial^{4} w}{\partial \phi^{4}}-\frac{\partial^{3} v}{\partial \phi^{3}}\right)+\frac{E A}{R^{2}}\left(w+\frac{\partial v}{\partial \phi}\right)+\frac{q}{R}\left(\frac{\partial^{2} w}{\partial \phi^{2}}-\frac{\partial v}{\partial \phi}\right)+\rho A \frac{\partial^{2} w}{\partial t^{2}}=0 \\
\frac{E I}{R^{4}}\left(\frac{\partial^{3} w}{\partial \phi^{3}}-\frac{\partial^{2} v}{\partial \phi^{2}}\right)-\frac{E A}{R^{2}}\left(\frac{\partial w}{\partial \phi}+\frac{\partial^{2} v}{\partial^{2} \phi}\right)+\frac{q}{R}\left(\frac{\partial w}{\partial \phi}+\frac{\partial^{2} v}{\partial \phi^{2}}\right)+\rho A \frac{\partial^{2} v}{\partial t^{2}}=0
\end{gathered}
$$




$$
\begin{gathered}
\frac{E \bar{I}}{R^{4}}\left(\frac{\partial^{4} u}{\partial \phi^{4}}-\frac{\partial^{2}(R \theta)}{\partial \phi^{2}}\right)-\frac{G J}{R^{4}}\left(\frac{\partial^{2} u}{\partial \phi^{2}}+\frac{\partial^{2}(R \theta)}{\partial \phi^{2}}\right)+\frac{q}{R} \frac{\partial^{2} u}{\partial \phi^{2}}+\rho A \frac{\partial^{2} u}{\partial t^{2}}=0 \\
\frac{E \bar{I}}{R^{4}}\left(R \theta-\frac{\partial^{2} u}{\partial \phi^{2}}\right)-\frac{G J}{R^{2}}\left(\frac{\partial^{2} u}{\partial \phi^{2}}+\frac{\partial^{2}(R \theta)}{\partial \phi^{2}}\right)+\frac{q}{R} \frac{I_{p}}{A} \frac{\partial^{2}(R \theta)}{\partial \phi^{2}}+\rho I_{p} \frac{\partial^{2}(R \theta)}{\partial t^{2}}=0
\end{gathered}
$$

where $w$ is the outward radial displacement, $v$ is the tangential displacement, $u$ is the displacement perpendicular to the plane of the ring, $\theta$ is the angular rotation of a cross-section of the ring, $A$ is the cross-sectional area of the ring, $R$ is the ring's radius, $I$ is the second moment of inertia about an axis perpendicular to the plane, $\bar{I}$ is the second moment of inertia about the radial axis, $I_{p}=I+\bar{I}$ is the polar moment of inertia, $J$ is the torsion constant of the cross-section, $\rho$ is the density, $E$ and $G$ are the moduli, $t$ is time, and $\phi$ is the circumferential coordinate. These parameters are shown on a ring in Figure 2.10

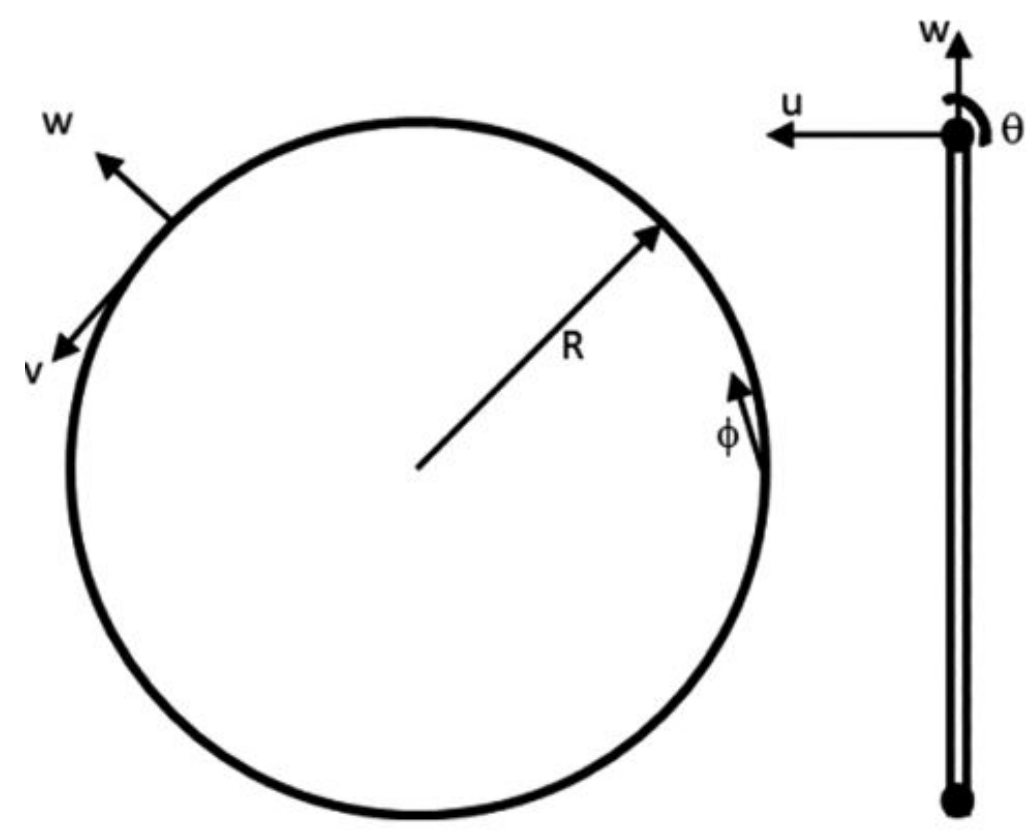

Figure 2.10: Ring parameters [1]

Thus the displacements for the ring are 


$$
\begin{aligned}
w & =\sum_{n=1}^{M} W_{n}(t) \cos \left(n \phi+\phi_{0}\right) \\
v & =\sum_{n=1}^{N} V_{n}(t) \sin \left(n \phi+\phi_{0}\right) \\
u & =\sum_{n=1}^{O} U_{n}(t) \sin \left(n \phi+\phi_{0}\right) \\
R \theta & =\sum_{n=1}^{P} R \Theta_{n}(t) \sin \left(n \phi+\phi_{0}\right)
\end{aligned}
$$

The $q / R$ term in Equations 2.9 to 2.12 is replaced with

$$
P_{c}\left[\delta\left(\phi-\frac{\pi}{2}\right)+\delta\left(\phi-\frac{3 \pi}{2}\right)\right]
$$

so that the two point concentrated load is accounted for. $\delta$ is the Dirac delta distribution and $P_{c}$ is the load magnitude.

The governing equations are thus:

$$
\begin{aligned}
& \frac{E I}{R^{4}}\left(\frac{\partial^{4} w}{\partial \phi^{4}}-\frac{\partial^{3} v}{\partial \phi^{3}}\right)+\frac{E A}{R^{2}}\left(w+\frac{\partial v}{\partial \phi}\right)+ \\
& P_{c}\left[\delta\left(\phi-\frac{\pi}{2}\right)+\delta\left(\phi-\frac{3 \pi}{2}\right)\right]\left(\frac{\partial^{2} w}{\partial \phi^{2}}-\frac{\partial v}{\partial \phi}\right)+\rho A \frac{\partial^{2} w}{\partial t^{2}}=0
\end{aligned}
$$

$$
\begin{aligned}
& \frac{E I}{R^{4}}\left(\frac{\partial^{3} w}{\partial \phi^{3}}-\frac{\partial^{2} v}{\partial \phi^{2}}\right)-\frac{E A}{R^{2}}\left(\frac{\partial w}{\partial \phi}+\frac{\partial^{2} v}{\partial^{2} \phi}\right)+ \\
& P_{c}\left[\delta\left(\phi-\frac{\pi}{2}\right)+\delta\left(\phi-\frac{3 \pi}{2}\right)\right]\left(\frac{\partial w}{\partial \phi}+\frac{\partial^{2} v}{\partial \phi^{2}}\right)+\rho A \frac{\partial^{2} v}{\partial t^{2}}=0
\end{aligned}
$$

$$
\begin{aligned}
\frac{E \bar{I}}{R^{4}}\left(\frac{\partial^{4} u}{\partial \phi^{4}}-\frac{\partial^{2}(R \theta)}{\partial \phi^{2}}\right)-\frac{G J}{R^{4}} & \left(\frac{\partial^{2} u}{\partial \phi^{2}}+\frac{\partial^{2}(R \theta)}{\partial \phi^{2}}\right)+ \\
P_{c}\left[\delta\left(\phi-\frac{\pi}{2}\right)+\delta\left(\phi-\frac{3 \pi}{2}\right)\right] & \frac{\partial^{2} u}{\partial \phi^{2}}+\rho A \frac{\partial^{2} u}{\partial t^{2}}=0
\end{aligned}
$$




$$
\begin{aligned}
\frac{E \bar{I}}{R^{4}}\left(R \theta-\frac{\partial^{2} u}{\partial \phi^{2}}\right)- & \frac{G J}{R^{2}}\left(\frac{\partial^{2} u}{\partial \phi^{2}}+\frac{\partial^{2}(R \theta)}{\partial \phi^{2}}\right)+ \\
& P_{c}\left[\delta\left(\phi-\frac{\pi}{2}\right)+\delta\left(\phi-\frac{3 \pi}{2}\right)\right] \frac{I_{p}}{A} \frac{\partial^{2}(R \theta)}{\partial \phi^{2}}+\rho I_{p} \frac{\partial^{2}(R \theta)}{\partial t^{2}}=0
\end{aligned}
$$

Then the elastic-viscoelastic correspondence principle is used to change Equations $2.18-2.21$ to have viscoelastic material properties. This is done by taking a Fourier or Laplace transform in time, and results in

$$
\begin{gathered}
\frac{E(0) I}{R^{4}\left(\frac{\partial^{4} w}{\partial \phi^{4}}-\frac{\partial^{3} v}{\partial \phi^{3}}\right)-} \\
\int_{0}^{t} \frac{E\left(t-t^{\prime}\right)}{d t^{\prime}} \frac{I}{R^{4}}\left(\frac{\partial^{4} w}{\partial \phi^{4}}-\frac{\partial^{3} v}{\partial \phi^{3}}\right) d t^{\prime}+ \\
\frac{E(0) A}{R^{2}}\left(w+\frac{\partial v}{\partial \phi}\right)- \\
\int_{0}^{t} \frac{E\left(t-t^{\prime}\right)}{d t^{\prime}} \frac{A}{R^{2}}\left(w+\frac{\partial v}{\partial \phi}\right) d t^{\prime}+ \\
{\left[\delta\left(\phi-\frac{\pi}{2}\right)+\delta\left(\phi-\frac{3 \pi}{2}\right)\right]\left(\frac{\partial^{2} w}{\partial \phi^{2}}-\frac{\partial v}{\partial \phi}\right)+\quad \rho A \frac{\partial^{2} w}{\partial t^{2}}=0}
\end{gathered}
$$

$$
\begin{gathered}
\frac{E(0) I}{R^{4}}\left(\frac{\partial^{3} w}{\partial \phi^{3}}-\frac{\partial^{2} v}{\partial \phi^{2}}\right)- \\
\int_{0}^{t} \frac{E\left(t-t^{\prime}\right)}{d t^{\prime}} \frac{I}{R^{4}}\left(\frac{\partial^{3} w}{\partial \phi^{3}}-\frac{\partial^{2} v}{\partial \phi^{2}}\right) d t^{\prime}- \\
\frac{E(0) A}{R^{2}}\left(\frac{\partial w}{\partial \phi}+\frac{\partial^{2} v}{\partial^{2} \phi}\right)+ \\
\int_{0}^{t} \frac{E\left(t-t^{\prime}\right)}{d t^{\prime}} \frac{A}{R^{2}}\left(\frac{\partial w}{\partial \phi}+\frac{\partial^{2} v}{\partial^{2} \phi}\right) d t^{\prime}+ \\
P_{c}\left[\delta\left(\phi-\frac{\pi}{2}\right)+\delta\left(\phi-\frac{3 \pi}{2}\right)\right]\left(\frac{\partial w}{\partial \phi}+\frac{\partial^{2} v}{\partial \phi^{2}}\right)+\quad \rho A \frac{\partial^{2} v}{\partial t^{2}}=0
\end{gathered}
$$




$$
\begin{gathered}
\frac{E(0) \bar{I}}{R^{4}}\left(\frac{\partial^{4} u}{\partial \phi^{4}}-\frac{\partial^{2}(R \theta)}{\partial \phi^{2}}\right)- \\
\int_{0}^{t} \frac{E\left(t-t^{\prime}\right)}{d t^{\prime}} \frac{\bar{I}}{R^{4}}\left(\frac{\partial^{4} u}{\partial \phi^{4}}-\frac{\partial^{2}(R \theta)}{\partial \phi^{2}}\right) d t^{\prime}- \\
\quad \frac{G(0) J}{R^{4}}\left(\frac{\partial^{2} u}{\partial \phi^{2}}+\frac{\partial^{2}(R \theta)}{\partial \phi^{2}}\right)+ \\
\int_{0}^{t} \frac{G\left(t-t^{\prime}\right)}{d t^{\prime}} \frac{J}{R^{4}}\left(\frac{\partial^{2} u}{\partial \phi^{2}}+\frac{\partial^{2}(R \theta)}{\partial \phi^{2}}\right) d t^{\prime}+ \\
P_{c}\left[\delta\left(\phi-\frac{\pi}{2}\right)+\delta\left(\phi-\frac{3 \pi}{2}\right)\right] \frac{\partial^{2} u}{\partial \phi^{2}}+\quad \rho A \frac{\partial^{2} u}{\partial t^{2}}=0
\end{gathered}
$$

$$
\begin{aligned}
\frac{E(0) \bar{I}}{R^{4}}\left(R \theta-\frac{\partial^{2} u}{\partial \phi^{2}}\right)- & \\
& \int_{0}^{t} \frac{E\left(t-t^{\prime}\right)}{d t^{\prime}} \frac{\bar{I}}{R^{4}}\left(R \theta-\frac{\partial^{2} u}{\partial \phi^{2}}\right) d t^{\prime}- \\
& \frac{G(0) J}{R^{2}}\left(\frac{\partial^{2} u}{\partial \phi^{2}}+\frac{\partial^{2}(R \theta)}{\partial \phi^{2}}\right)+ \\
& \int_{0}^{t} \frac{G\left(t-t^{\prime}\right)}{d t^{\prime}} \frac{J}{R^{2}}\left(\frac{\partial^{2} u}{\partial \phi^{2}}+\frac{\partial^{2}(R \theta)}{\partial \phi^{2}}\right) d t^{\prime}+ \\
& P_{c}\left[\delta\left(\phi-\frac{\pi}{2}\right)+\delta\left(\phi-\frac{3 \pi}{2}\right)\right] \frac{I_{p}}{A} \frac{\partial^{2}(R \theta)}{\partial \phi^{2}}+
\end{aligned}
$$

$$
\rho I_{p} \frac{\partial^{2}(R \theta)}{\partial t^{2}}=0
$$

An elastic structure's integrity only depends on the load, while for a viscoelastic structure, there is a time dependency as well. To find the time to failure of a viscoelastic ring, Drozdov and Kolmanovskii's modification to Lyapunov stability

$$
\ddot{u}(t)+\bar{A} u(t)+\int_{0}^{t} \dot{Q}(t-s) \bar{B} u(s) d s=0
$$

is used where $u(t)$ is a function for the displacements. The following changes

$$
A=U^{-1} \bar{A} U
$$




$$
\begin{gathered}
B=U^{-1} \bar{B} U \\
v=U^{-1} u
\end{gathered}
$$

turn Equation 2.26 into

$$
\ddot{v}(t)+A v(t)+\int_{0}^{t} \dot{Q}(t-s) B v(s) d s=0
$$

Equation 2.30 can be used if the following equation is true

$$
\left\|A^{-1 / 2} B_{-} A^{-1 / 2}\right\|<\frac{1+t_{m} a x}{2 \eta}
$$

The viscoelastic relaxation measure

$$
Q(t)=-E \chi[1-\exp (-t / T)]
$$

is used where $\chi$ is the material viscosity and $T$ is the relaxation time.

The stability condition in Equation 2.31 can be changed to become

$$
\left\|A^{-1 / 2} B_{-} A^{-1 / 2}\right\|<\frac{1-2 \chi\left(1-\exp \left(\frac{-t_{\max }}{T}\right)\right)+\chi^{2}\left(1-\exp \left(\frac{-t_{\max }}{T}\right)\right)^{2}}{\frac{4}{T} \chi^{2}\left[T\left(1-\exp \left(\frac{-t_{\max }}{T}\right)\right)^{2}-t_{\max } \exp \left(\frac{-t_{\max }}{T}\right)\left(1-\exp \left(\frac{-t_{\max }}{T}\right)\right)\right]}
$$

which can be rearraged to form a polynomial, which produces

$$
\left(\alpha_{2}-\delta_{2} t_{\max }\right) \exp \left(\frac{-2 t_{\max }}{T}\right)+\left(\beta+\delta_{2} t_{\max }\right) \exp \left(\frac{-t_{\max }}{T}\right)+\gamma=0
$$

where 


$$
\begin{array}{r}
\alpha_{2}=\chi^{2}\left(1-4 H^{2}\right) \\
\delta_{2}=\frac{4 \chi^{2} H^{2}}{T} \\
\beta=-2 \chi^{2}\left(1-4 H^{2}\right)+2 \chi \\
\gamma=\chi^{2}\left(1-4 H^{2}\right)-2 \chi+1 \\
H^{2}=\left\|A^{-1 / 2} B_{-} A^{-1 / 2}\right\|
\end{array}
$$

Using the quadratic equation and taking a Maclaurin expansion for the exponential term produces

$$
\begin{gathered}
{\left[\left(1-\frac{t_{\text {max }}}{T}+\frac{t_{\text {max }}^{2}}{2 T^{2}}-\frac{t_{\text {max }}^{3}}{6 T^{3}}+R_{3}\left(\frac{t_{\text {max }}}{T}\right)\right)\left[2 \alpha_{2}-2 \delta_{2} t_{\text {max }}\right]+\right.} \\
\left.\beta+\delta_{2} t_{\text {max }}\right]^{2}= \\
\delta_{2}^{2} t_{\text {max }}^{2}+(\beta+2 \gamma) 2 \delta_{2} t_{\text {max }}+\beta^{2}-4 \gamma \alpha_{2}
\end{gathered}
$$

Now there exists a stability condition that includes the ring life time, $t_{\max }$, Galerkin's method is used to remove the spatial component.

Since the time to failure testing was done at a constant temperature, to produce a comparable graph, Figure 2.11 was bisected at a viscosity of $\chi=0.2$ to produce Figure 2.12. A viscosity value of $\chi=0.2$ was chosen from previous research done by one of C. G. Merrett's previous Master's students [20] whose data was fitted to the standard viscoelastic model. The critical time / $\mathrm{T}$ values are multiplied by the estimated relaxation period to calculate the estimated time to failure. The values shown below in table 2.3 were used in the MATLAB program.

The graph in Figure 2.12 is discontinuous and appears to overlap. The plot is made by plotting lines that are not adjoined, and that is why it appears to overlap in places. The code functions by selecting the lowest real root that will satisfy the equation, and this value is selected and plotted. The code currently takes no considerations for continuity. The only difference between the code used in 
Table 2.3: Acrylic ring dimensions used for MATLAB simulation

\begin{tabular}{cc}
\hline Parameter & Value \\
\hline \hline Density $\left(\mathrm{kg} / \mathrm{m}^{3}\right)$ & 1130 \\
Radius of ring $(\mathrm{m})$ & 0.01397 \\
Base of cross section $(\mathrm{m})$ & 0.001524 \\
Height of cross section (m) & 0.0137 \\
Elastic Modulus (GPa) & 2.82 \\
Shear Modulus (GPa) & 1.08 \\
Estimated Relaxation Period (s) & 44875 \\
\hline
\end{tabular}

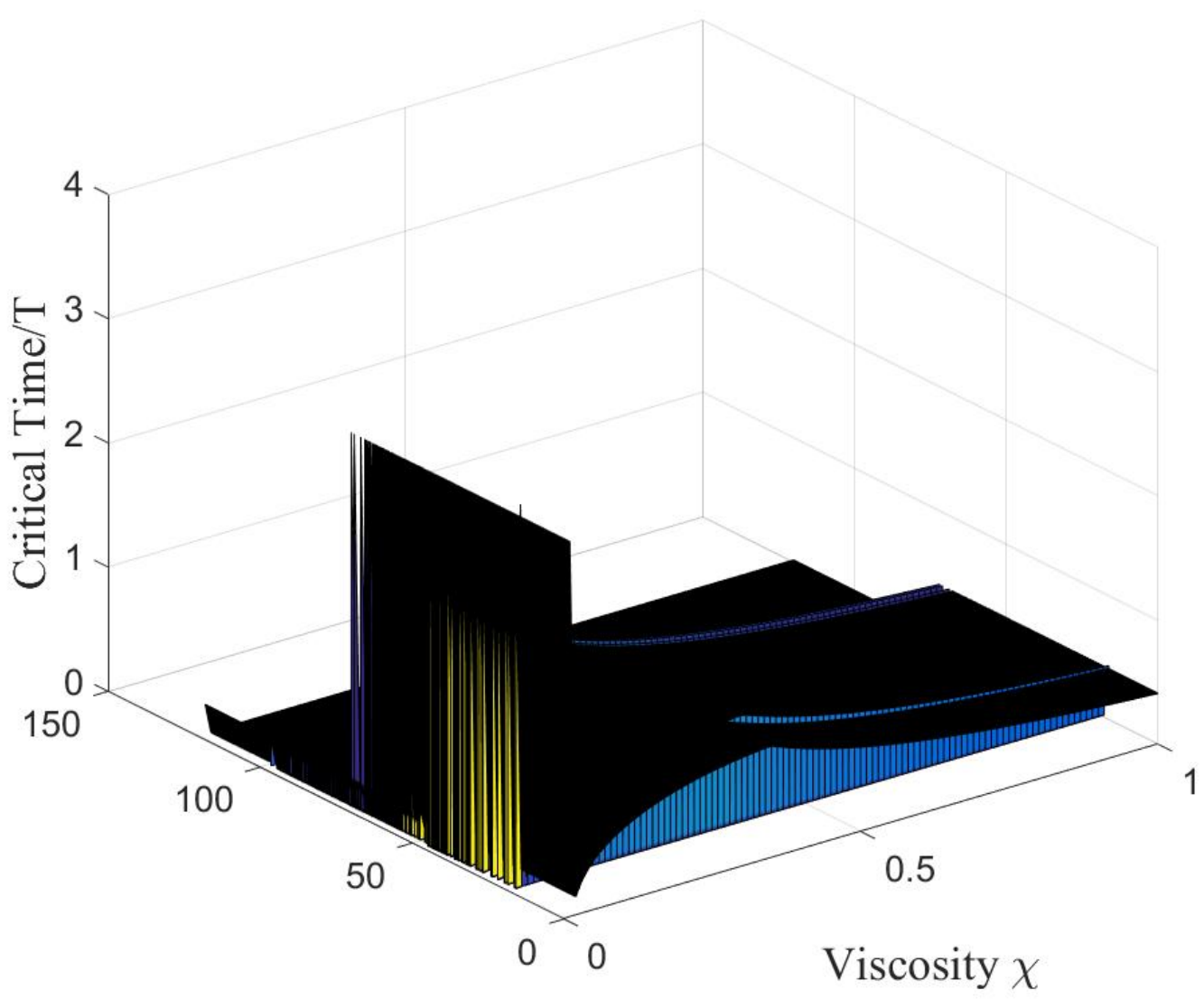

Concentrated Load $[\mathrm{N}]$

Figure 2.11: MATLAB code output graph 


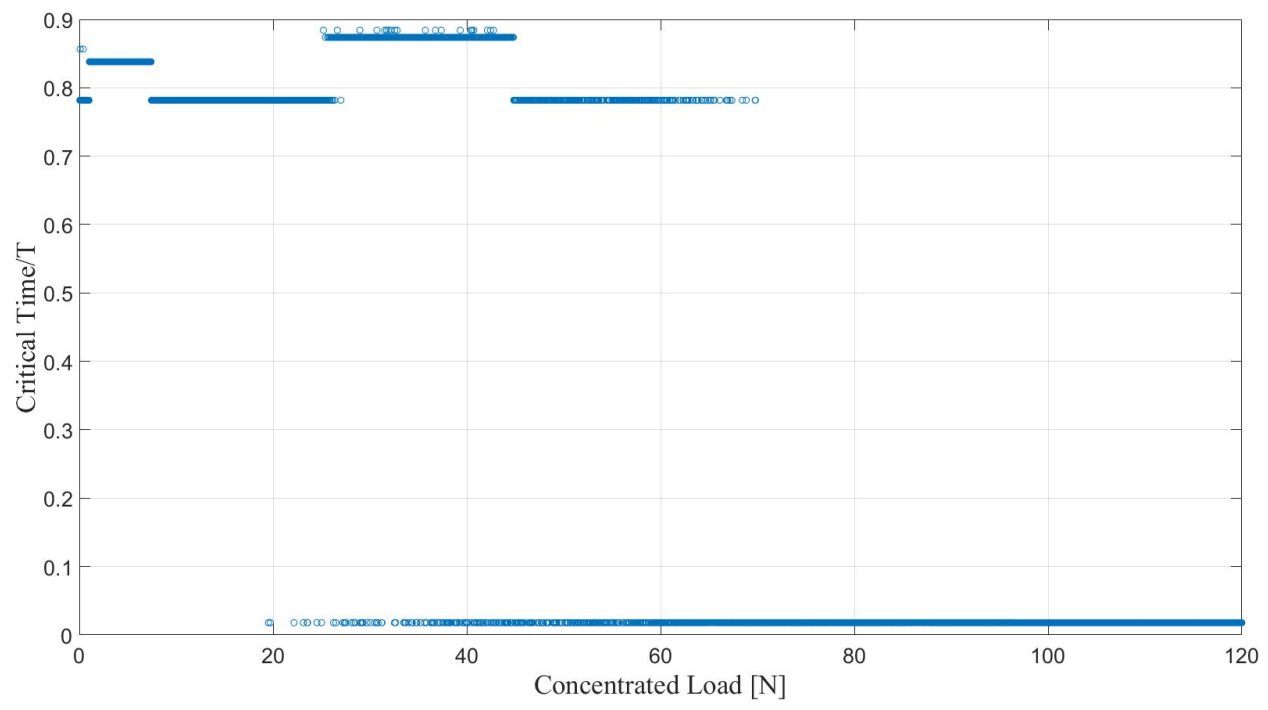

Figure 2.12: 2-D graph at viscosity $=0.2$

reference [1] and the code used for these experiments is that the number of steps to generate the surface plot was increased, and the necessary changes were made to predict the life of the acrylic rings (geometry and material properties).

The theoretical result as output by the MATLAB code is independent of temperature. The time to failure is calculated by multiplying the non-dimensional life by the relaxation time of the material at temperature. The relaxation time is calculated with Equations 2.41 and 2.42 [21].

$$
\begin{gathered}
\log \left(a_{T}\right)=\frac{E_{\alpha}}{2.303 R}\left(\frac{1}{T}-\frac{1}{T_{\alpha}}\right) \\
\log \left(a_{T}\right)=\log \left[\frac{\mathcal{T}(T)}{\mathcal{T}\left(T_{0}\right)}\right]
\end{gathered}
$$

where $\mathcal{T}$ is the relaxation time, $R$ is the universal gas constant of $8.314 \mathrm{~J} / \mathrm{mol} \mathrm{K}, E_{\alpha}$ is the activation energy for acrylic of $65 \mathrm{~kJ} / \mathrm{mol}$, and $T_{0}$ is the initial temperature of $297 \mathrm{~K}$ in our case. 


\section{Chapter 3}

\section{Experimental Setup}

\subsection{Material Choice and Manufacturing Samples}

Polycarbonate was initially chosen for its good photoelastic sensitivity and its ductility, but it was found that the polycarbonate took a long time to manufacture the rings because it had to be machined manually. Acrylic, on the other hand, could be quickly and accurately laser cut using a CNC laser cutter. Hence it was chosen to use acrylic to validate the time to failure model and use polycarbonate to investigate the changing stresses in the rings over time as they failed.

Both rings would bend out of plane until failure. The polycarbonate failed in a ductile manner, where the out of plane bending would increase until the ring buckled into a $\mathrm{C}$ shape in the side view. The acrylic rings would fracture in two once a certain amount of out of plane bending was reached.

Two ring geometries were used in the experiments, one for the polycarbonate rings and one for the acrylic rings. Both ring designs have an outer diameter of 1.65 " (41.9 mm), but have different inner diameters to allow for a reasonable time to failure at a reasonable load condition (load and temperature). The ring dimensions were somewhat arbitrary, driven by available materials and tooling. The ring dimensions are shown in Figure 3.1 and 3.2.

The acrylic rings were laser cut from $1 / 16 "$ (0.0625" or $1.587 \mathrm{~mm})$ extruded acrylic sheet. The nominal dimensions are as below in Table 3.1. Rings were cut in batches of 40. Note that the design dimensions in Table 3.1 and the measured 
dimensions in Figure 3.1 differ due to the width of cut of the laser and the variation in the thickness of the material sheet.

Table 3.1: Nominal Dimensions of Rings.

\begin{tabular}{cccc}
\hline Material & OD & ID & Thickness \\
\hline \hline C Series Acrylic & $1.650 "$ & $0.555 "$ & $0.0625 "$ \\
D2 Series Polycarbonate & $1.650 "$ & $0.937 "$ & $0.0937 "$ \\
\hline
\end{tabular}

The rings were measured after they were cut and the typical actual dimensions are shown in Figure 3.1 . Actual measured dimensions can be found in appendix A.1.5. Note that none of the laser cut rings were ever perfectly circular, and that the outer dimension value is the mean of the OD max and OD min dimensions.
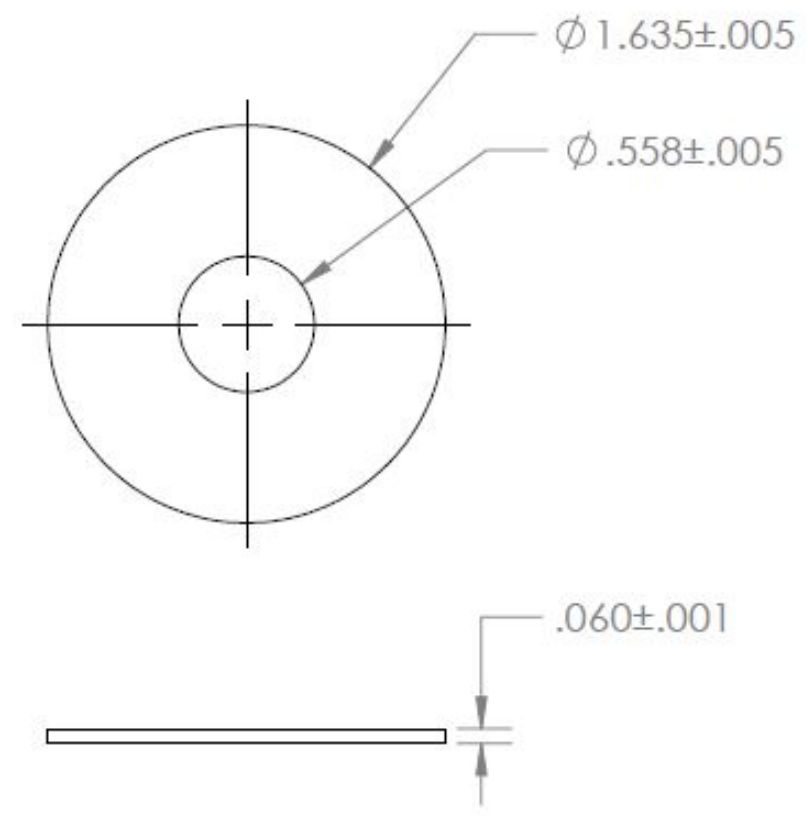

Figure 3.1: $\mathrm{C}$ series acrylic ring design dimensions and tolerance. 


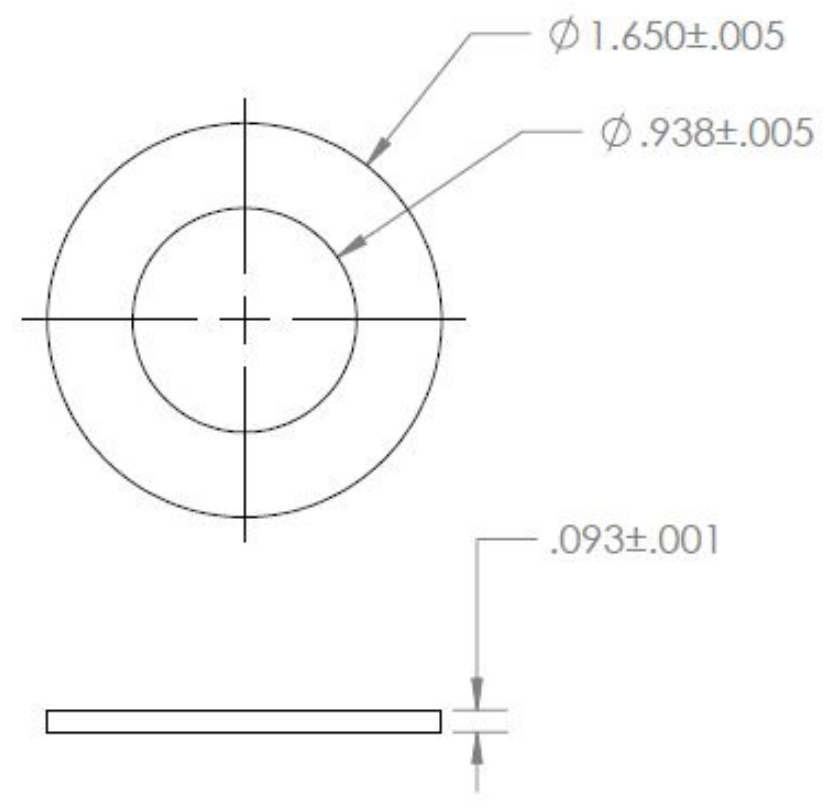

Figure 3.2: D2 series polycarbonate ring dimensions and tolerance

The polycarbonate rings were machined out of $3 / 32$ " $(0.0937$ " or $2.38 \mathrm{~mm})$ extruded Bayer Makrolon polycarbonate sheet. Because the sheet was thicker, a larger bore was used to achieve a reasonable time to failure.

Polycarbonate cannot be laser cut since it melts and re-fuses; hence to make rings from commercially available extruded sheet, the rings were machined using the following procedure:

- Cut out circle out of polycarbonate sheet using hole saw

- Turn to size using $1 / 4$ " bolt as mandrel

- Put in holder (see appendix A.2) and drill centre hole to size

- Anneal (see Section 3.3)

It was found that using a tool steel parting tool or flat-faced tool produced a better surface finish that using a DNMG carbide insert. Cuts up to 0.050" (radial) were good, and high cutting speed, around $1300 \mathrm{rpm}$, gave a good surface finish and did 
not melt the material. It was important to tighten both the mandrel and holder adequately such that the rings did not spin when being cut.

\subsection{Polariscope}

A Riken Keiki polariscope and load frame, shown in Figure 3.3 was used for this experiment. The polariscope setup consists of the following items:

- Fluorescent diffused light source

- Polarizer / Analyzer units, consisting of a polarizer capable of being remotely rotated using a controller, and a stationary quarter wave plate

- Load frame with 4:1 load amplification

- Insulating chamber containing test specimen

- Nikon D3200 digital single lens reflex camera on ball head stand, with 100$300 \mathrm{~mm} \mathrm{f} / 5.6$ zoom lens

A fluorescent light source is desirable because it has higher resolution of higher order fringes [14]. A large light source with a diffuser is used instead of the traditional small incandescent light with collimator.

The polarizer and analyzer are fitted with synchronous motors which allow them to be rotated remotely from a controller. This feature was not used in this experiment. The polarizer and analyzer were set up for dark field photoelasticity.

The load frame, shown in Figures 3.4 and 3.5 has a balanced lever arm with a 4:1 magnification of the load placed on the end. A crank and acme screw are used to raise or lower the inner portion of the load frame, allowing the specimen to be loaded. This load frame was used to provide constant load on the rings. 


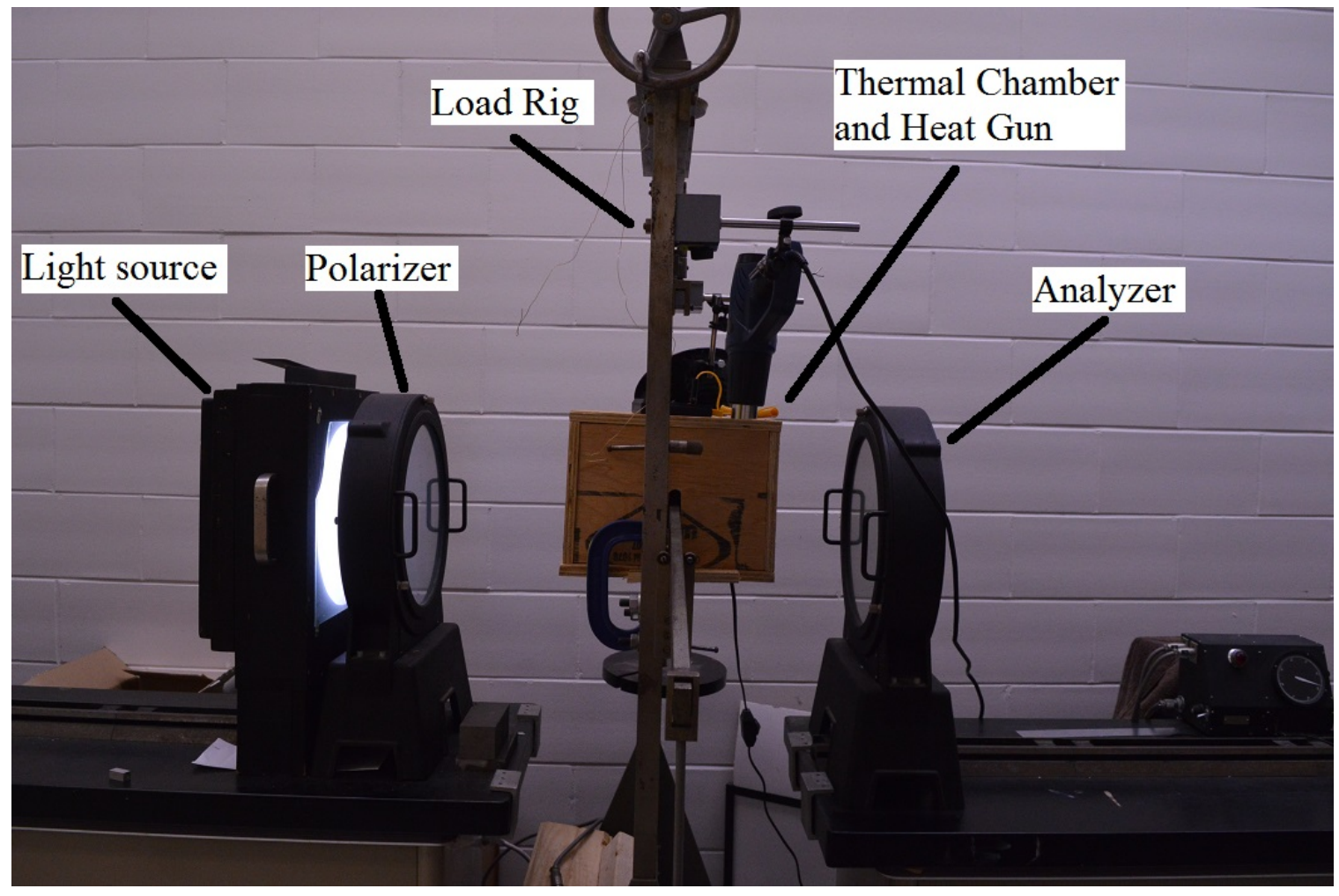

Figure 3.3: Polariscope with labeled components

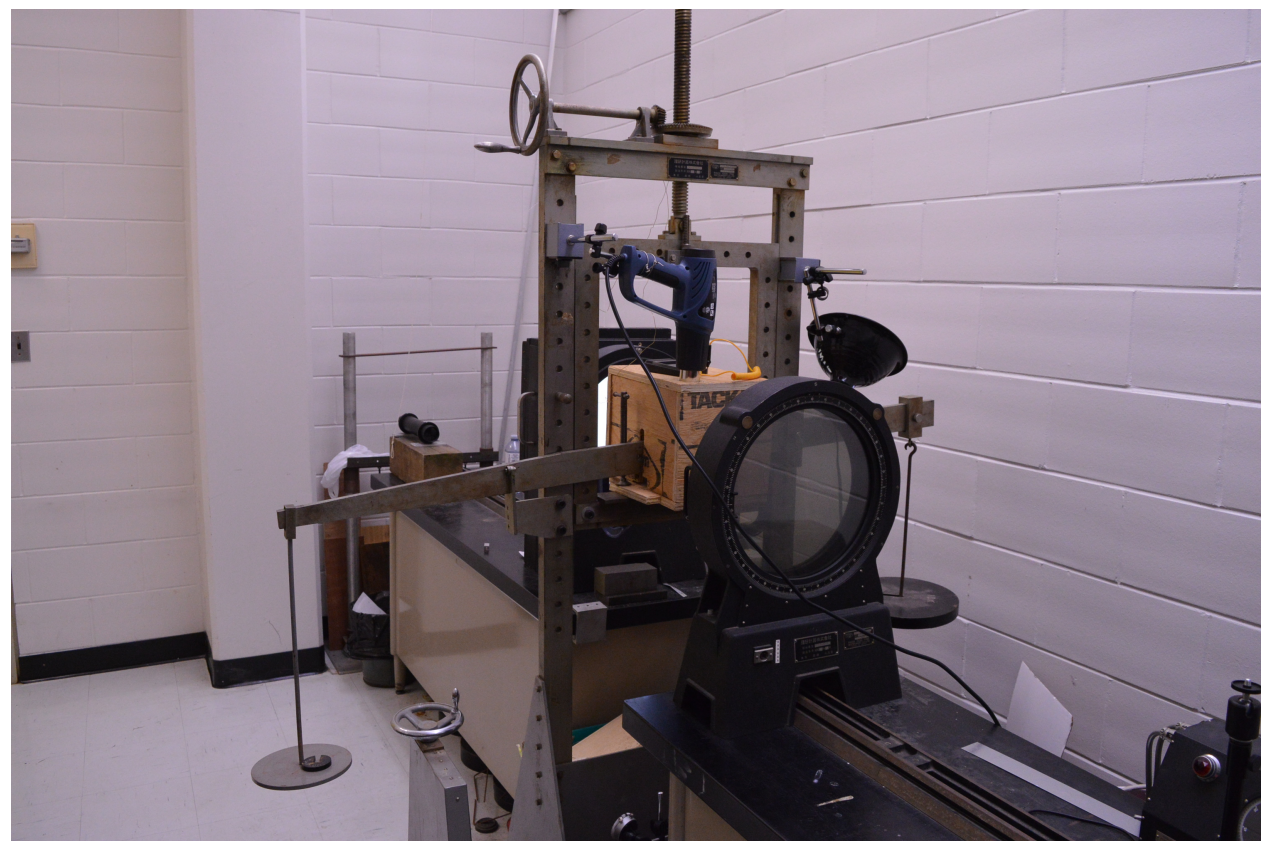

Figure 3.4: Polariscope view from camera end 


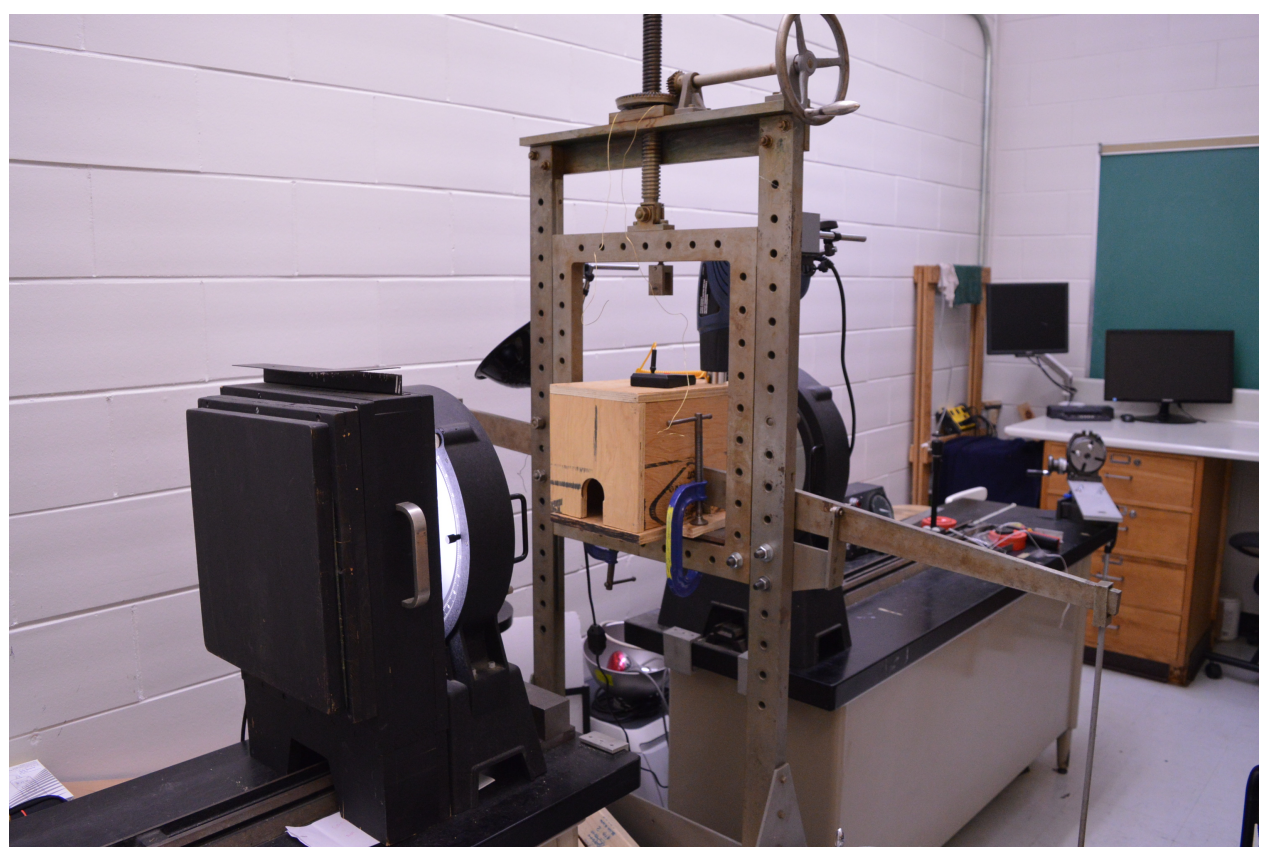

Figure 3.5: Polariscope view from light source end

The experiments take place in an insulating box, which is heated by a heat gun. The purpose of the box is to maintain a uniform temperature gradient over the ring.

The camera is fitted with a remote trigger to automatically take photographs at a specified interval. This interval was varied according to the expected life of the ring being tested. The exposure of the camera is set manually to avoid the camera's autoexposure being affected by the adverse lighting conditions. The correct exposure depends on light output, relative orientation of polarizers, distance from light source to camera, etc., and was experimentally determined to be f/16, 1/13s at ISO 1600 . To avoid flicker effects from the fluorescent lamp a shutter speed longer than $1 / 25 \mathrm{~s}$ was used. A long focal length lens is required for taking the photographs because of the small size of the rings and since the polarizers block the camera from being closer to the load frame. 


\subsection{Annealing Procedure}

Both materials have similar annealing procedures: slow heating to the annealing temperature, holding at the annealing temperature and then slow cooling to room temperature. A lower annealing temperature can be used but then the material needs to be held at that temperature for longer. Several annealing procedures were tried for both materials and none consistently fully annealed the materials.

The polycarbonate rings were annealed according to the procedure in [22]. The rings were placed between two $3 / 4$ " aluminum plates as thermal masses, and inserted in the oven, preheated to the annealing temperature of $150^{\circ} \mathrm{C}$. The rings would be left for at least 3 hours at that setting for the aluminum and rings to reach temperature, and then the oven would be switched off and left to cool over the next 4 hours. The rings could not be placed in the oven before it was switched on because of the large overtemperature spike that would ensue. Other annealing methods tried are described in [23] and [24]; these procedures did not seem to work as well with the material that was used in the experiments.

The acrylic rings were annealed according to the method in reference [25]. The rings were annealed in the oven between $3 / 4$ " aluminum plates as thermal masses. 18 rings were annealed at a time. The temperature on the oven is set to $80{ }^{\circ} \mathrm{C}$ and once the temperature is reached, the rings and aluminum plates are put in the oven and left for at least 7 hours, after which the rings are left to cool in the oven until they reach room temperature. The method described in reference [26] was also tried but it was found that the aforementioned method was more consistent.

\subsection{Thermal Chamber}

To allow the rings to creep and fail at a reasonable time, a method to raise the temperature of the rings was needed. Several iterations of the apparatus were used to achieve this, but the first attempts, which used a heat gun blowing directly on the ring, produced a significant thermal gradient in the rings, which caused inconsistency in the results. 
The final apparatus is shown in Figure 3.6 and 3.7. It is a wooden chamber with a wooden base, with cutouts for the load arm, viewing through the polariscope, a heat gun and a thermocouple probe.

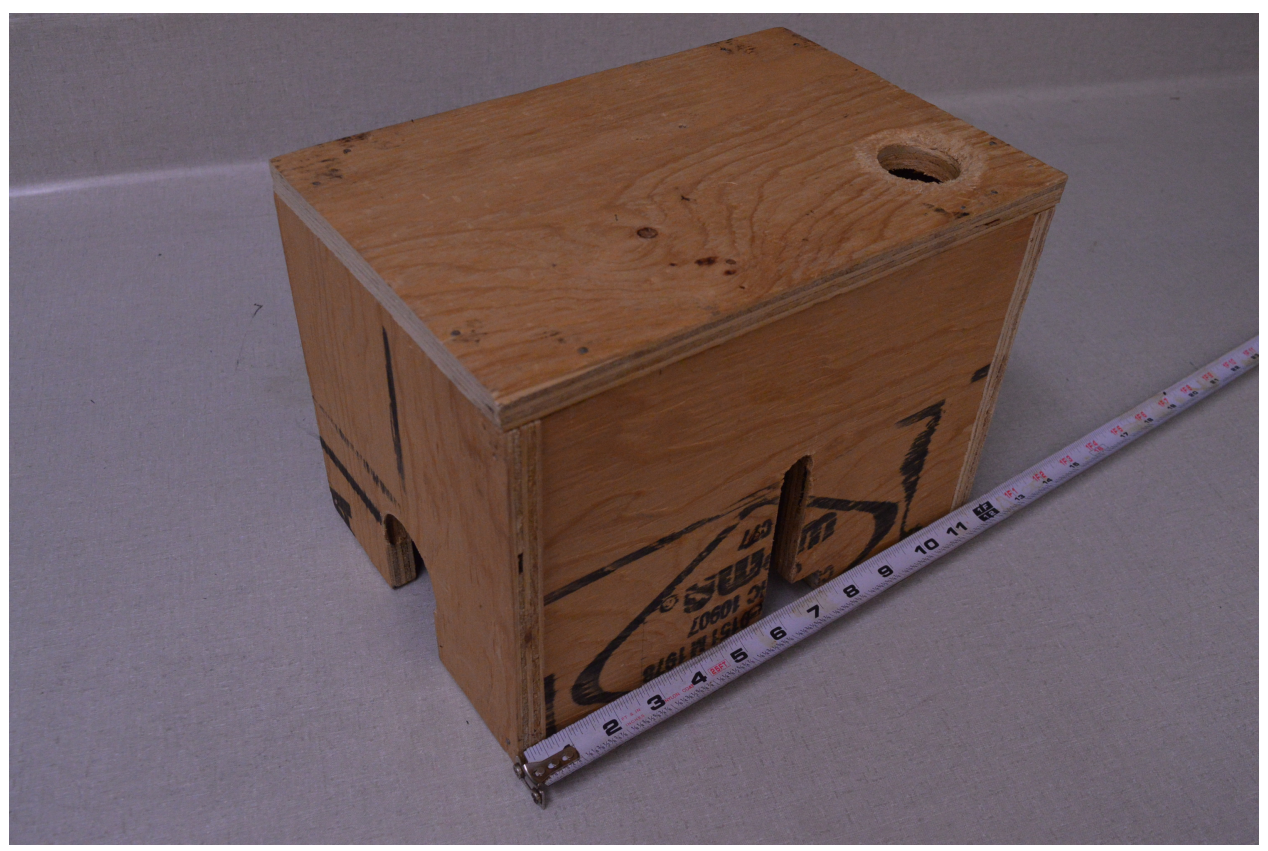

Figure 3.6: Thermal chamber

The heat gun has multiple settings for temperature and fan speed, and is feedback controlled so to keep the chamber at a steady temperature. The chamber requires about an hour for it and the load arm to reach steady state (about $90{ }^{\circ} \mathrm{C}$ ) from room temperature.

A ring positioner serves to hold the ring upright and in position as the apparatus is heated up. It is made of two pieces of 1 " $\mathrm{x} 3 / 32$ " aluminum angle bolted together with a $1 / 16$ " or $3 / 32$ " spacer (depending on the thickness of the ring), and a wire is tied around the bolt to allow for the positioner to be retrieved once the load is applied. The positioner is aligned with marks on the base of the thermal chamber to align the ring with the centre of the load arm, and to allow for repeatable ring placement. This positioner is shown in Figure 3.8. 


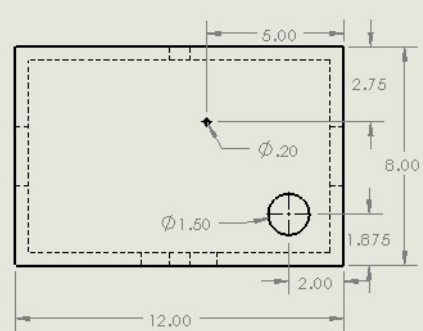

SLOTFOR LOAD ARM

SLOT FOR RING HOLDER
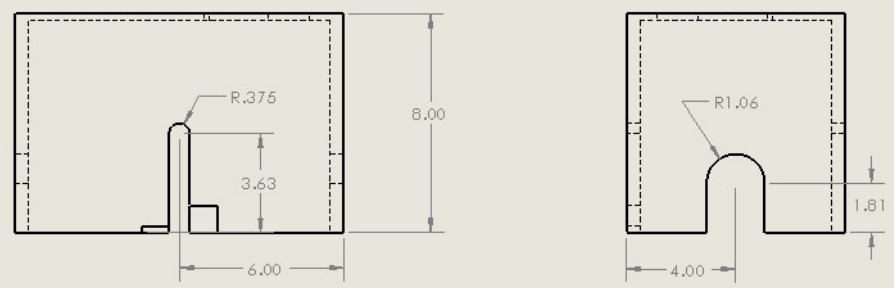

Figure 3.7: 3 view of thermal chamber with annotations for cutouts

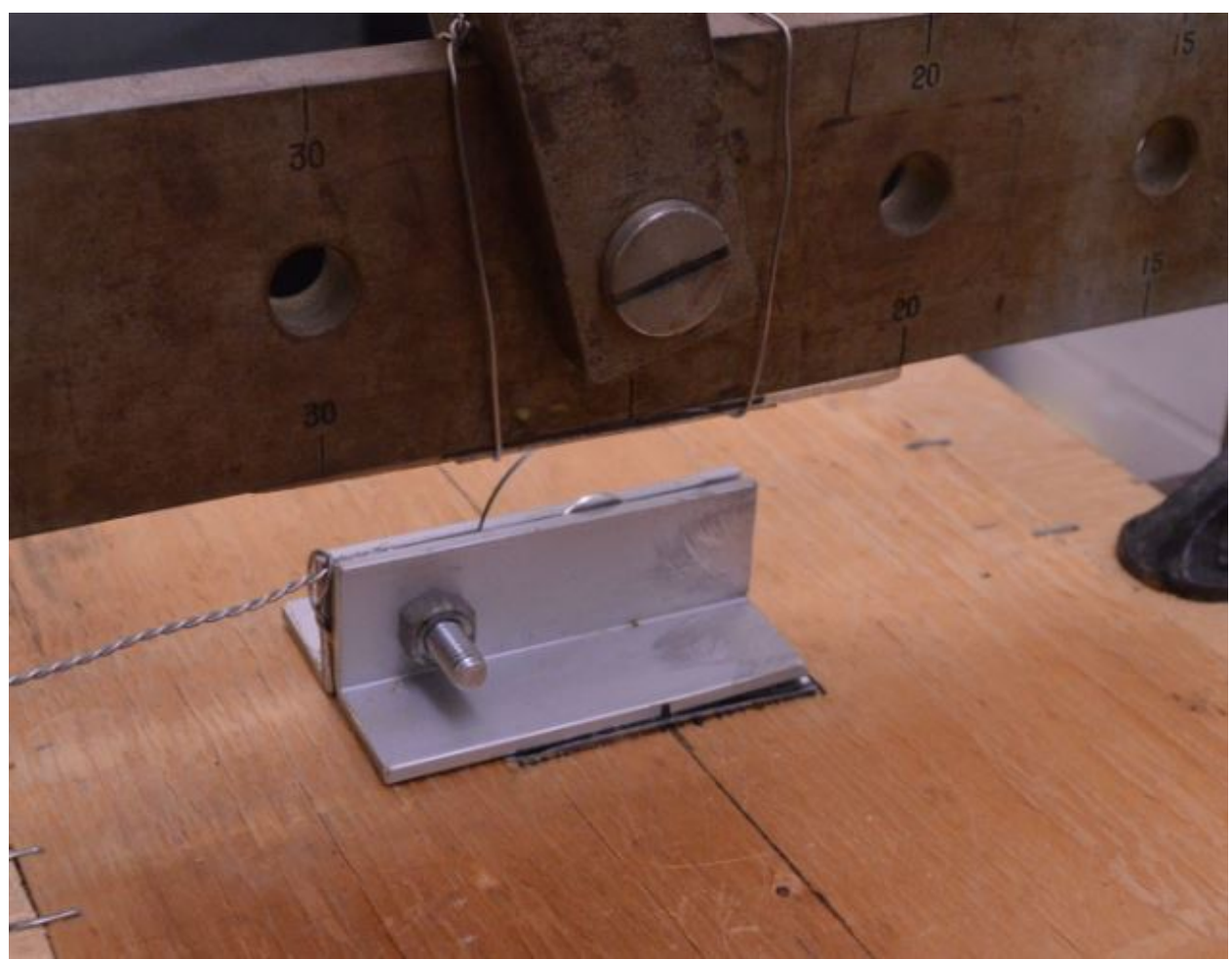

Figure 3.8: Ring positioner with ring aligned with marks 
A small piece of 0.040 " galvanized steel was placed on the base of the wooden box where the ring would sit; this prevents the wood base from deforming and applying unwanted loads to the ring. This piece of steel is also sanded with a cross pattern so that the ring does not slip as it is being loaded. The load arm was insulated with a thin piece of wood and again a small piece of steel was put in contact with the ring such that the wood does not deform.

A TM902c thermocouple reader with a type $\mathrm{K}$ thermocouple probe, shown in figure 3.9 was used to monitor the temperature inside the chamber. Because the thermocouple was placed above and away from the ring, the thermocouple reading was about $5{ }^{\circ} \mathrm{C}$ less than the average ring temperature. However if the thermocouple reading deviates from the norm it suggests the ring temperature is deviating as well.

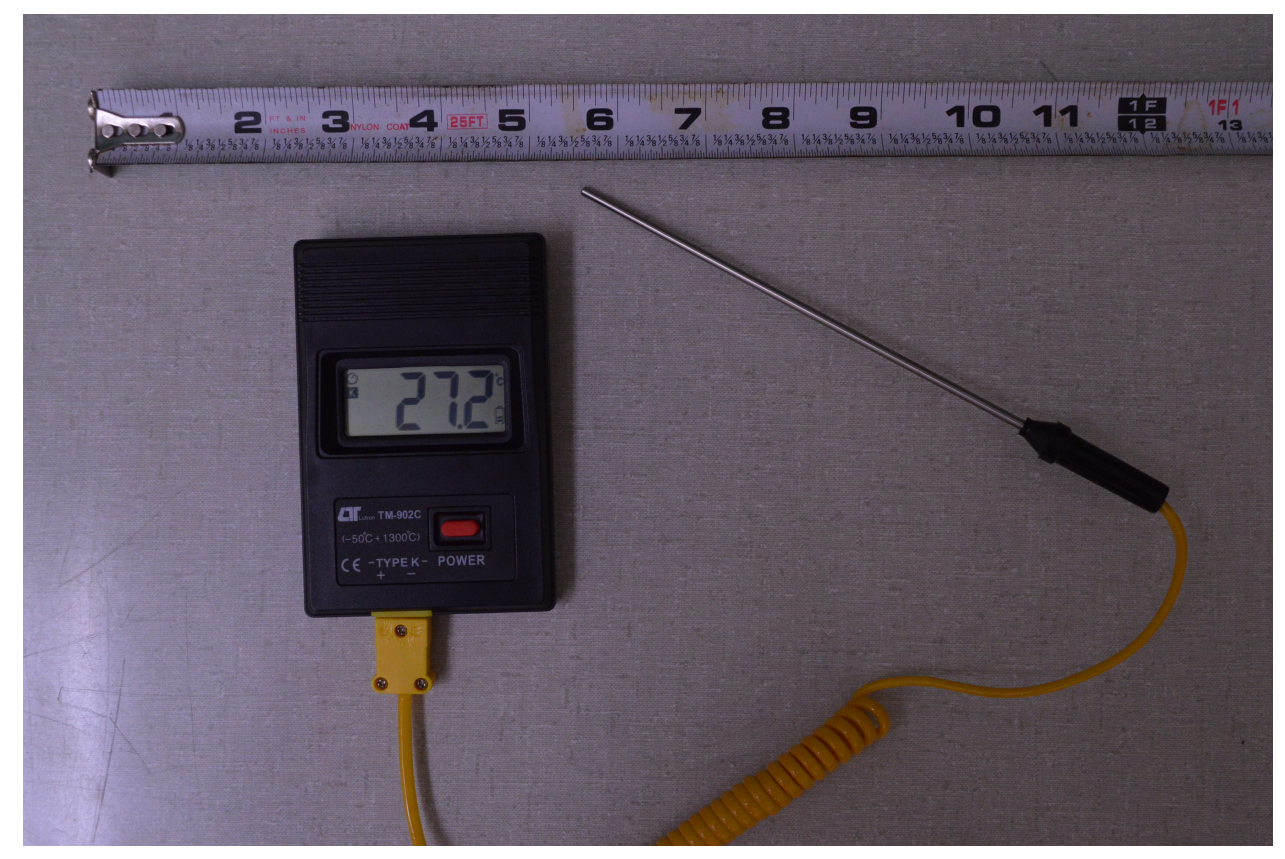

Figure 3.9: Thermocouple reader and probe 


\subsection{Testing Procedures}

\subsubsection{Testing procedure: Photoelastic testing}

The testing procedures for the photoelastic and time to failure testing are described below. The procedures are very similar, except for the temperature being lowered for the acrylic and no camera being required for the time to failure testing.

- Set up polariscope: Polarizer/analyzer units are placed as close to the load frame as the table allows, with polarizer scales facing outwards. Fluorescent light source is switched on and placed adjacent to polarizer.

- Heat gun is turned on and set to $290^{\circ} \mathrm{C}$. Thermal chamber is allowed 1 hour to reach steady state, at around $135{ }^{\circ} \mathrm{C}$.

- Polycarbonate ring is placed in holder, and holder is slid to align with marks in chamber such that the ring is centered and upright. Ring is allowed 5 minutes for thermal stabilization

- Load is applied to load frame, placing ring in compression. Camera intervalometer is turned on. Ring holder is removed. Start time, temperature and load are recorded.

- Experiment ends when the ring fails due to out of plane buckling. End time and temperature are recorded.

\subsubsection{Testing procedure: Time to failure testing}

- Heat gun is switched on and set to $140{ }^{\circ} \mathrm{C}$. Thermal chamber is allowed 1 hour to reach steady state. The steady state temperature of the chamber is $90{ }^{\circ} \mathrm{C}$.

- Acrylic ring is inserted into holder and holder is placed to align with marks such that ring is centered in load frame. Ring is left for 5 minutes to reach steady state temperature.

- Load is applied to load frame, timer is started and ring holder is removed. Temperature using infrared sensor and thermocouple, heat gun setting, ring number and load are recorded.

- Timer is stopped once the ring fractures and load arm drops. 


\section{Chapter 4}

\section{Results}

In this section, the results of the photoelastic and time to failure experiments are discussed.

\subsection{Photoelastic observation of stresses}

Initially, only one material was to be used for both the photoelastic and time to failure testing. This however was deemed impractical given the number of rings required to perform the time to failure testing. Then the material was switched to acrylic, where the rings could be manufactured much quicker, but do not show fringe patterns due to their low photoelastic sensitivity. More than 100 polycarbonate rings were tested before the material was changed to acrylic.

The photographs of three rings will be discussed. Their load and geometries were the same, but they had differing times to failure, as shown below in Table 4.1. The ring dimensions and conditions are shown in Table 4.2 - these conditions were identical for the three rings in question. The three rings were cut from the same polycarbonate sheet.

Figures 4.1, 4.2 and 4.3 show rings $26-28$ under their initial loading. The same load was used for each ring, and they have the same geometry, so they should all appear identical. Note that the images are slightly rolled to the left, from an inaccuracy of the camera mount, and the load arm of the polariscope is higher than centre and thus not putting the ring in exact diametral compression for rings 26 and 
Table 4.1: Time to failure of three polycarbonate rings

\begin{tabular}{cc}
\hline Ring number & Time to failure \\
\hline \hline D2-26 & $1120 \mathrm{~s}$ \\
D2-27 & $880 \mathrm{~s}$ \\
D2-28 & $440 \mathrm{~s}$ \\
\hline
\end{tabular}

Table 4.2: Ring dimensions and conditions for photoelastic analysis

\begin{tabular}{cccccc}
\hline OD & ID & Thickness & Load & Temperature & Camera interval \\
\hline \hline $41.9 \mathrm{~mm}$ & 23.8 & $2.4 \mathrm{~mm}$ & $100 \mathrm{~N}$ & $135{ }^{\circ} \mathrm{C}$ & $10 \mathrm{~s}$ \\
\hline
\end{tabular}

27.

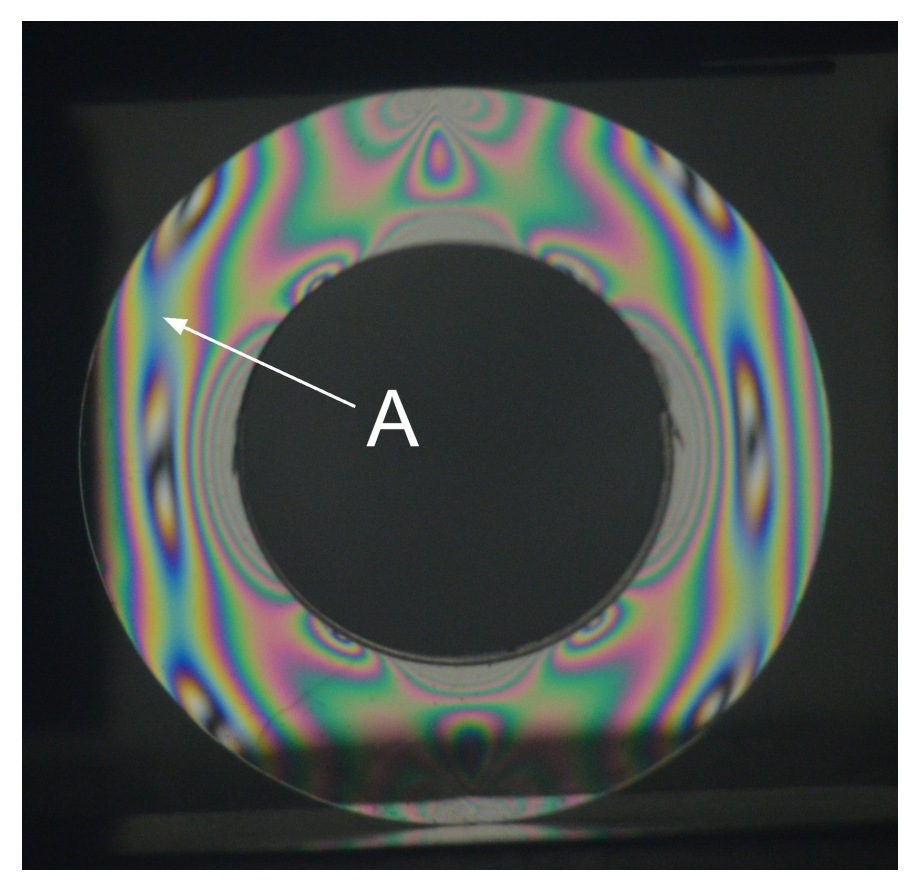

Figure 4.1: Ring 26 at initial load 


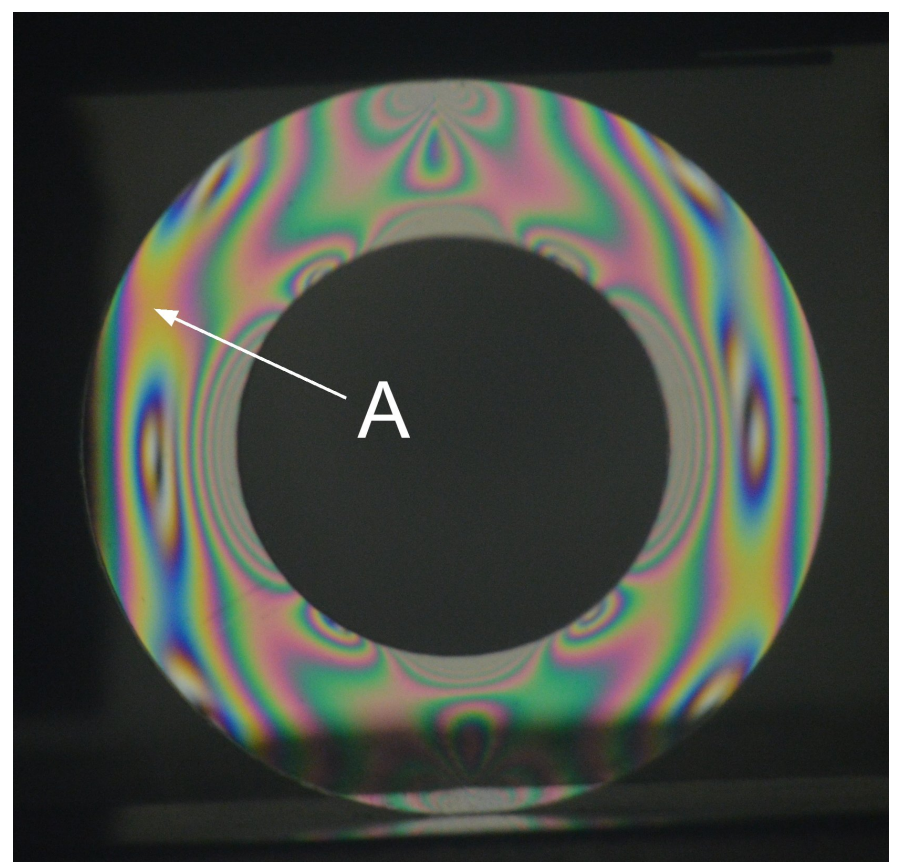

Figure 4.2: Ring 27 at initial load

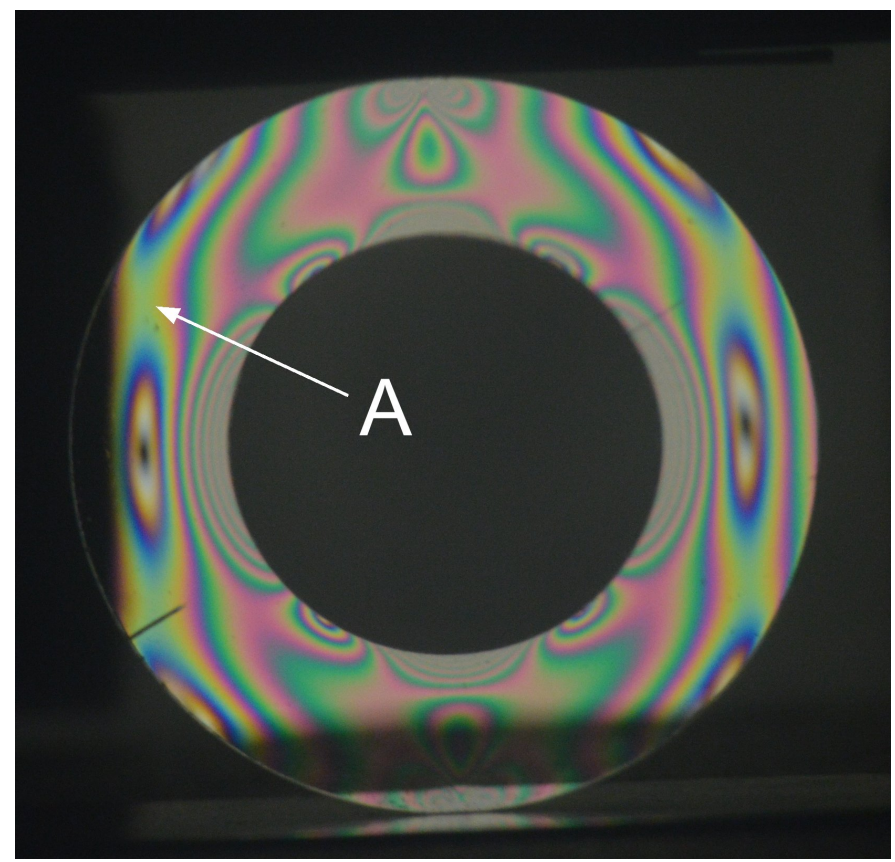

Figure 4.3: Ring 28 at initial load

Some small differences can be seen in the initial photographs, most obviously at position A indicated by the arrow, ring 26 is at the lowest stress while ring 27 is at 
the highest stress.

Figures 4.4, 4.5 and 4.6 show the same rings just before buckling. Because of the high load required to make the rings fail in a reasonable length of time, the fringe orders are very high and thus quite difficult to distinguish. However since the camera was not moved we can compare the images with each other to see which one has deflected the most. The arrows in the photographs show the heights of the rings before they buckled. Ring 26 lasted the longest, but deformed less than ring 27 . Ring 28 had the shortest life and unsurprisingly has the least deflection and lower order fringe patterns.

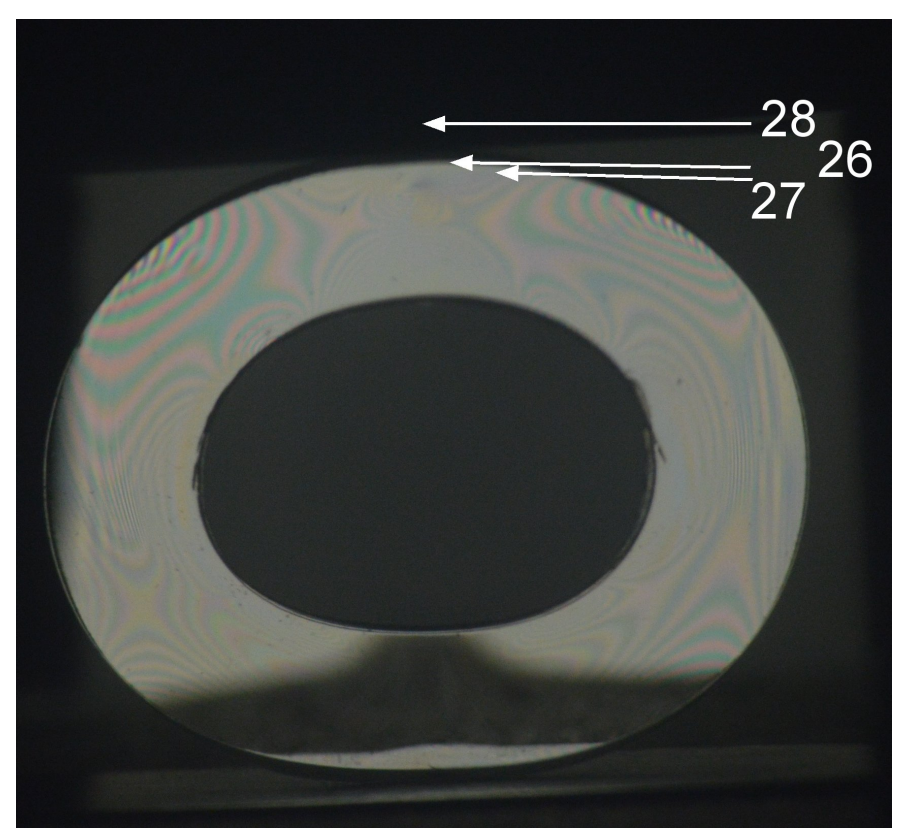

Figure 4.4: Ring 26 before buckling, with arrow 26 indicating its height 


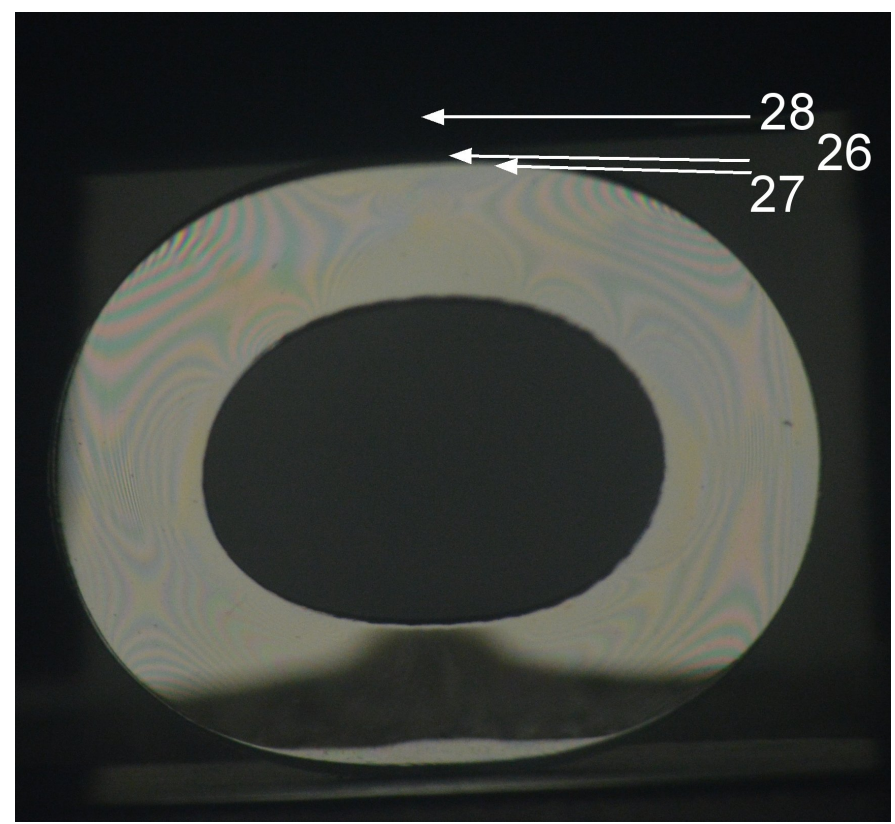

Figure 4.5: Ring 27 before buckling, with arrow 27 indicating its height

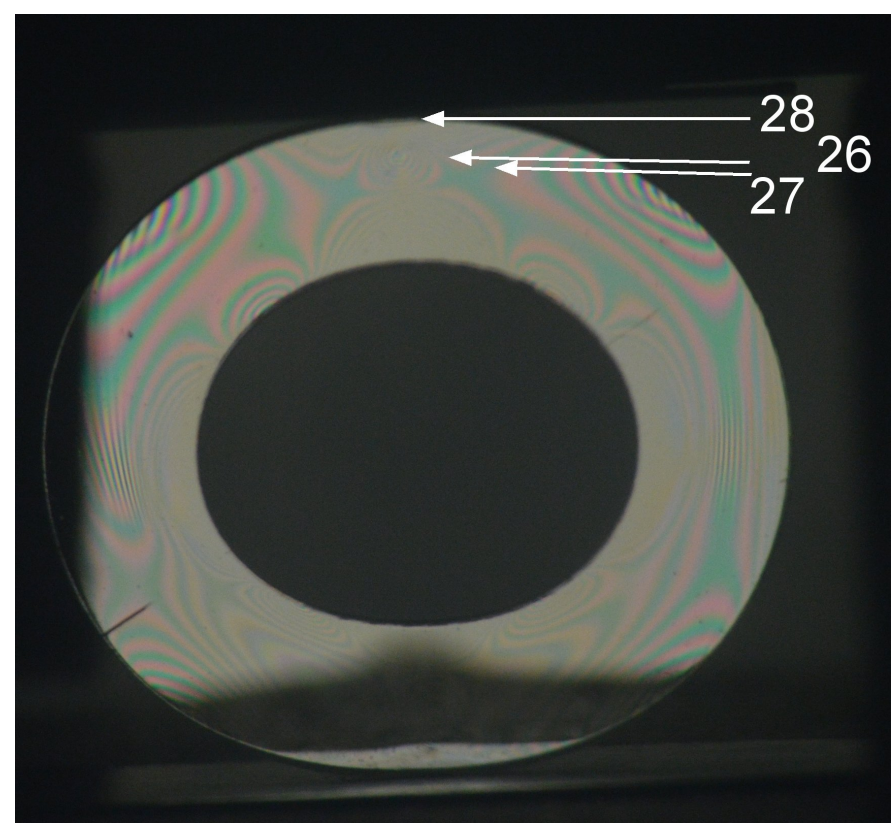

Figure 4.6: Ring 28 before buckling, with arrow 28 indicating its height

The photographs were used to determine the time to failure of the rings by counting the number of frames, and compiled in the image processing software Image J to be cropped, resized and made into a time lapse movie. To show the progression of 
the fringe patterns in a still image, the image series was also processed in a MATLAB code which took a slice of each image at half the image height, and arranged these slices sequentially. Hence the first line of the processed image is from the ring's initial state and the last line is at the ring's final (buckled) state. The code does not have any means of tracking the ring's centreline until its collapse. Crops of the resultant images are shown in Figures 4.7, 4.8, and 4.9. From the images generated by the MATLAB code, it appears that the strain increases most rapidly in ring 27 , as the third fringe appears closest to the top. The fringe order also appears to be greatest at failure in ring 27, and least in ring 28, despite ring 27 having a longer life than ring 26.

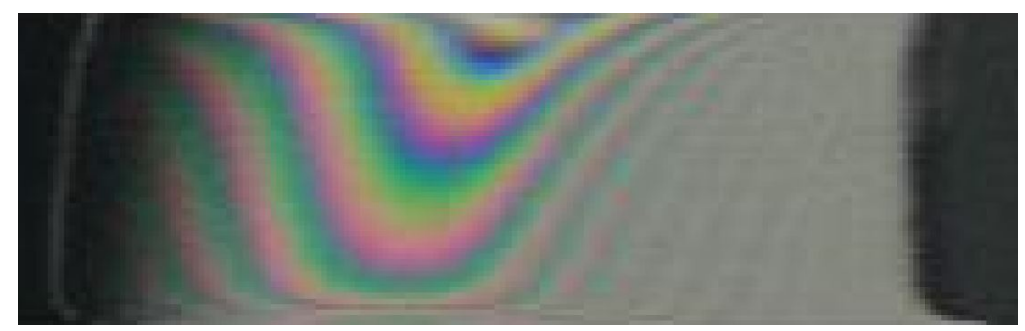

Figure 4.7: Ring 26 dynamic visualization

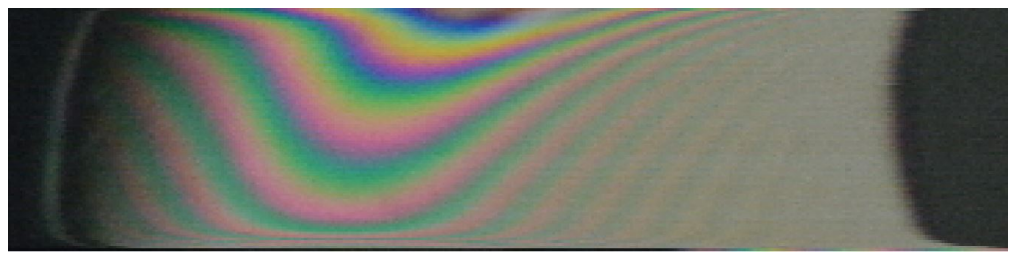

Figure 4.8: Ring 27 dynamic visualization

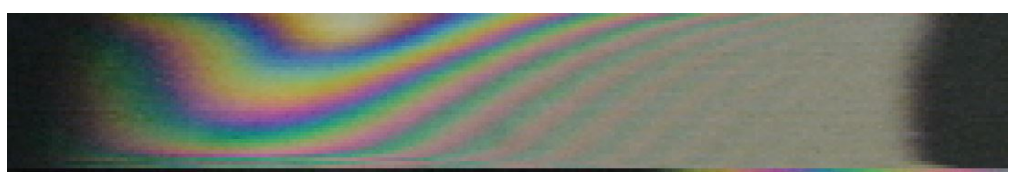

Figure 4.9: Ring 28 dynamic visualization

The fact that the three rings were subjected to the same amount of load but had different times to failure and stresses could be due to the random nature of polymers. For instance, if a particular ring has polymer strands that are shorter or less entangled than usual, this would cause the ring to fail sooner than a different ring. 


\subsection{Time to failure testing}

A total of 154 acrylic rings were tested in the time-to-failure testing to produce a plot to compare to the viscoelastic life theory. Testing was performed to find the highest load that would provide a reasonable (greater than two minute) time to failure for the rings, and then loads were chosen to increment up to that load. This was done to keep the tests at a reasonable length so that it would take less time to do multiple tests at each load case. More than 19 tests were performed for each load to allow for a reasonable confidence in the average.

\subsubsection{Trend comparison}

The experimental results for the time-to-failure testing were plotted alongside the theoretical results, and the two are shown below in Figures 4.10 and 4.11. A plot with all of the data points is shown in Figure 4.12

Time to failure of $\mathrm{C}$ series acrylic rings, compared to viscoelastic life theory

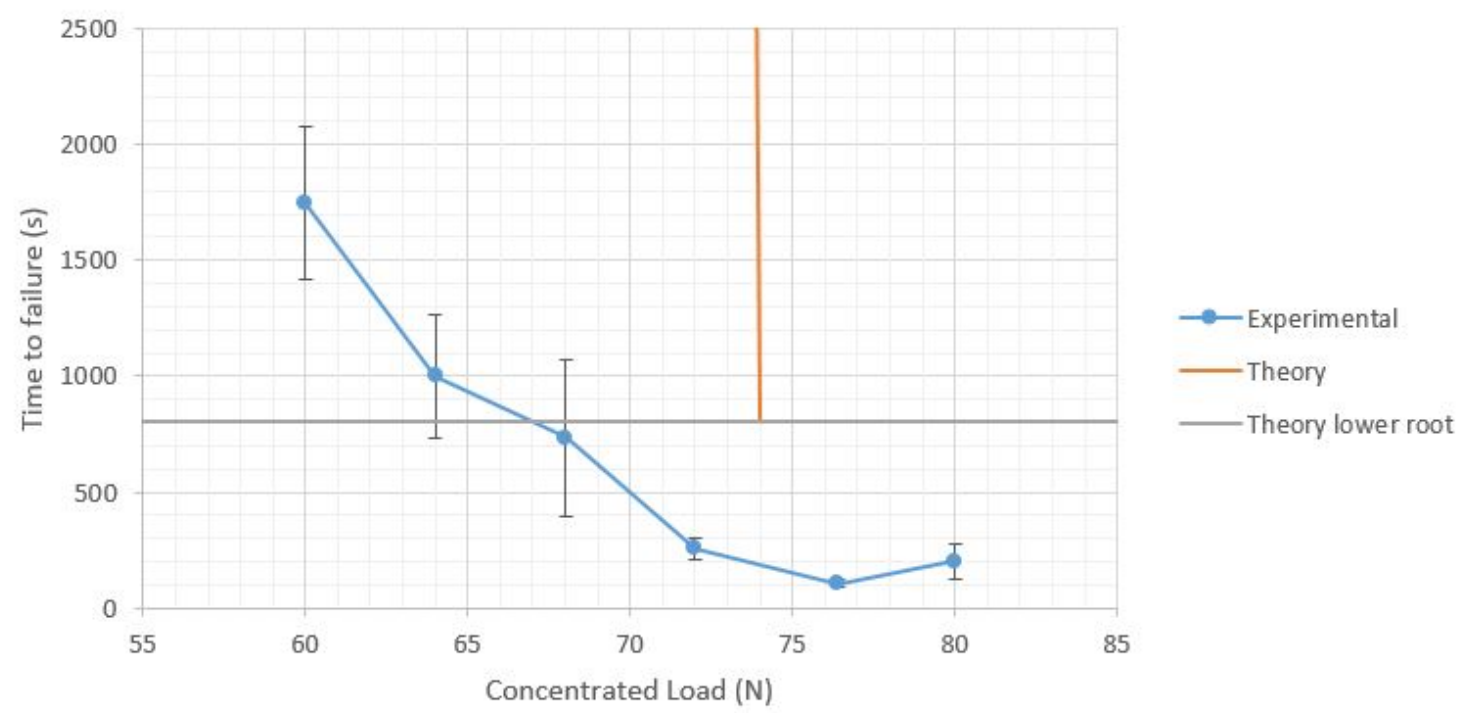

Figure 4.10: Experimental results versus theory over experimental load range 


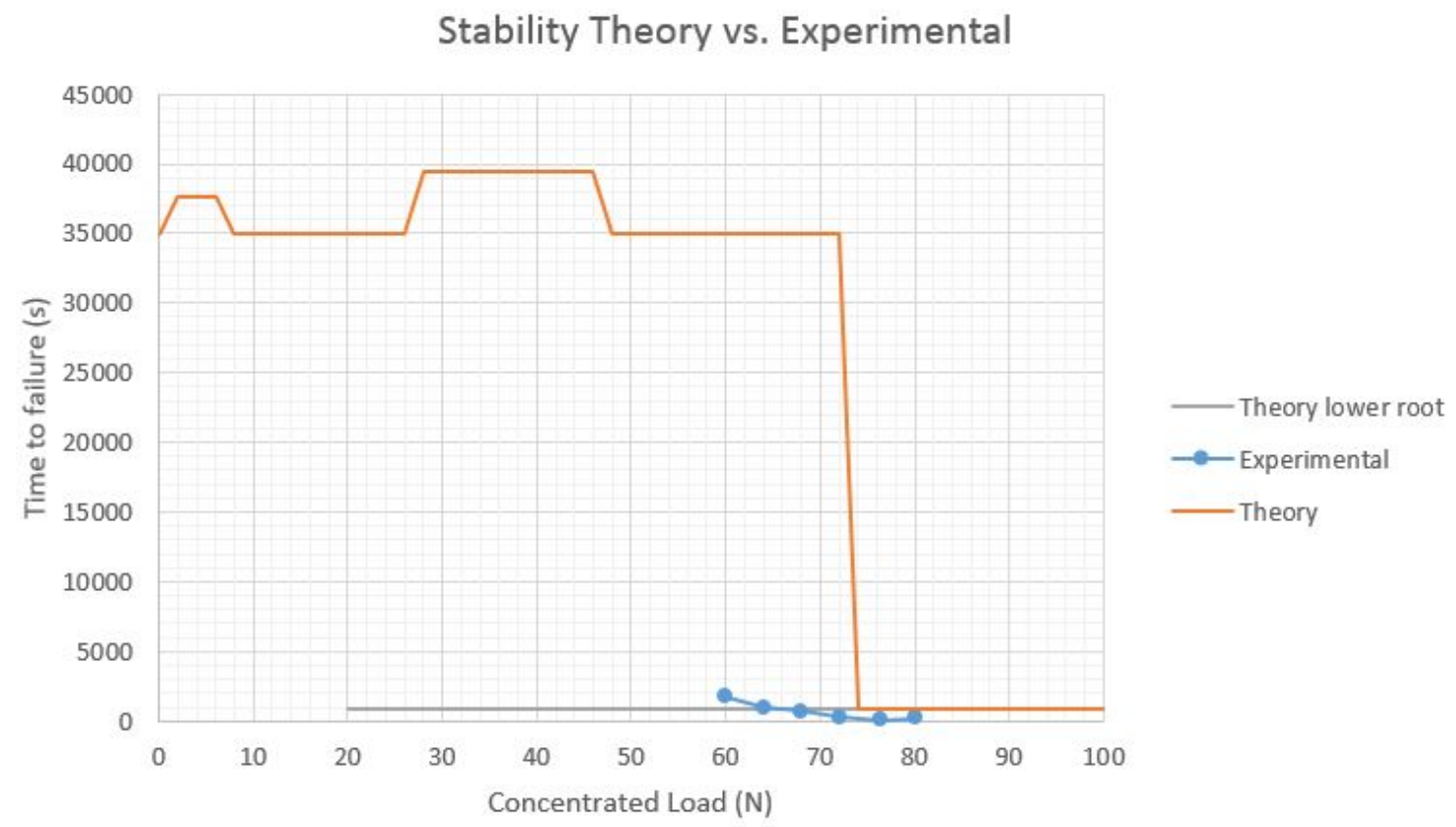

Figure 4.11: Experimental results versus theory over theoretical load range

Time to failure of $\mathrm{C}$ series acrylic rings, compared to viscoelastic stability theory

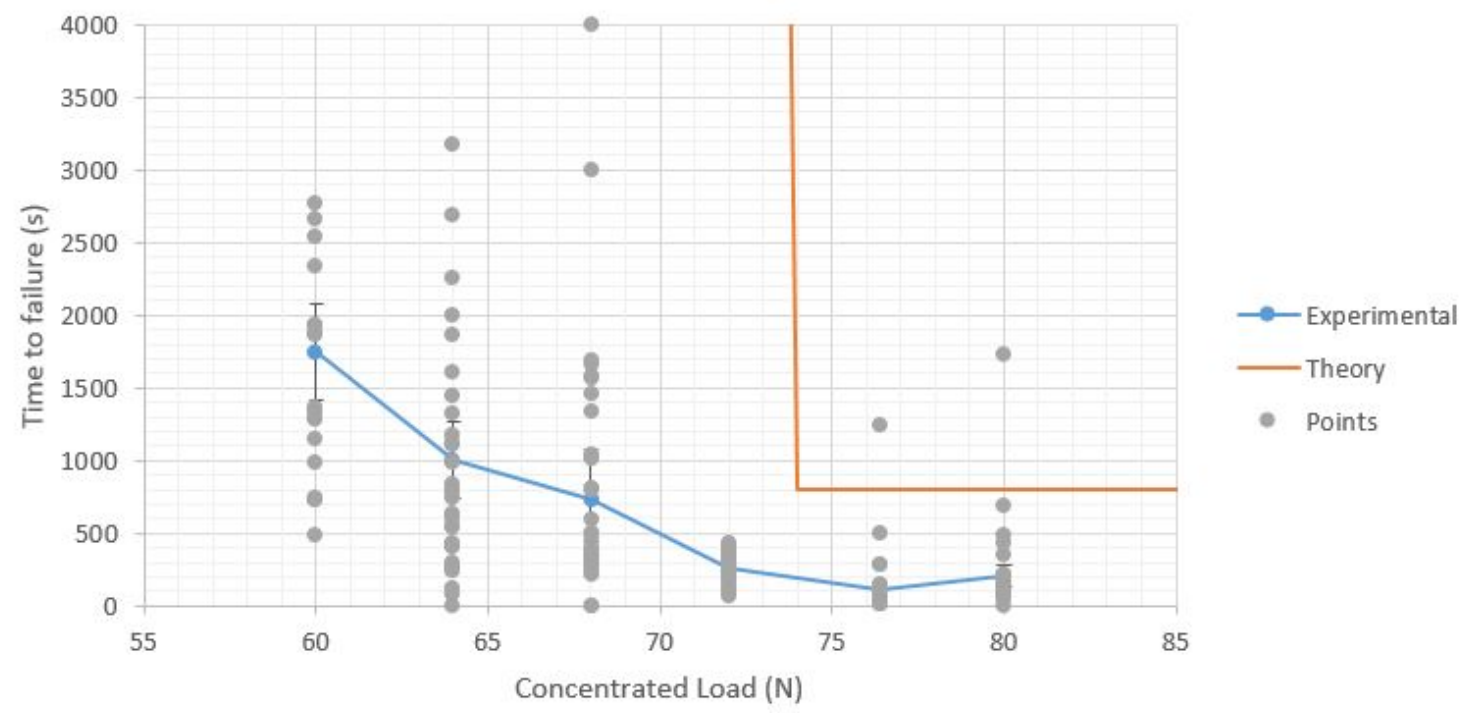

Figure 4.12: Experimental results versus theory over theoretical load range 
The experimental results show a clear downward trend in the life of the rings as the load was increased, and this trend is not shown in the theoretical results. This appears to indicate that the theory is incorrect or incomplete.

At an applied load of around $90 \mathrm{~N}$ it was found that the rings would fail instantly. This is in contrast to the theory which predicts a failure time of about $800 \mathrm{~s}$ beyond $120 \mathrm{~N}$. Note that this is not applicable to elastic buckling since the ring is assumed to be viscoelastic. Hence testing at room temperature for a buckling can not be compared to the viscoelastic stability theory since the ring behaves mostly as an elastic material at room temperature. The inability of the code to predict an instantaneous failure load does not appear to be correct.

Below $72 \mathrm{~N}$ the theory predicts either a failure time of 807 seconds or 35000 seconds. The ambiguity of the results comes from the code choosing the lowest real root that satisfies the equation. There were some outliers with no explanation as to why they lasted more than 5 times the average time to failure of the other rings, so maybe the two roots imply that there is a lower probability of a much longer life. This is discussed further in Section 4.5.2.

\subsection{Sources of error}

In this section, sources of error and there influence on the results are discussed.

\subsubsection{Thermal effects}

The heat gun used to heat the thermal chamber is temperature controlled, so it has a limited amount of thermal stability built in; but once the thermal chamber is given about an hour to settle the system stays constant around $90{ }^{\circ} \mathrm{C}$. The average temperature in the chamber usually fluctuates $\pm 2^{\circ} \mathrm{C}$, but especially towards the end of the experiment taking, could fluctuate more. Experiments where the temperature fluctuated more than $\pm 3{ }^{\circ} \mathrm{C}$ were discounted. An overview of thermal variation in a ring is shown in Figure 4.13 and the locations of the minimum and maximum temperatures in a ring are shown in Figures 4.14 and 4.15 
Efforts to minimize the thermal gradient were described previously in Section 3.4 The thermal gradient was finally reduced to $4{ }^{\circ} \mathrm{C}$, with the maximum temperature at about the 10 o'clock position on the ring and the minimum temperature at the 2 o'clock position on the ring. This thermal variance was constant for all rings.

Change in temperature changes the relaxation period of the material, which in turn effects the time to failure. From the usual $90^{\circ} \mathrm{C}$ temperature, decreasing the temperature $2{ }^{\circ} \mathrm{C}$ would increase the time to failure by $5.3 \%$. Increasing the temperature the same amount would reduce the time to failure by $5.0 \%$. This is shown below in Table 4.3. The relaxation times were determined by the method described in Section 2.7.

Table 4.3: Temperature effect on time to failure

\begin{tabular}{ccc}
\hline Temperature $\left({ }^{\circ} \mathrm{C}\right)$ & Relaxation (Seconds) & Percent difference \\
\hline \hline 88 & 47,258 & $+5.3 \%$ \\
90 & 44,875 & 0 \\
92 & 42,633 & $-5.0 \%$ \\
\hline
\end{tabular}

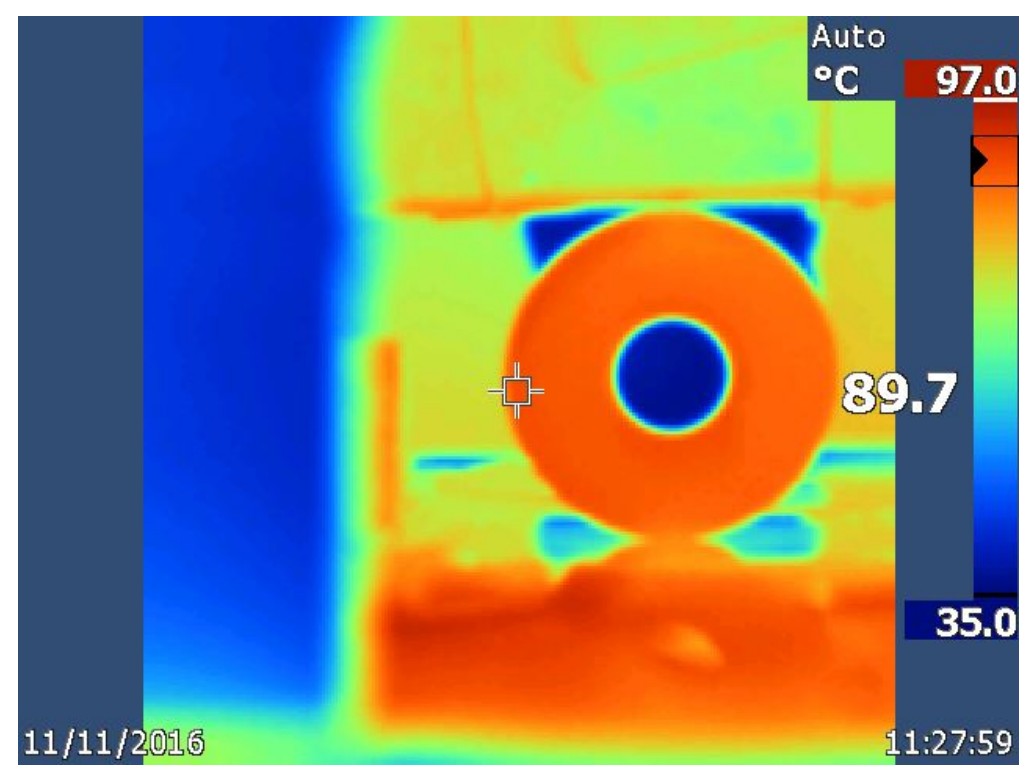

Figure 4.13: Overview of thermal gradient in ring showing average temperature 


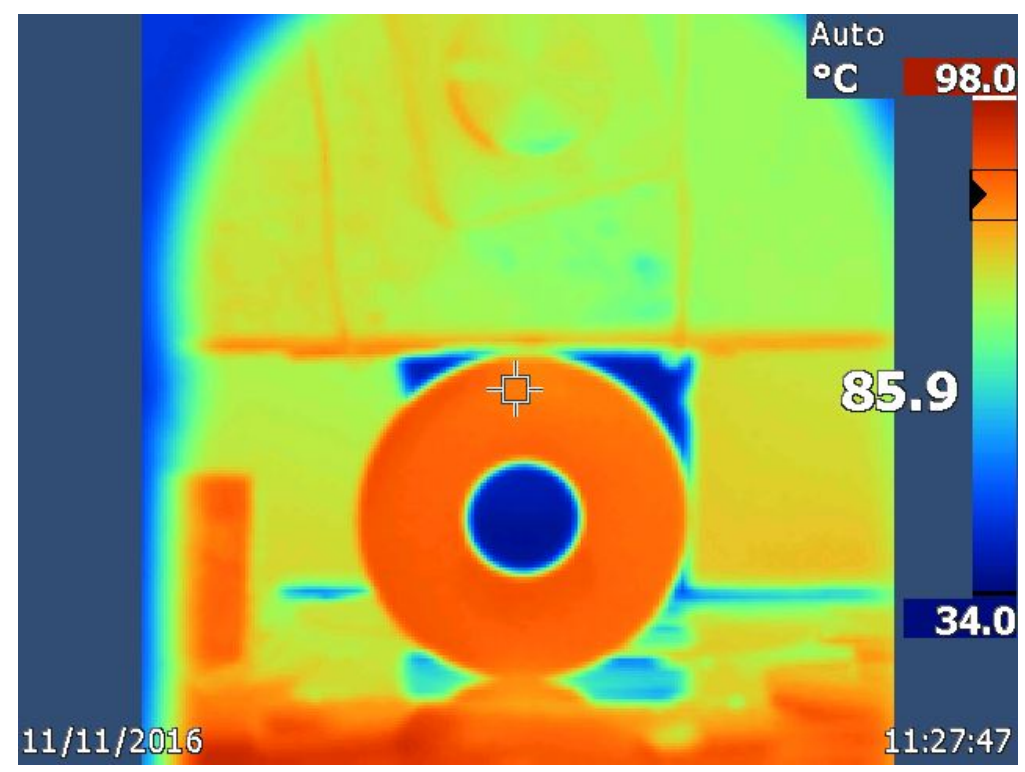

Figure 4.14: Location of lowest temperature

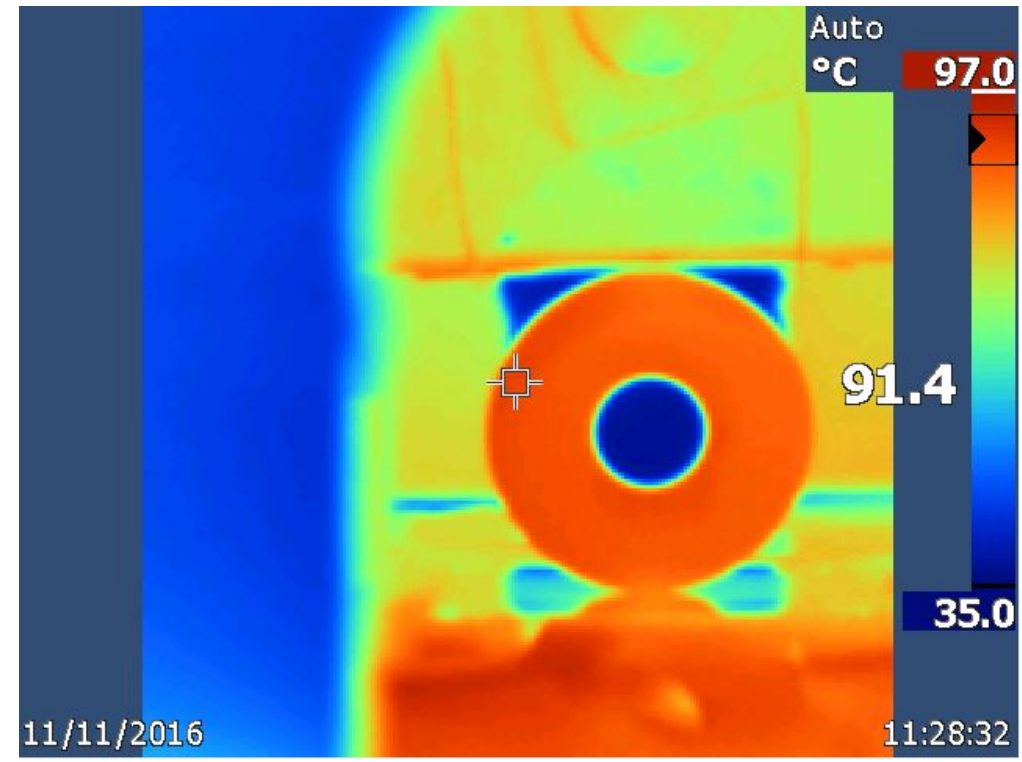

Figure 4.15: Location of highest temperature

\subsubsection{Misalignment}

The rings were placed under the load arm and aligned with marks in the thermal chamber base. Alignment in the optical axis (the axis of the polariscope) is not crucial since misalignment does not change the amount of load the ring is subjected 
to, and large amounts of misalignment would result in the ring slipping off of the load arm. Misalignment in the load axis is not possible because the load arm will force the ring to contact the base of the chamber. Misalignment in the axis of the load arm will change the amount of load the ring is subjected to (since the moment arm is changed). The maximum amount of misalignment in this direction is $2 \mathrm{~mm}$, which results in $0.8 \%$ change in the load. Angular misalignment is minimal due to the use of the alignment jig and would be consistent between trials.

\subsubsection{Ring dimension variation}

The typical variation in ring size and reasons of variation are described in Section 3.1. In addition to the variance in dimensions, the rings were cut from multiple sheets of material, which provides another potential source of variability between batches of acrylic. The variation in ring diameter was calculated to have a negligible effect on the time to failure as determined by the theory, see Table 4.4.

Table 4.4: Ring dimension effect on time to failure

\begin{tabular}{cccc}
\hline Dimension & $\mathrm{b}(\mathrm{m})$ & $\mathrm{h}(\mathrm{m})$ & Critical time / T at 100N concentrated load \\
\hline \hline Max tolerance & 0.00155 & 0.0138 & 0.0179 \\
Average & 0.001524 & 0.01372 & 0.0180 \\
Minimum tolerance & 0.001524 & 0.01355 & 0.0179 \\
\hline
\end{tabular}

\subsubsection{Ring orientation}

Issues in annealing the rings resulted in residual stresses remaining in the rings. The problem with residual stress is that the stress remains from the extrusion and rolling of the polycarbonate and thus is in line with the extrusion direction. When the rings are placed in the chamber, the residual stress and compression load are not always in the same orientation with regards to each other. A residual compressive stress oriented in the direction of the compression load will tend to shorten the time to failure of the ring, while a residual compressive stress perpendicular to the compression load will tend to lengthen the time to failure of the ring. Similarly to 
residual stresses, the oblong orientation of the rings also has an effect on the time to failure. The laser cut rings were all measured to be slightly elliptical, and hence the orientation of the ring relative to the load would affect its time to failure.

\subsubsection{Weights}

The same weights were used consistently throughout the experiments; hence the $15 \mathrm{~N}$ load may not be exactly $15 \mathrm{~N}$, but it was the same for all the trials at $15 \mathrm{~N}$. The same follows for all the other loads. The counterbalance was left unchanged for the duration of the experiments once it had been set for the arm weight.

\subsubsection{Annealing}

In the annealing process, the rings are heated and held at a temperature for long enough that the stresses from manufacturing are relieved. The process used for the experiments was described previously in Section 3.3. After annealing, the rings are checked for residual stresses in the polariscope, which appear as tints or colour patterns other than the background colour. This is shown below in Figure 4.16. The ring segment labeled 'A' has no residual stresses and has no tint difference from the background shade. The annealed ring ' $\mathrm{C}$ ' has a tint to it, which shows that it has remaining residual stresses, but less than ring 'B' which has not been annealed at all.

Numerous annealing procedures were tried, but none seemed to produce consistent, zero stress annealed rings. In the end, an annealing procedure was used that may have not removed all residual stresses in the rings, but at least brought the residual stresses to a uniform level amongst the rings in that particular annealing batch.

Residual stresses that differ between annealing batches will obviously cause the time to failure to vary between batches, as a higher stressed ring will fail earlier at a given load than a lower stressed one. Residual stresses come from two processes in the acrylic rings: extrusion and rolling of the acrylic sheet and laser cutting of the ring. The laser cutting affects the edge of the ring, whereas extrusion and rolling 


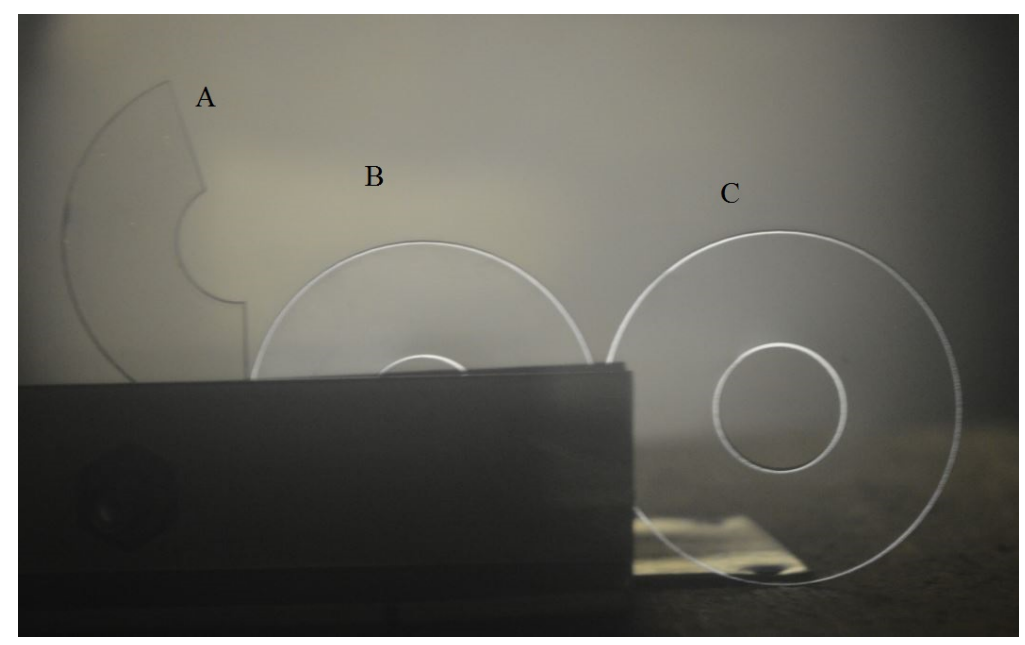

Figure 4.16: Appearance of annealed rings. Ring segment $\mathrm{A}$ is fully annealed, ring $\mathrm{B}$ has had no annealing done to it; ring $\mathrm{C}$ has been annealed but has residual stresses.

leaves a stress in the direction of the rolling process. Hence the orientation of the residual stresses of rolling and extrusion can have different effects on the time to failure of the ring depending on the way the ring is oriented in compression.

Inconsistency between batches was also an issue with annealing - despite a standardized procedure, the rings would have differing residual stresses between batches. This difference was not enough to see in the polariscope (due to the photoelastic insensitivity of acrylic) but was apparent in the recorded time to failures - certain batches would be very consistent, and others would vary within the batch and be shifted from the first patch. This is especially apparent in the rings used for the 76.4 $\mathrm{N}$ applied load (see appendix A.1.1). The first batch of rings used was very consistent, and failed at around the 60 second mark. The next batch of rings used had all its rings fail under 20 seconds, and all of the rings bent and did not shatter, which is not typical. The next batch used had times that averaged 346 seconds, with much variation. All of these rings were cut from the same sheet of acrylic from the same laser cutter.

Because of the low photoelastic sensitivity of acrylic, it was not possible to determine the residual stresses or stress directions in the rings, so the effect of residual stresses on the results could not be estimated. 


\subsubsection{Experimental error}

Summing up the errors that can be quantified above, a deviation of about $\pm 7 \%$ can be expected. Scatter greater than $100 \%$ is present in the data, so clearly the non-homogeneous nature of polymers and the effect of inconsistent annealing have a greater impact on the scatter of the results than variance in the ring dimensions, temperature or small variations in load.

\subsection{Validity of results}

Though the scatter in the experimental testing seems excessive, it is expected to some degree and improving the scatter would not change the results. Scatter in viscoelastic polymer testing is known and expected, as mentioned in Section 2.6.1. The main results of these experiments is that the theory and experiments do not agree in trend and the theory does not reach an instantaneous buckling load, as opposed to the experimental results. Reducing the scatter in the results may shift the trend line up or down but it does not change the fact that there is a decrease in life time as load is increased and there is a load where the ring will buckle instantly.

\subsection{Observations}

This section describes observations made on the failure of the rings, and long life outliers.

\subsubsection{Failure mode}

In all cases, the rings failed due to out of plane buckling. Once loaded, the ring would have some degree of out of plane bending, as shown in Figure 4.17. This type of bending is expected, as the rings have a large "wall thickness" compared to their thickness, so in plane deformation is less likely to occur.

Bending continues until the ring fractures, as shown in Figure 4.18. On occasion the rings would not fracture and would bend as shown in Figure 4.19. This failure 


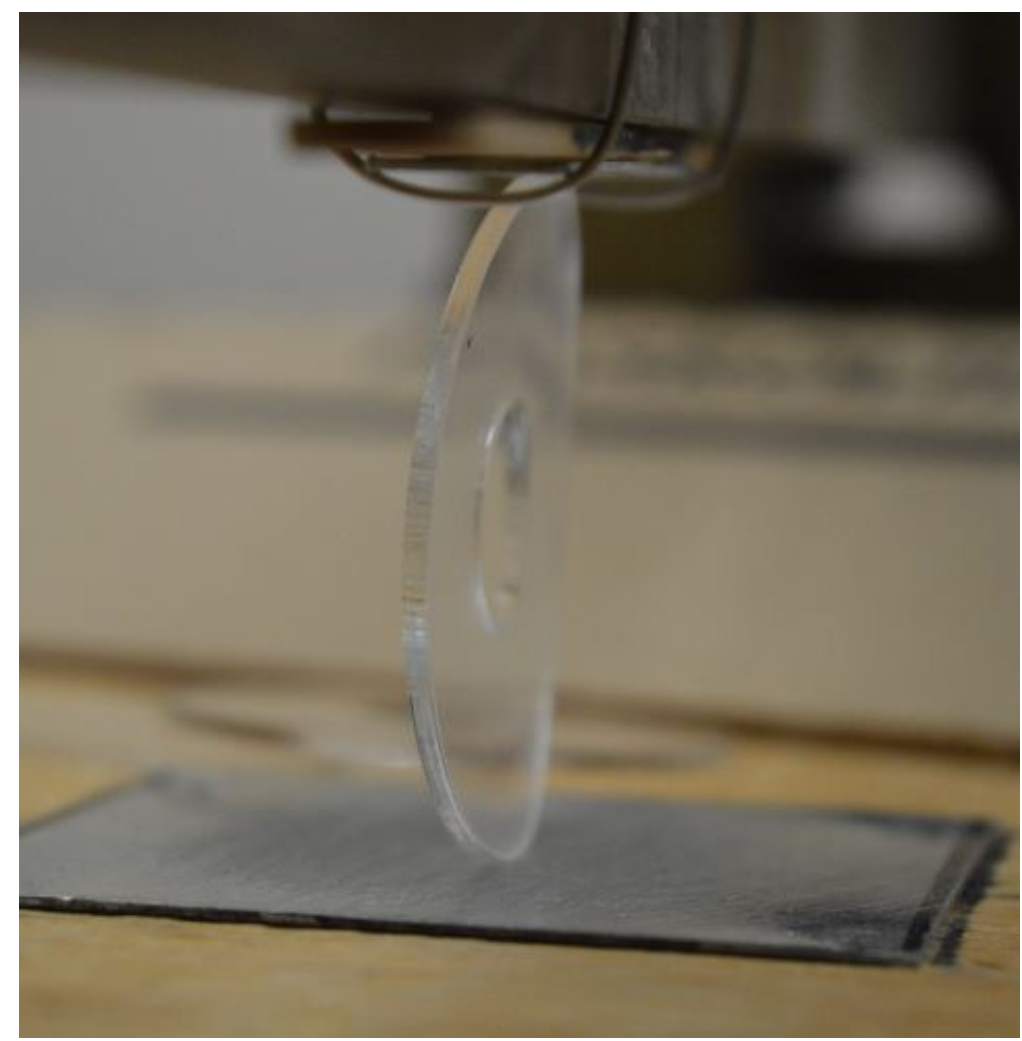

Figure 4.17: Ring showing out of plane bending 
mode is typical of overheating as near the glass transition temperature the material becomes rubbery and buckles instantly - however sometimes the rings would bend and not shatter at the usual testing temperature of $90^{\circ} \mathrm{C}$. A certain batch for the $76.4 \mathrm{~N}$ load had all of its rings bend, and those results were discounted. Some rings would fracture on one side and bend on the other, like in Figure 4.20. The reason for these differences in failure modes appears to be partially random and potentially induced by variations in the annealing process, as demonstrated by rings nr. 183-186 (see appendix A.1.4).

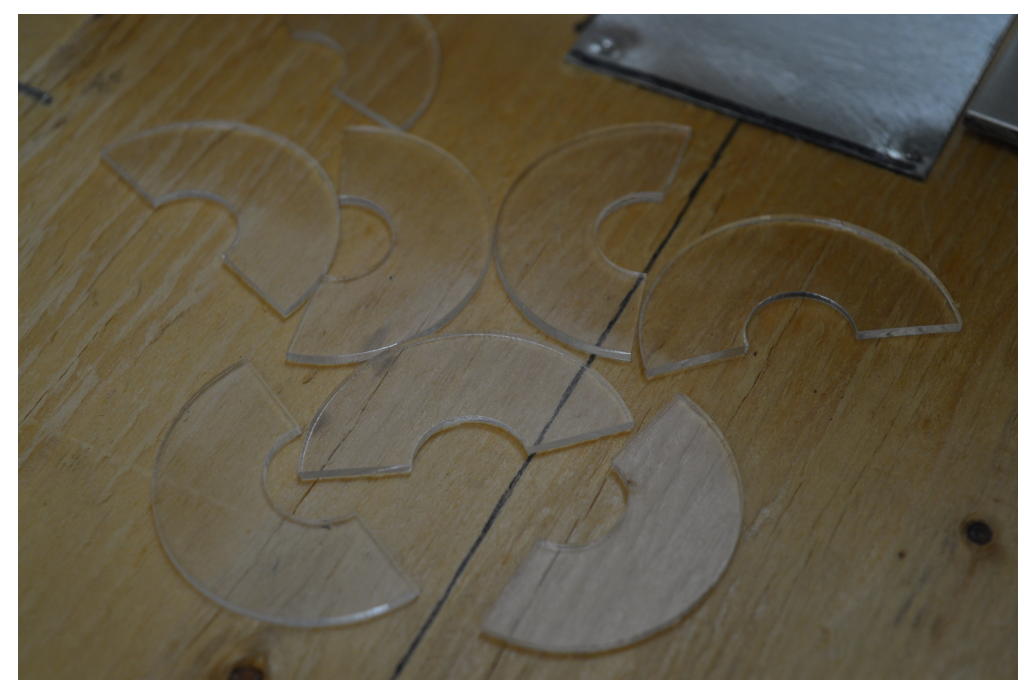

Figure 4.18: Failed acrylic rings, showing typical failure mode. 


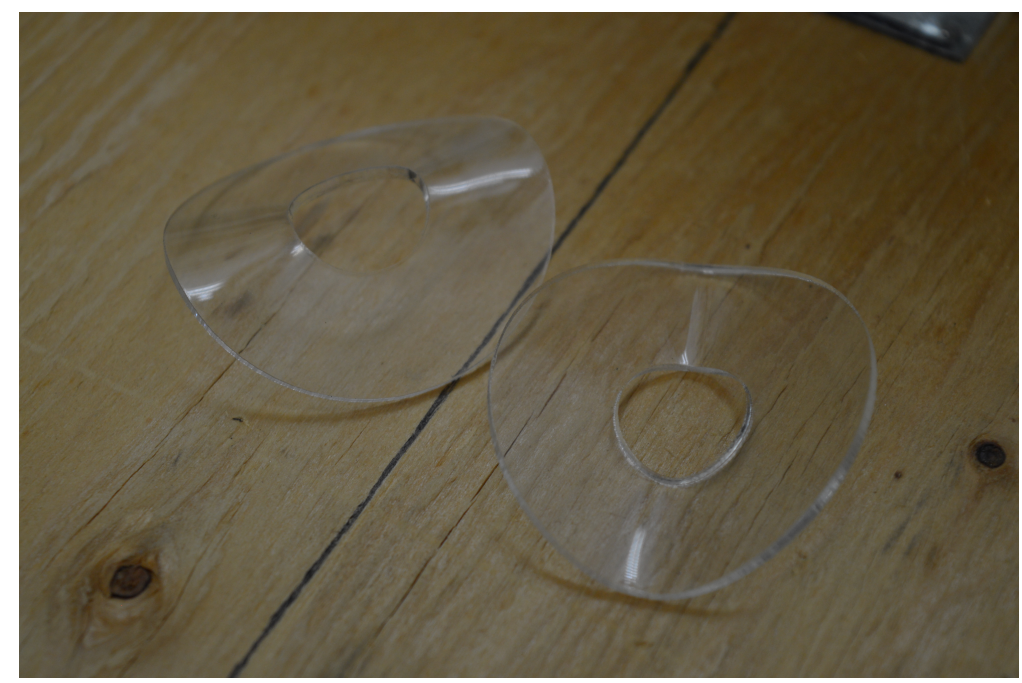

Figure 4.19: Bent ring, showing failure mode typical at glass transition temperature, but not expected at testing temperature.

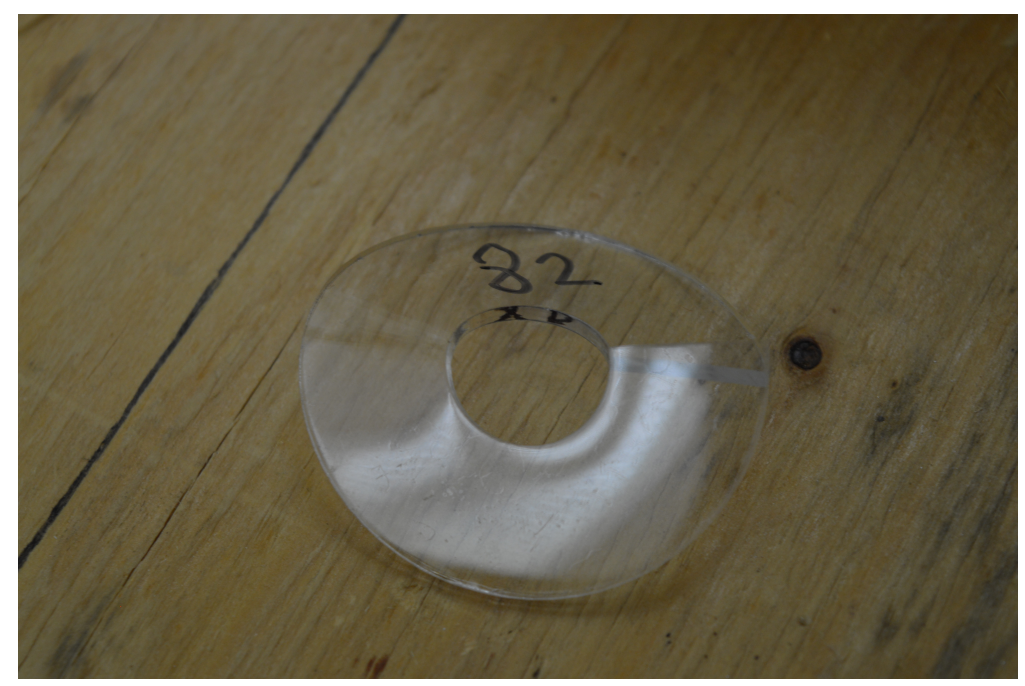

Figure 4.20: Partially snapped ring.

All three of these failure modes were observed at the temperature used in the experiments of $90^{\circ} \mathrm{C}$, which could be the result of inconsistencies in the acrylic sheets, as all of the rings are expected to fail in a brittle manner. 


\subsubsection{Long life outliers}

While some data points were discounted due to temperature issues (either the chamber was too hot or too cold greater than the acceptable $\pm 3^{\circ} \mathrm{C}$ ), occasionally rings would take a long time to fail with no apparent explanation. An example is no. 119, which was removed before failure after $10800 \mathrm{~s}$, compared to the average time to failure of 938 seconds for that load. Other rings were removed for the sake of conserving time, as it was thought that these were simply material anomalies and of no meaning to the results. However in light of the theoretical results perhaps it is possible that there are two different times to failure for viscoelastic rings for a given load - one short life, and a lower probability long life. More testing will have to be performed to verify this observation. 


\section{Chapter 5}

\section{Conclusions and Future Work}

\subsection{Conclusions}

The time to failure experiments showed a downward trend of time to failure as the load was increased. This downward trend is continuous. There also exists a load for at which a viscoelastic ring will buckle instantaneously. These three key results in the experiments are not reflected in the MATLAB code produced with the Merrett's viscoelastic time to instability theory, and hence the mathematical theory requires further refinement.

\section{$5.2 \quad$ Future work}

As stated previously, there is much future work left to be done in terms of testing - to conclusively prove or disprove the viscoelastic life theory, more physical testing has to be done over a greater range of loads, and preferably, different materials, temperatures and geometries should be tested as well. The accuracy of the testing leaves much to be desired; an annealing procedure that works consistently is essential, and so is a thermal chamber that is uniform and repeatable to a fraction of a degree. The process of loading rings and collecting times could be automated to make mass testing less tedious. The photoelastic testing also could be compared with finiteelement simulation and automated photoelasticity to determine the stresses at any point in the ring as it creeps over time. 


\section{List of References}

[1] C. Merrett, "Stability of viscoelastic rings under radial loads with applications to nuclear technology," Journal of Applied Mechanics, 2015.

[2] C. E. Inc., "Ec6 enhanced candu 6 technical summary." http://canwea.ca/ wind-energy/installed-capacity/, 2012.

[3] M. Trelinski, "Application of ultrasonic testing methods for volumetric and surface inspection of candu pressure tubes," 1st Pan American Conference for Nondestructive Testing, 1998.

[4] J. D. Whitlock, "Candu nuclear power technology." http://www.nuclearfaq. ca/cnf_sectionA.htm, 2011.

[5] E. Ibrahim, "Examinaion of garter springs from candu reactors," Atomic Energy of Canada Limited, 1985.

[6] M. Griffiths, "The effect of irradiation on ni-containing components in candu reactor cores: A review," AECL Nuclear Review, pp. 1-16, 2013.

[7] R. Ziaei, "Fuel channel annulus spacer," Patent US 0311015 A1, 2010.

[8] W. Flugge, Viscoelasticity. Berlin: Springer, 1975.

[9] W. Sharpe, Springer Handbook of Experimental Solid Mechanics. New York: Springer, 2008.

[10] N. Mills, Plastics Microstructure and Engineering Applications. Oxford: Elsevier, 2005.

[11] A. W. Hendry, An introduction to Photo-elastic Analysis. London: Blackie and Son Limited, 1948.

[12] R. Nave, "Classification of polarization." http://hyperphysics .phy-astr.gsu . edu/hbase/hph . html.

[13] W. R. J. Dally, Experimental Stress Analysis. Chicago: McGraw-Hill, 1965.

[14] A. Ajovalasit, G. Petrucci, and M. Scafidi, "Review of rgb photoelasticity," Optics and Lasers in Engineering, 2014.

[15] M. Fontanille and Y. Gnanou, "A history of polymers," Polymer Expert, 2002. 
[16] ProfessionalPlastics, "Machine grade polycarbonate data sheet." https://www.professionalplastics.com/professionalplastics/ MachineGradePolycarbonateDataSheet.pdf.

[17] Plaskolite, "Optix acrylic sheet." http://www.plaskolite.com/ ProductCatalog/OPTIX-Acrylic.

[18] M. Cook, "Creep characterization of seven automotive composite materials in the proceedings of international sampe technical conference," 2008.

[19] J. Simsiriwong, R. Sullivan, T. L. Jr, and H. Hilton, "A statistical approach to characterize the viscoelastic creep compliances of a vinyl ester polymer," Polymer Testing, pp. 183-198, 2015.

[20] C. Goudie, The Effect of Viscoelasticity on the Life Expectancy of Light Composite Aircraft. 2015.

[21] PerkinElmer, "Relaxation of pmma and calculation of the activation energy." http://www. perkinelmer.ca/lab-solutions/resources/docs/APP_ 007771B_17_Relaxation_of_PMMA_and_Calculation_of_the_Activation_ Energy.pdf.

[22] C. Pappalettere, "Annealing polycarbonate sheets," strain, pp. 179-180, 1978.

[23] PlasticsInternational, "Annealing of polycarbonate." https://www. plasticsintl.com/documents/Polycarbonate\%20Annealing.pdf.

[24] BoedeckerPlastics, "Annealing (stress relief) for plastics stock shapes." http: //www. boedeker.com/anneal.htm.

[25] Plaskolite, "Acrylic sheet fabrication guide." http://www.plaskolite.com/ Media/Get/97?inline=True.

[26] Plexiglas.com, "Plexiglas Sheet: Annealing Conditions." http://www . plexiglas.com/export/sites/plexiglas/. content/medias/downloads/ plexiglas-expert-pdf/Fabrication-Guidlines-Plexiglas-Annealing. pdf. Accessed: 09-03-2016. 


\section{Appendix A}

\section{A.1 Data collected during acrylic ring testing}

\begin{tabular}{|l|l|l|l|l|l|l|}
\hline \multicolumn{2}{|c|}{ Data } & Weight $(\mathrm{N})$ & Heat gun $\left({ }^{\circ} \mathrm{C}\right)$ & IR $\left({ }^{\circ} \mathrm{C}\right)$ & TC $\left({ }^{\circ} \mathrm{C}\right)$ & Date \\
\hline Nr & Time (s) & 25 & 130 & 80 & - & 08 Oct \\
\hline 23 & 19 & 20 & 140 & 84 & - & \\
\hline 24 & 1087 & - & - & - & - & - \\
\hline 25 & - & 20 & 140 & 83 & - & \\
\hline 26 & 538 & 20 & 140 & 87 & 91 & - \\
\hline 27 & 3711 & 20 & 140 & - & 92 & - \\
\hline 28 & 143 & 20 & 140 & - & 92 & - \\
\hline 29 & 264 & 20 & 140 & - & 92 & - \\
\hline 30 & 123 & 20 & 140 & - & - & \\
\hline 31 & 206 & 20 & 140 & - & - & \\
\hline 32 & 421 & 20 & 140 & - & 90 & - \\
\hline 33 & 349 & 20 & 140 & - & 77 & 14 Oct \\
\hline 34 & $2700+$ & 20 & 150 & - & 84 & - \\
\hline 35 & 30 & 20 & 150 & - & 81 & - \\
\hline 36 & 87 & & & & - & - \\
\hline
\end{tabular}




\begin{tabular}{|c|c|c|c|c|c|c|}
\hline \multicolumn{7}{|c|}{ Continuation of Table A.1 } \\
\hline $\mathrm{Nr}$ & Time (s) & Weight $(\mathrm{N})$ & Heat gun $\left({ }^{\circ} \mathrm{C}\right)$ & $\operatorname{IR}\left({ }^{\circ} \mathrm{C}\right)$ & $\mathrm{TC}\left({ }^{\circ} \mathrm{C}\right)$ & Date \\
\hline 37 & - & 20 & 150 & - & 83 & - \\
\hline 38 & 5 & 20 & 140 & - & 81 & - \\
\hline 39 & 687 & 20 & 140 & - & 80 & - \\
\hline 40 & 209 & 20 & 140 & 89 & 80 & 17 Oct \\
\hline 41 & 86 & 20 & 140 & 89 & 81 & - \\
\hline 42 & 113 & 20 & 140 & 89 & 81 & - \\
\hline 43 & 111 & 20 & 140 & 89 & 82 & - \\
\hline 44 & 48 & 20 & 140 & 89 & 82 & - \\
\hline 45 & 0 & 0 & 0 & 0 & 0 & - \\
\hline 46 & 148 & 20 & 140 & 90 & 81 & - \\
\hline 47 & 105 & 20 & 140 & 89 & 82 & - \\
\hline 48 & 0 & 20 & 140 & 91 & 82 & - \\
\hline 49 & 355 & 20 & 140 & 90 & 81 & - \\
\hline 50 & 158 & 20 & 140 & 92 & 82 & - \\
\hline 51 & 159 & 20 & 140 & 94 & 80 & - \\
\hline 52 & 691 & 20 & 140 & 88 & 82 & $18 \mathrm{Oct}$ \\
\hline 53 & 431 & 20 & 140 & 89 & 82 & - \\
\hline 54 & 1731 & 20 & 140 & 90 & 82 & - \\
\hline 55 & 485 & 20 & 140 & 89 & 83 & $20 \mathrm{Oct}$ \\
\hline 56 & 80 & 20 & 140 & 90 & 82 & - \\
\hline 57 & 157 & 20 & 140 & 88 & 82 & - \\
\hline 58 & 49 & 20 & 140 & 89 & 80 & - \\
\hline
\end{tabular}




\begin{tabular}{|c|c|c|c|c|c|c|}
\hline \multicolumn{7}{|c|}{ Continuation of Table A.1 } \\
\hline $\mathrm{Nr}$ & Time (s) & Weight $(\mathrm{N})$ & Heat gun $\left({ }^{\circ} \mathrm{C}\right)$ & $\operatorname{IR}\left({ }^{\circ} \mathrm{C}\right)$ & $\mathrm{TC}\left({ }^{\circ} \mathrm{C}\right)$ & Date \\
\hline 59 & 207 & 20 & 140 & 89 & 83 & - \\
\hline 60 & 190 & 20 & 140 & 89 & 83 & - \\
\hline 61 & 77 & 20 & 140 & 91 & 79 & - \\
\hline 62 & 1871 & 15 & 140 & 91 & 85 & - \\
\hline 63 & 486 & 15 & 140 & 91 & 83 & - \\
\hline 64 & 2333 & 15 & 140 & 90 & 80 & - \\
\hline 65 & 2765 & 15 & 140 & 95 & 85 & - \\
\hline 66 & 1925 & 15 & 140 & 94 & 85 & 26 Oct \\
\hline 67 & 733 & 15 & 140 & 98 & 83 & - \\
\hline 68 & 2660 & 15 & 140 & 93 & 83 & - \\
\hline 69 & 1870 & 15 & 140 & 94 & 84 & - \\
\hline 70 & 2534 & 15 & 140 & 95 & 86 & - \\
\hline 71 & 1140 & 15 & 140 & 94 & 83 & - \\
\hline 72 & 5160 & 15 & 140 & 92 & 86 & - \\
\hline 73 & 1282 & 15 & 140 & 93 & 85 & 27 Oct \\
\hline 74 & 1365 & 15 & 140 & 93 & 85 & - \\
\hline 75 & 1334 & 15 & 140 & 93 & 86 & - \\
\hline 76 & 1930 & 15 & 140 & 95 & 85 & - \\
\hline 77 & 1302 & 15 & 140 & 93 & 85 & - \\
\hline 78 & 990 & 15 & 140 & 95 & 85 & - \\
\hline 79 & 740 & 15 & 140 & 97 & 87 & - \\
\hline 80 & 730 & 15 & 140 & 96 & 85 & 31 Oct \\
\hline
\end{tabular}




\begin{tabular}{|c|c|c|c|c|c|c|}
\hline \multicolumn{7}{|c|}{ Continuation of Table A.1 } \\
\hline $\mathrm{Nr}$ & Time (s) & Weight $(\mathrm{N})$ & Heat gun $\left({ }^{\circ} \mathrm{C}\right)$ & $\operatorname{IR}\left({ }^{\circ} \mathrm{C}\right)$ & $\mathrm{TC}\left({ }^{\circ} \mathrm{C}\right)$ & Date \\
\hline 81 & 608 & 16 & 140 & 91 & 82 & - \\
\hline 82 & 1995 & 16 & 140 & 91 & 84 & - \\
\hline 83 & 3175 & 16 & 140 & 91 & 82 & - \\
\hline 84 & 1446 & 16 & 140 & 91 & 85 & - \\
\hline 85 & 2253 & 16 & 140 & 91 & 82 & - \\
\hline 86 & 293 & 16 & 140 & 94 & 81 & - \\
\hline 87 & 414 & 16 & 140 & 93 & 83 & - \\
\hline 88 & 1126 & 16 & 140 & 91 & 81 & - \\
\hline 89 & 786 & 16 & 140 & 91 & 82 & 03 Nov \\
\hline 90 & 239 & 16 & 140 & 90 & 81 & - \\
\hline 91 & 789 & 16 & 140 & 91 & 83 & - \\
\hline 92 & 743 & 16 & 140 & 92 & 84 & - \\
\hline 93 & 398 & 16 & 140 & 91 & 84 & - \\
\hline 94 & 691 & 15 & 140 & 92 & 84 & - \\
\hline 95 & 235 & 16 & 140 & 91 & 84 & - \\
\hline 96 & 257 & 16 & 140 & 92 & 82 & - \\
\hline 97 & - & 16 & 140 & 92 & - & - \\
\hline 98 & 80 & 16 & 140 & 94 & 85 & - \\
\hline 99 & 122 & 16 & 140 & 95 & 84 & - \\
\hline 100 & 1328 & 16 & 130 & 92 & 83 & - \\
\hline 101 & 554 & 16 & 140 & 92 & 83 & 07 Nov \\
\hline 102 & 1100 & 16 & 140 & 91 & 83 & - \\
\hline
\end{tabular}




\begin{tabular}{|c|c|c|c|c|c|c|}
\hline \multicolumn{7}{|c|}{ Continuation of Table A.1 } \\
\hline $\mathrm{Nr}$ & Time (s) & Weight $(\mathrm{N})$ & Heat gun $\left({ }^{\circ} \mathrm{C}\right)$ & $\operatorname{IR}\left({ }^{\circ} \mathrm{C}\right)$ & $\mathrm{TC}\left({ }^{\circ} \mathrm{C}\right)$ & Date \\
\hline 103 & 532 & 16 & 140 & 92 & 83 & - \\
\hline 104 & 613 & 16 & 140 & 92 & 84 & - \\
\hline 105 & 1605 & 16 & 140 & 92 & 83 & - \\
\hline 106 & 832 & 16 & 140 & 92 & 83 & $10 \mathrm{Nov}$ \\
\hline 107 & 984 & 16 & 140 & 92 & 82 & - \\
\hline 108 & 1173 & 16 & 140 & 92 & 82 & - \\
\hline 109 & 283 & 16 & 140 & 92 & 83 & - \\
\hline 110 & 431 & 16 & 140 & 93 & 83 & - \\
\hline 111 & 2683 & 16 & 140 & 94 & 84 & - \\
\hline 112 & 639 & 16 & 140 & 92 & 83 & 11 Nov \\
\hline 113 & 1857 & 16 & 140 & 92 & 82 & - \\
\hline 114 & 588 & 17 & 140 & 92 & 82 & - \\
\hline 115 & 253 & 17 & 140 & 92 & 82 & - \\
\hline 116 & 1453 & 17 & 140 & 94 & 84 & - \\
\hline 117 & 4000 & 17 & 140 & 94 & 84 & - \\
\hline 118 & 1338 & 17 & 140 & 90 & 82 & 14 Nov \\
\hline 119 & 10800 & 17 & 140 & 90 & 79 & - \\
\hline 120 & 207 & 17 & 150 & 93 & 80 & - \\
\hline 121 & - & 17 & 150 & 95 & 83 & - \\
\hline 122 & - & 17 & 140 & 92 & 83 & 17 Nov \\
\hline 123 & 1691 & 17 & 140 & 92 & 82 & - \\
\hline 124 & 493 & 17 & 140 & 93 & 82 & - \\
\hline
\end{tabular}




\begin{tabular}{|c|c|c|c|c|c|c|}
\hline \multicolumn{7}{|c|}{ Continuation of Table A.1 } \\
\hline $\mathrm{Nr}$ & Time (s) & Weight $(\mathrm{N})$ & Heat gun $\left({ }^{\circ} \mathrm{C}\right)$ & $\operatorname{IR}\left({ }^{\circ} \mathrm{C}\right)$ & $\mathrm{TC}\left({ }^{\circ} \mathrm{C}\right)$ & Date \\
\hline 125 & 1570 & 17 & 130 & 93 & 83 & - \\
\hline 126 & 1008 & 17 & 130 & 95 & 83 & - \\
\hline 127 & 797 & 17 & 140 & - & 91 & 18 Nov \\
\hline 128 & 328 & 17 & 150 & - & 85 & - \\
\hline 129 & 3000 & 17 & 150 & - & 87 & - \\
\hline 130 & 17 & 140 & - & 84 & - & \\
\hline 131 & 1654 & 17 & 140 & - & 84 & - \\
\hline 132 & 804 & 17 & 140 & - & 80 & - \\
\hline 133 & 442 & 17 & 140 & - & 82 & - \\
\hline 134 & 318 & 17 & 140 & - & 82 & - \\
\hline 136 & 369 & 18 & 140 & - & 82 & 21 Nov \\
\hline 137 & 110 & 18 & 140 & - & 82 & - \\
\hline 138 & 124 & 18 & 140 & - & 84 & - \\
\hline 139 & 400 & 18 & 140 & - & 82 & - \\
\hline 140 & 270 & 18 & 140 & - & 82 & - \\
\hline 141 & 305 & 18 & 140 & - & 82 & - \\
\hline 142 & 170 & 18 & 140 & - & 81 & - \\
\hline 143 & 182 & 18 & 140 & - & 82 & - \\
\hline 144 & 129 & 18 & 140 & - & 83 & - \\
\hline 145 & 63 & 18 & 140 & - & 85 & - \\
\hline 146 & 492 & 17 & 140 & - & 83 & - \\
\hline 147 & 287 & 17 & 140 & - & 83 & - \\
\hline
\end{tabular}




\begin{tabular}{|c|c|c|c|c|c|c|}
\hline \multicolumn{7}{|c|}{ Continuation of Table A.1 } \\
\hline $\mathrm{Nr}$ & Time (s) & Weight $(\mathrm{N})$ & Heat gun $\left({ }^{\circ} \mathrm{C}\right)$ & $\operatorname{IR}\left({ }^{\circ} \mathrm{C}\right)$ & $\mathrm{TC}\left({ }^{\circ} \mathrm{C}\right)$ & Date \\
\hline 148 & 374 & 17 & 140 & - & 82 & - \\
\hline 149 & 1034 & 17 & 140 & - & 81 & - \\
\hline 150 & 371 & 17 & 140 & - & 82 & - \\
\hline 151 & 1573 & 17 & $150 / 140$ & - & 83 & - \\
\hline 152 & 268 & 18 & 140 & - & 82 & $24 \mathrm{Nov}$ \\
\hline 153 & 319 & 18 & 150 & - & 81 & - \\
\hline 154 & 300 & 18 & 140 & - & 81 & - \\
\hline 155 & 227 & 18 & 140 & - & 82 & - \\
\hline 156 & 262 & 18 & 140 & - & 82 & - \\
\hline 157 & 365 & 18 & 140 & - & 82 & - \\
\hline 158 & 353 & 18 & 140 & - & 82 & - \\
\hline 159 & 388 & 18 & 140 & - & 83 & - \\
\hline 160 & 103 & 18 & 140 & - & 83 & - \\
\hline 161 & 425 & 18 & 140 & - & 83 & - \\
\hline 162 & 227 & 17 & 140 & - & 83 & - \\
\hline 163 & 351 & 17 & 140 & - & 83 & - \\
\hline 164 & 390 & 17 & 140 & - & 82 & - \\
\hline 165 & 293 & 17 & 140 & - & 83 & - \\
\hline 166 & 60 & 19.1 & 140 & - & 82 & $25 \mathrm{Nov}$ \\
\hline 167 & 118 & 19.1 & 140 & - & 82 & - \\
\hline 168 & 136 & 19.1 & 140 & - & 82 & - \\
\hline 169 & 58 & 19.1 & 140 & - & 83 & - \\
\hline
\end{tabular}




\begin{tabular}{|l|l|l|l|l|l|l|}
\hline \multicolumn{2}{|c|}{ Continuation of Table A.1 } & \multicolumn{5}{|l|}{} \\
\hline Nr & Time (s) & Weight $(\mathrm{N})$ & Heat gun $\left({ }^{\circ} \mathrm{C}\right)$ & IR $\left({ }^{\circ} \mathrm{C}\right)$ & TC $\left({ }^{\circ} \mathrm{C}\right)$ & Date \\
\hline 170 & 57 & 19.1 & 140 & - & 83 & - \\
\hline 171 & 60 & 19.1 & 140 & - & 82 & - \\
\hline 172 & 37 & 19.1 & 140 & - & 82 & - \\
\hline 173 & 52 & 19.1 & 140 & - & 82 & - \\
\hline 174 & 56 & 19.1 & 140 & - & 82 & - \\
\hline 175 & 32 & 19.1 & 140 & - & - & - \\
\hline 176 & 60 & 19.1 & 140 & - & 82 & - \\
\hline 177 & 57 & 19.1 & 140 & - & 81 & - \\
\hline 178 & 37 & 19.1 & 140 & - & 80 & - \\
\hline 179 & 66 & 19.1 & 140 & - & 81 & - \\
\hline 180 & 102 & 19.1 & 140 & - & 81 & - \\
\hline 181 & 47 & 19.1 & 140 & - & 80 & - \\
\hline 182 & 26 & 19.1 & 140 & - & 81 & - \\
\hline 183 & 10 & 19.1 & 140 & - & 81 & - \\
\hline 184 & 14 & 19.1 & 140 & - & 82 & 28 Nov \\
\hline 185 & 17 & 19.1 & 130 & - & 82 & - \\
\hline 186 & 11 & 19.1 & 130 & - & 82 & - \\
\hline 187 & 277 & 19.1 & $130 / 140$ & - & 77 & - \\
\hline 188 & 83 & 19.1 & 150 & - & 80 & - \\
\hline 189 & 491 & 19.1 & 150 & - & 82 & - \\
\hline 190 & 141 & 19.1 & 150 & - & 82 & - \\
\hline 191 & 130 & 19.1 & 140 & - & 83 & - \\
\hline & 57 & & - & - & - \\
\hline
\end{tabular}




\begin{tabular}{|l|l|l|l|l|l|l|}
\hline \multicolumn{2}{|c|}{ Continuation of Table A.1 } & \multicolumn{5}{|l|}{} \\
\hline $\mathrm{Nr}$ & Time $(\mathrm{s})$ & Weight $(\mathrm{N})$ & Heat gun $\left({ }^{\circ} \mathrm{C}\right)$ & $\mathrm{IR}\left({ }^{\circ} \mathrm{C}\right)$ & $\mathrm{TC}\left({ }^{\circ} \mathrm{C}\right)$ & Date \\
\hline 192 & 135 & 19.1 & 140 & - & 83 & - \\
\hline 193 & 275 & 19.1 & 140 & - & 84 & - \\
\hline 194 & 1240 & 19.1 & 140 & - & 78 & - \\
\hline
\end{tabular}

\section{A.1.1 Graphs of times to failure for each load case}

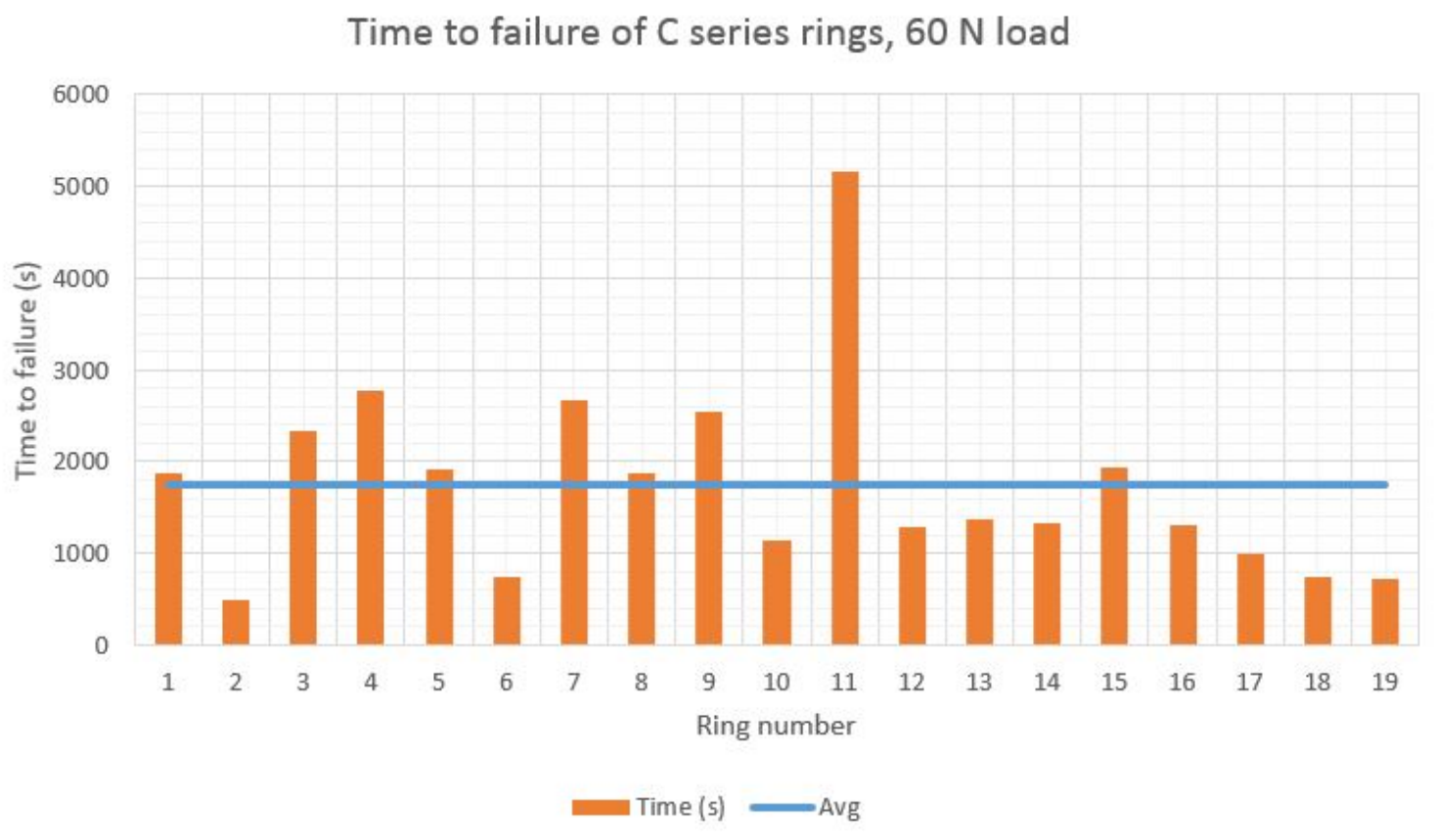

Figure A.1: Times to failure for $60 \mathrm{~N}$ load 
Time to failure of $\mathrm{C}$ series ring, $64 \mathrm{~N}$ load

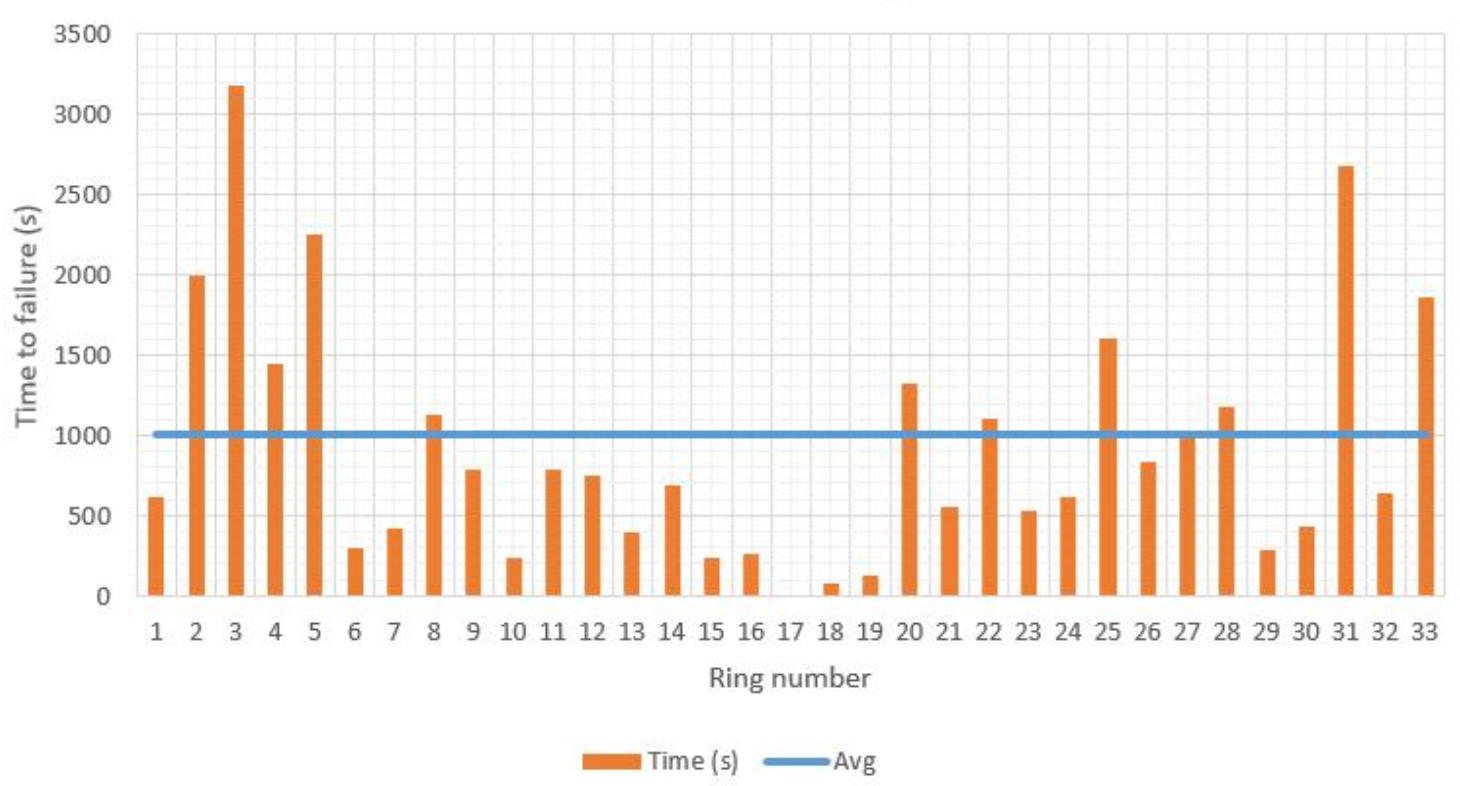

Figure A.2: Times to failure for $64 \mathrm{~N}$ load

Time to failure of $\mathrm{C}$ series ring, $68 \mathrm{~N}$ load

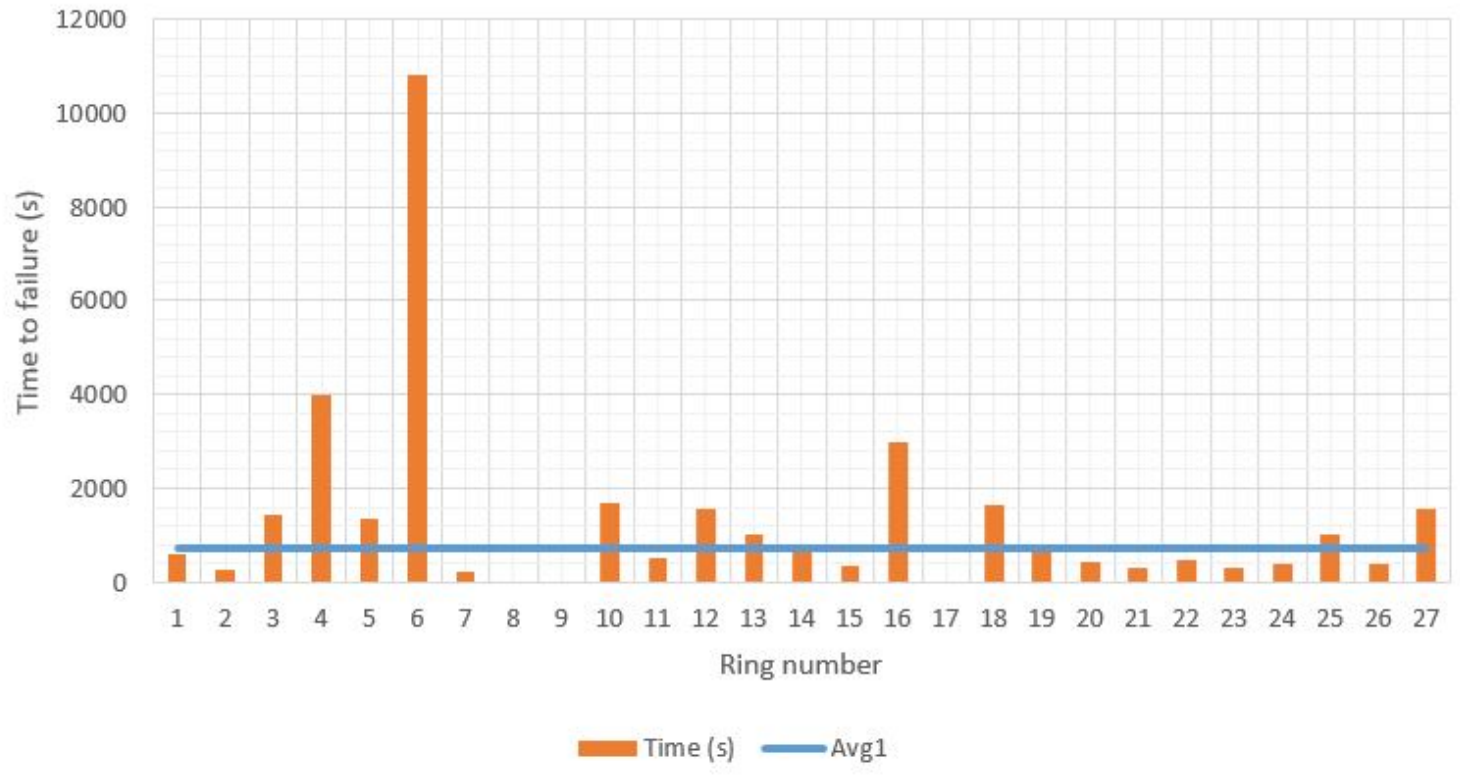

Figure A.3: Times to failure for $68 \mathrm{~N}$ load 
Time to failure of $\mathrm{C}$ series rings, $72 \mathrm{~N}$ load

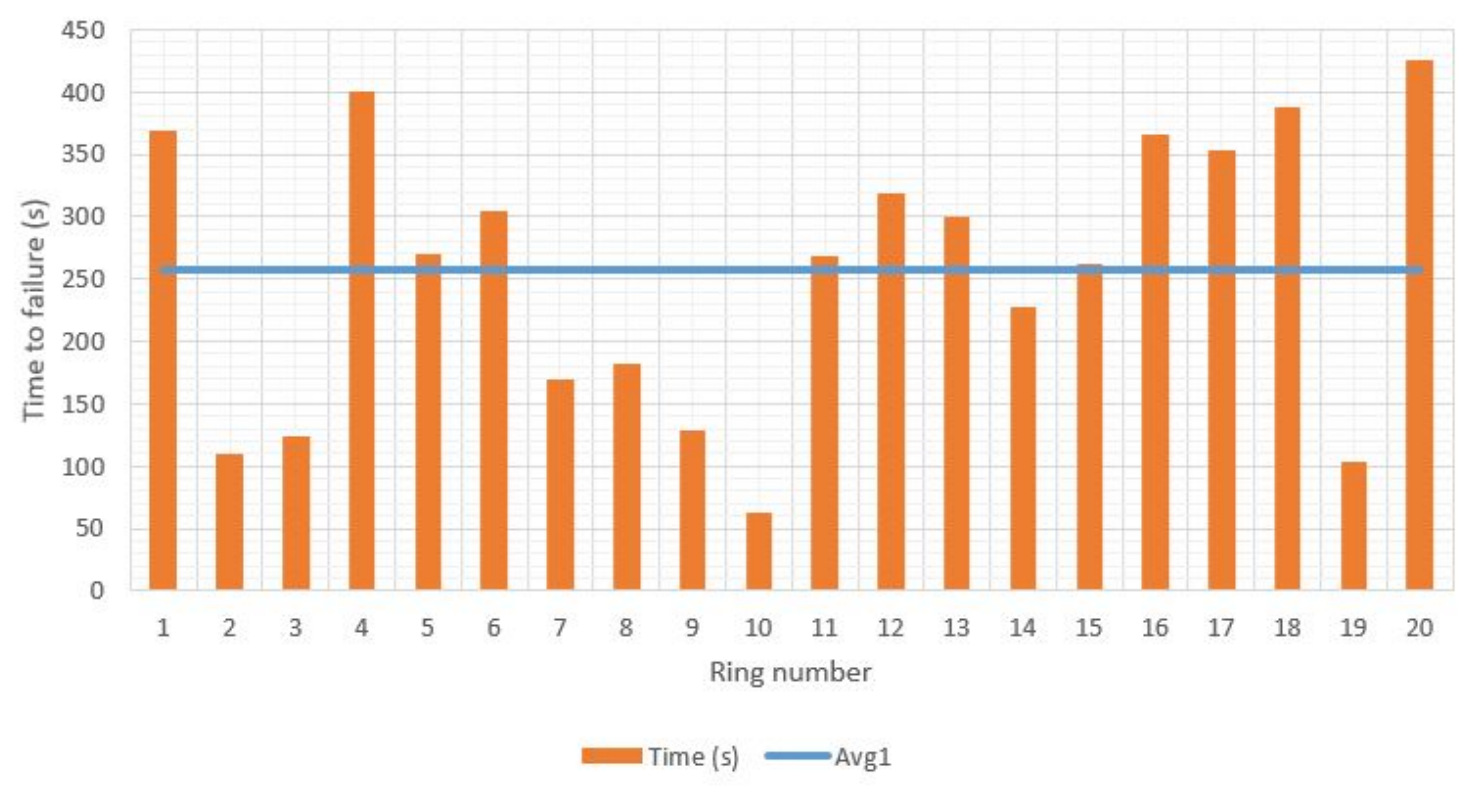

Figure A.4: Times to failure for $72 \mathrm{~N}$ load

Time to failure of $\mathrm{C}$ series rings, $76.4 \mathrm{~N}$ load

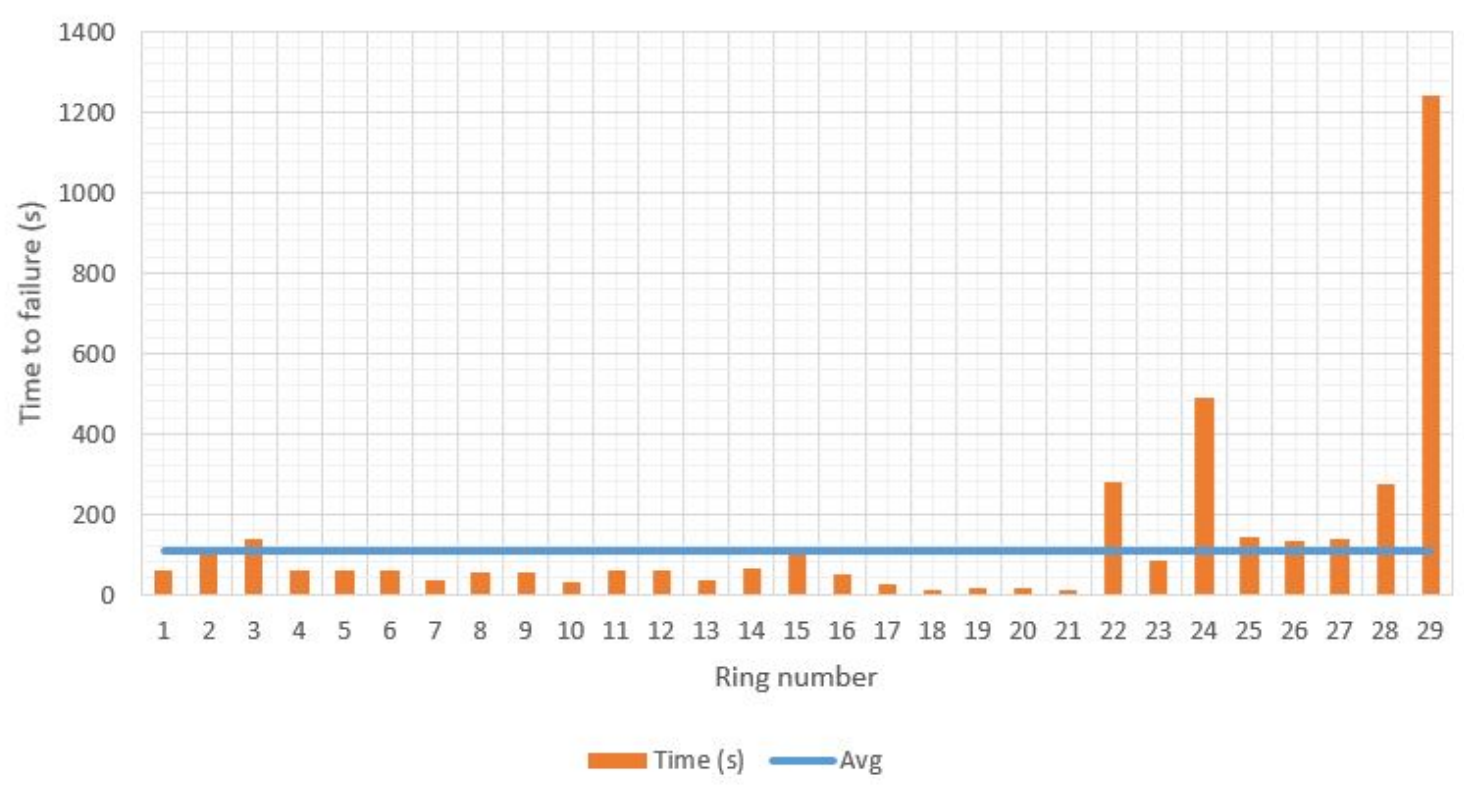

Figure A.5: Times to failure for $76.4 \mathrm{~N}$ load 
Time to failure of $\mathrm{C}$ series rings, $80 \mathrm{~N}$ load

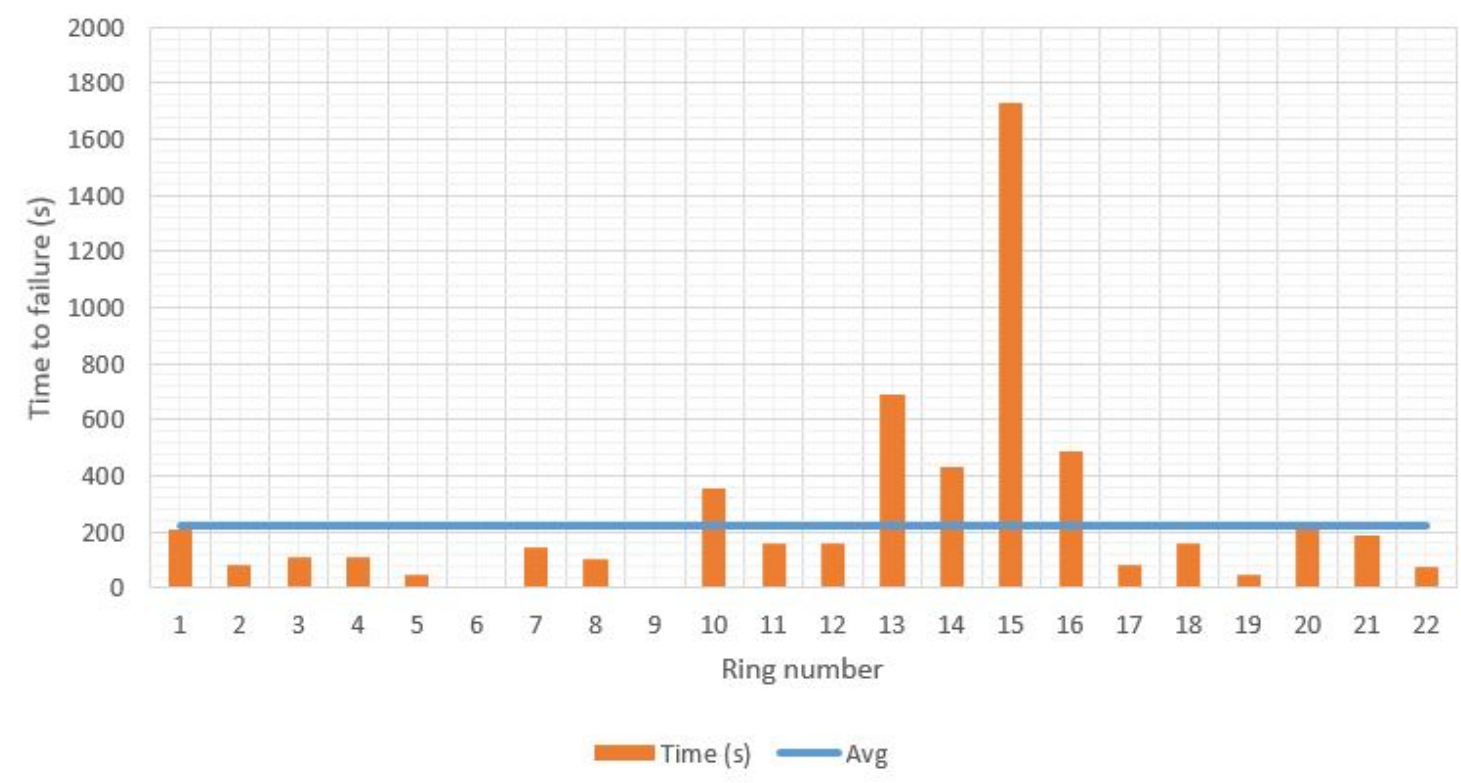

Figure A.6: Times to failure for $80 \mathrm{~N}$ load

\section{A.1.2 Plot with trend and all data points}

Time to failure of $\mathrm{C}$ series acrylic rings, compared to viscoelastic stability theory

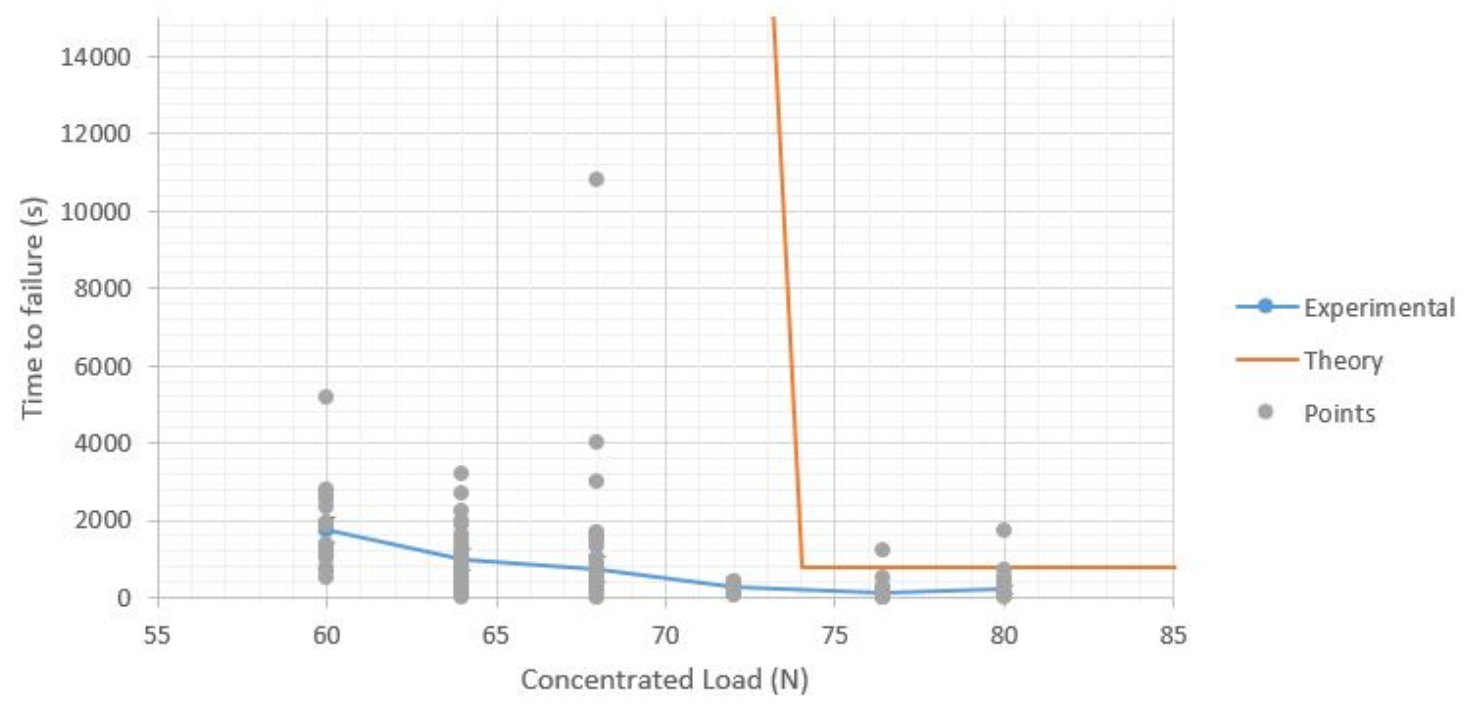

Figure A.7: Averages with individual data points (all points) 
Time to failure of $\mathrm{C}$ series acrylic rings, compared to viscoelastic stability theory

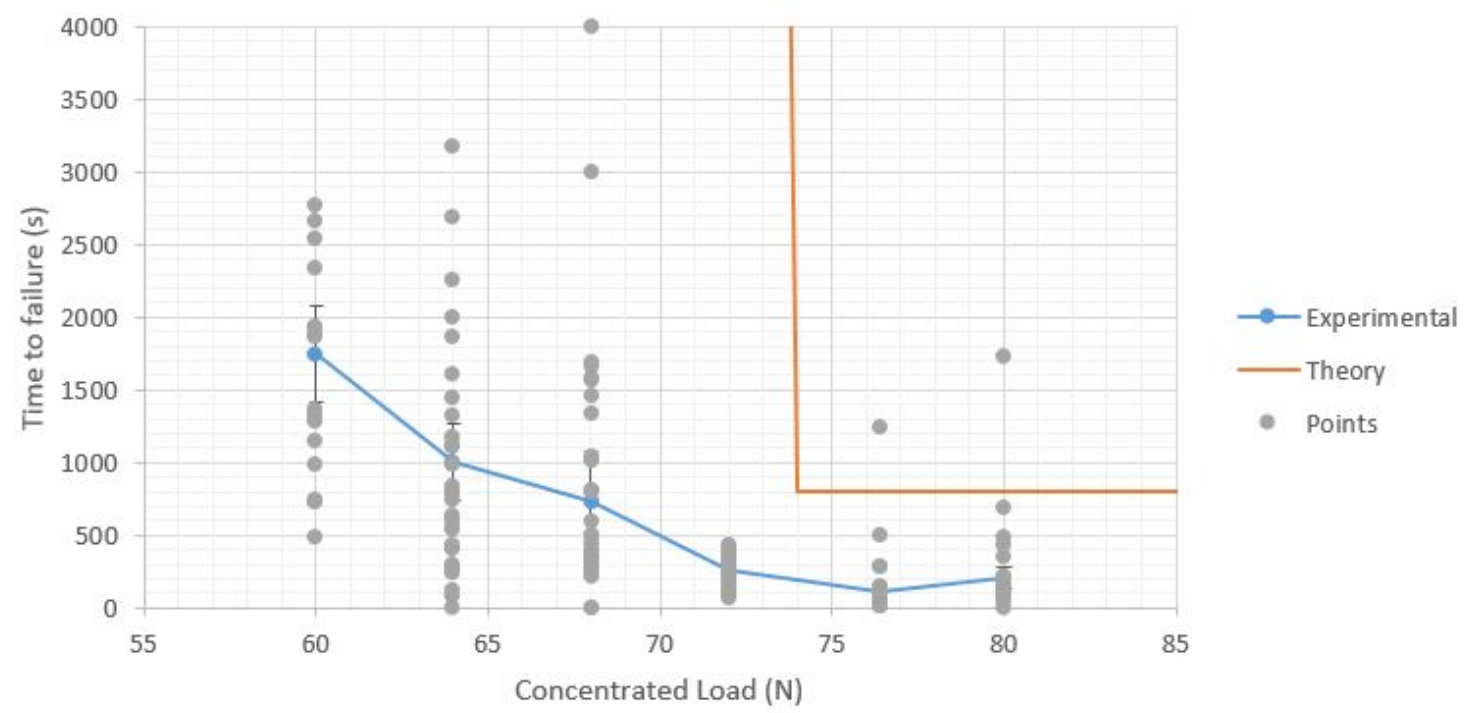

Figure A.8: Averages with individual data points (showing concentration of points

\section{A.1.3 Confidence and variance}

\begin{tabular}{|l|l|l|l|}
\hline Load $(\mathrm{N})$ & Experimental time to failure $(\mathrm{s})$ & $95 \%$ Confidence interval & Variance \\
\hline 60 & 1744.7 & 328.6 & 1100826.5 \\
\hline 64 & 1002.0 & 267.6 & 549257.1 \\
\hline 68 & 733.4 & 340.1 & 258748.8 \\
\hline 72 & 256.6 & 49.1 & 11934.7 \\
\hline 76.4 & 108.0 & 14.8 & 10646.1 \\
\hline 80 & 203.1 & 76.4 & 136921.0 \\
\hline
\end{tabular}




\begin{tabular}{|c|c|c|c|c|c|c|c|c|c|c|c|c|c|}
\hline & 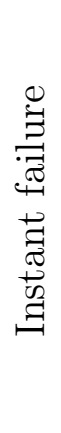 & & 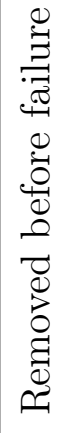 & 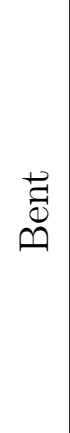 & 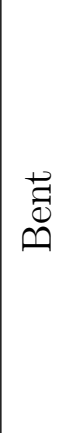 & 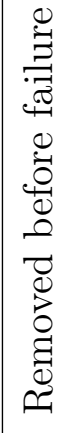 & 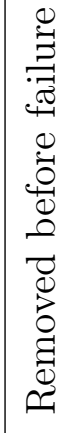 & 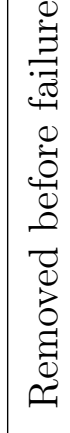 & صृّ & ضै & 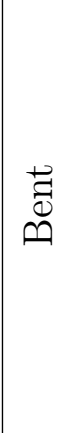 & $\mid \begin{array}{c}\overrightarrow{0} \\
\ddot{n}\end{array}$ & \\
\hline 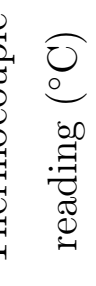 & $\widetilde{\infty}$ & $\tilde{\infty}$ & $\infty$ & $\vec{\infty}$ & 18 & $\vec{\infty}$ & $\mathscr{R}$ & & & & & & \\
\hline $\begin{array}{l}0 \\
0 \\
0\end{array}$ & $\vec{\sigma}$ & 8 & $\mathscr{\delta}$ & $\vec{\sigma}$ & $\vec{\sigma}$ & ठే & 8 & & $\vec{\infty}$ & $\infty$ & ని & ळి & $\frac{\infty}{1}$ \\
\hline 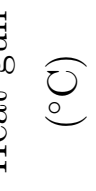 & 号 & 왐 & $\stackrel{\text { q }}{\rightarrow}$ & $\stackrel{ }{\underset{1}{二}}$ & 尽 & $\underset{f}{\stackrel{9}{\sim}}$ & $\underset{f}{\stackrel{9}{f}}$ & & $\underset{ }{\stackrel{9}{1}}$ & $\stackrel{8}{9}$ & $\stackrel{\infty}{\stackrel{m}{\rightarrow}}$ & $\stackrel{\circ}{\stackrel{9}{+}}$ & $\stackrel{9}{\stackrel{9}{1}}$ \\
\hline 乙 & จิ & ন & $\stackrel{10}{\rightarrow}$ & $\stackrel{\bullet}{\sim}$ & 0 & $\stackrel{\curvearrowright}{\sim}$ & $\bumpeq$ & 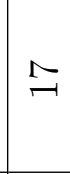 & $\vec{\Phi}$ & $\vec{S}$ & $\overrightarrow{\stackrel{g}{\rightarrow}}$ & $\stackrel{\vec{S}}{\stackrel{\vec{\rho}}{\sim}}$ & $\overrightarrow{\stackrel{g}{\rightarrow}}$ \\
\hline 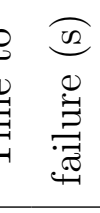 & 0 & $\vec{P}$ & $\begin{array}{l}8 \\
\frac{8}{10}\end{array}$ & 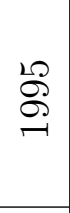 & $\infty$ & ‡ & $\begin{array}{l}8 \\
0 \\
0 \\
0\end{array}$ & §্ণ & $\stackrel{ }{\ddots}$ & $\exists$ & $\stackrel{\simeq}{=}$ & $\exists$ & 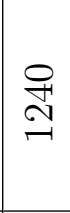 \\
\hline 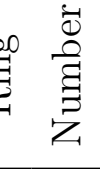 & $\stackrel{\infty}{\not+}$ & स' 10 & $\stackrel{N}{N}$ & $\widetilde{\infty}$ & $\stackrel{\infty}{\infty}$ & $\stackrel{N}{=}$ & $\stackrel{\rho}{=}$ & $\stackrel{\mathbb{N}}{\mathfrak{U}}$ & $\stackrel{\mathscr{\infty}}{\infty}$ & $\underset{\infty}{-\infty}$ & $\stackrel{20}{\rightarrow \infty}$ & $\underset{\infty}{\infty}$ & 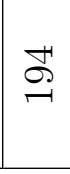 \\
\hline
\end{tabular}




\section{A.1.5 Sample ring dimensions}

\begin{tabular}{|l|l|l|l|}
\hline Ring number & OD $(0.001 ")$ & ID $(0.001 ")$ & Thickness $(0.001 ")$ \\
\hline 57 & 1637 & 558 & 60 \\
\hline 58 & 1635 & 557 & 60 \\
\hline 59 & 1637 & 559 & 61 \\
\hline 60 & 1636 & 558 & 60 \\
\hline 61 & 1635 & 558 & 60 \\
\hline 62 & 1637 & 558 & 60 \\
\hline 63 & 1636 & 558 & 60 \\
\hline 64 & 1637 & 558 & 60 \\
\hline 65 & 1613 & 553 & 61 \\
\hline
\end{tabular}

\section{A.2 Ring manufacturing jig}

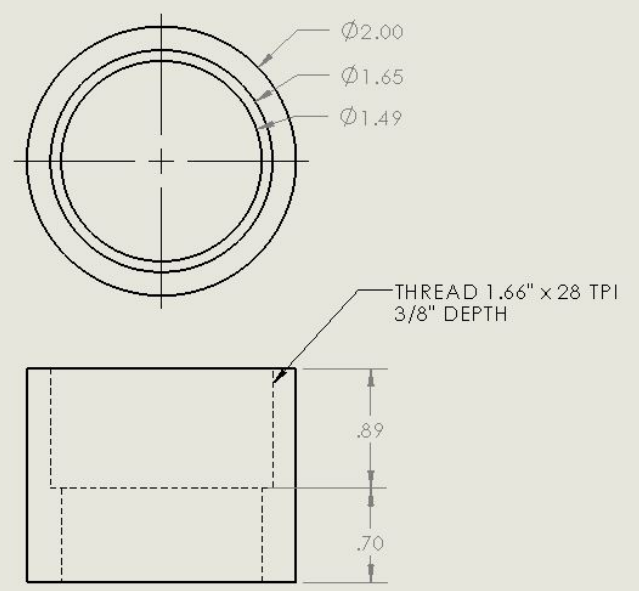

Figure A.9: Collet part A for holding polycarbonate rings for drilling centre hole. 


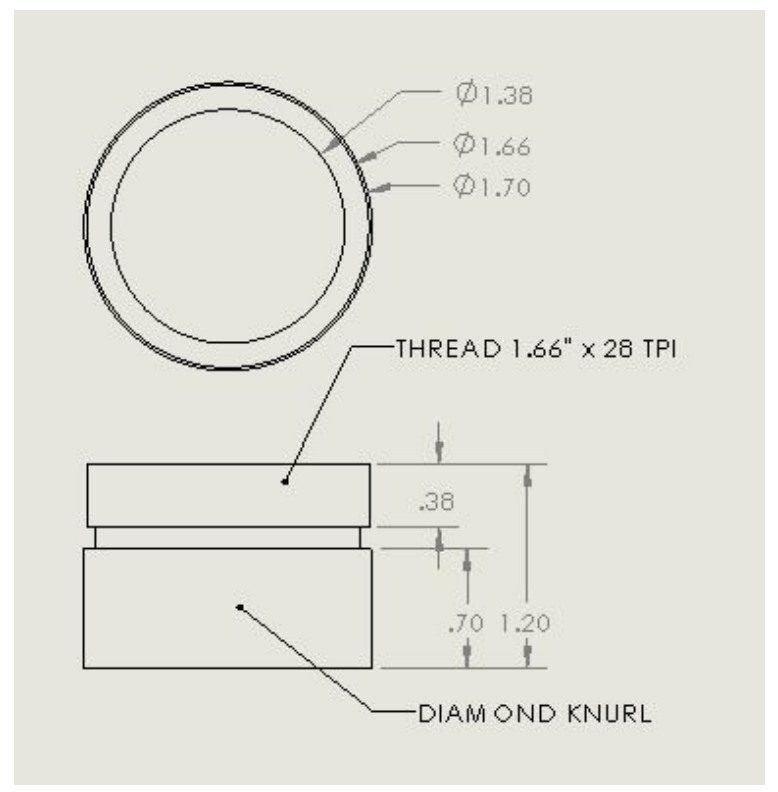

Figure A.10: Collet part B threads into part A 